Chapter 2

\title{
Cigarette Smoking and Hypertension Two Risk Factors for Age-Related Macular Degeneration
}

\author{
Maria E. Marin-Castaño \\ Additional information is available at the end of the chapter \\ http://dx.doi.org/10.5772/53958
}

\section{Introduction}

\subsection{Age-related macular degeneration}

Age-related macular degeneration (AMD) is a progressive retinal degeneration that is untreatable in up to $90 \%$ of patients and is the leading cause of blindness in the elderly worldwide [1]. Although much effort is invested in understanding this condition, there is neither a cure nor a way to prevent it, and treatment options are very limited. AMD affects $30 \%$ of people age 70 or older, and 60 million people worldwide are affected. Over 10 million people are affected in the United States and it is estimated that more than 300,000 new cases are diagnosed annually [2-4]. Since persons over 60 represent the fastest growing segment of the population, AMD will remain a significant public health problem for the foreseeable future $[5,6]$.

AMD is a multifactorial disease with age, systemic health, genetic and environmental risk factors influencing disease progression $[7,8]$. The most important pathogenic factors leading up to AMD include oxidative stress, inflammation, and local production of angiogenic factors [9]. A substantial body of literature suggests a role for oxidant injury to the RPE and local inflammation as putative mechanisms in the pathogenesis of AMD [10-12]. However, to date, little is known about the molecular signal(s) linking oxidation to inflammation in this lateonset disease.

In AMD loss or dysfunction of retinal photoreceptors is the ultimate cause of vision loss. However, the initial pathogenic target of AMD is the retinal pigment epithelium (RPE), Brusch's membrane (BrM), and choriochapillaris [13,14]. Clinical manifestations of AMD may present in early or a late form [15]. In early AMD (commonly known as dry degeneration) (Fig. 1B), variuos lipic-derived and protein-rich extracellular deposits, known as drusen, accumu- 
late under the RPE (Fig. 2) [14-16]. Ultimately, early AMD can progress to the late form of the disease; geographic atrophy (commonly known as advanced dry AMD) (Fig. 1C) or neovascular AMD (commonly known as wet or exudative AMD) (Fig. 1D). Geographic atrophy is characterized by death of RPE and photoreceptors (Fig. 1C) [14,15].
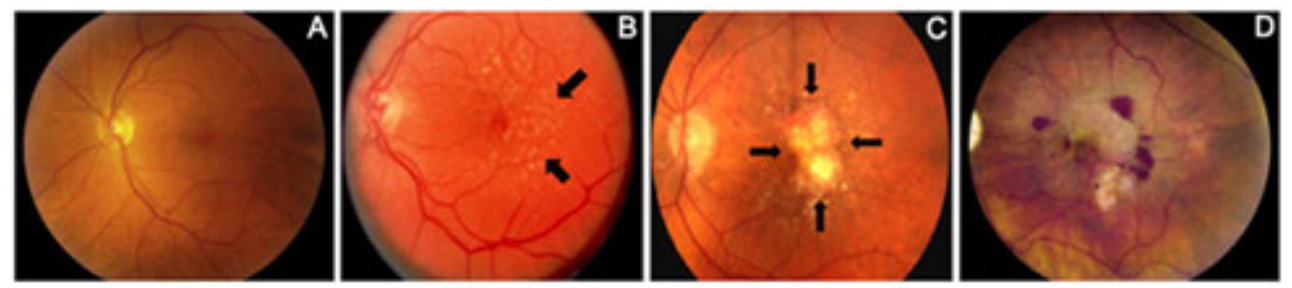

Figure 1. Fundus Photographs in health, early age-related macular degeneration (AMD), late forms of atrophic AMD and neovascular AMD. The ocular fundus of a healthy eye, showing normal pigmentation and retinal blood vessels (A). Drusen (thick arrows), seen as multiple discrete round yellow sub-retinal pigment epithelium (RPE) deposits, are the first sign of early AMD (B). Atrophic AMD (C) is characterized by a window defect (thin arrows) with loss of RPE and overlying photoreceptors. Neovascular AMD (D) is characterized by choroidal neovascularization (CNV), which is prone to fluid exudation, hemorrhage, and fibrosis. The late-stage dry form of AMD, known as geographic atrophy. Note large regions of depigmentation, especially in the macula, which is at the center of the image.(C) In wet AMD, leaky blood vessels from the choroid invade the overlying retina.

Neovascular AMD is characterized by the growth of new abnormal blood vessels, with leaky walls, under the RPE from the subjacent choroid, resulting in choroidal neovascularization $(\mathrm{CNV})$ and subsequent dysfunction or death of the overlying neurosensory retina $[14,15]$. Neovascular AMD progresses much more rapidly than early AMD and leads to a greater loss of central vision. What both forms have in common, however, is pathology at the RPE/choroid interface, which includes a thickening of BrM, due to the deposition of extracellular material between the RPE and BrM (sub-RPE deposits and drusen) (Fig. 2). This review will focus on the pathobiology of the early AMD by exploring the role of cigarette smoking and hypertension in the onset and development of the disease.

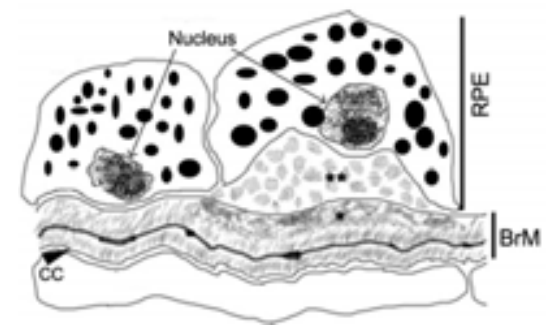

Figure 2. Schematic image of the RPE-Bruch's membrane-choriocapillaris interface in AMD. Basal laminar deposits $\left(B L D ;{ }^{* *}\right)$ appear between the RPE cell and the RPE basement membrane, while basal linear deposits (BlinD; $\left.{ }^{*}\right)$ localize at the inner collagenous layer beneath the RPE basement membrane. Arrowhead indicates endothelial cell basement membrane. 


\section{The outer retina and choroid}

As mentioned above, the pathology at the RPE/choroid interface, which includes deposition of extracellular material between the RPE and BrM, is what both AMD forms have in common. BrM undergoes several biochemical and anatomical changes with aging, including collagenous thickening, calcification, and lipid infiltration, in the absence of apparent retinal dysfunction [17,18]. The accumulation of specific deposits under the RPE is the hallmark histopathological feature of eyes with early AMD, when visual function is still not irreversibly impaired [14,19].

The RPE is a monolayer of hexagonally arranged, highly pigmented cells, located between the neural retina and the choroid, and forming part of the blood-retina barrier (Fig. 3). Its many functions include; the absorption of light that did not get captured by the photoreceptor outer segment pigments; epithelial transport of molecules (nutrients, ions, water, and metabolites) between the subretinal space and the choroidal blood supply; spatial ion buffering; reisomerization of the chromophore 11-cis-retinal from all-trans retinal; the daily removal of photoreceptor outer segments by phagocytosis; the secretion of molecules such as growth factors, proteases, and others that control the stability of the photoreceptor cells, BrM and the choroid; and finally, the modulation of the immune response, since the RPE participates in control of the immune privilege in the healthy eye or the mounting of an immune response in the diseased eye [20]. Abnormalities in any of these processes might participate in RPE cell pathology.

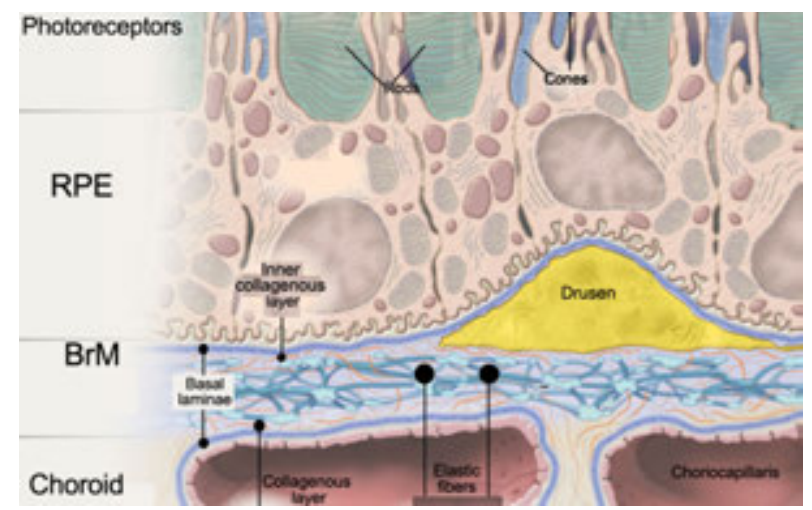

Figure 3. Schematic image of the photoreceptors-RPE-Bruch's membrane-choriocapillaris interface and drusen in AMD.

BrM occupies a crucial interface between the RPE and choroid and contains the basement membrane of both the RPE and choroid (Fig. 3). BrM is traditionally considered to be a fivelayered stratified extracellular matrix that provides structural support to the overlying RPE and retina $[6,18,21]$. BrM also provides a semipermeable filtration barrier through which major metabolic exchange takes place between the RPE and the choriocapillaris. In the center of BrM 
is the elastic fiber layer (Fig. 3) sandwiched between the inner and outer collagenous layers. Finally, two basal laminas define the innermost and outermost layers. The innermost layer is the basal lamina of the RPE; the outermost layer is formed by the basement membrane of the endothelial cells that comprise the choriocapillaris $[6,18,21]$. The collagen layers contain striated collagen fibers mainly type I, III, and V $[6,18]$. Type I confers tensile strength to the tissue, type III is normally present in tissues with elastic properties, and type $\mathrm{V}$ acts to anchor basement membranes to stromal matrixes $[17,18]$. The interfiber matrix of BrM is comprised largely of glycosaminoglycans such as heparan sulfate (25\%) and chondroitin/dermatan sulfate (75\%). These provide an electrolytic barrier to diffusion and serve important regulatory roles by binding extracellular proteins and growth factors that are vital for cellular processes such as adhesion, migration, and differentiation $[17,22,23]$.

The basement membrane of both the choriocapillaris and RPE are comprised of mostly type IV collagen $[17,18]$. The basement membranes additionally contain laminin, heparan sulfate, proteoglycans, and fibronectin. The outermost basal lamina also incorporates type VI collagen, which is associated with the choriocapillaris $[17,18]$. It has been suggested that this collagen may act to anchor fenestrated capillaries to the underlying choroid.

\section{Subretinal deposit formation and progression: Pathogenic mechanisms}

The accumulation of specific deposits under the RPE is a very prominent histopathologic feature of eyes with AMD [24-27]. Sub-RPE deposits were first described nearly 160 years ago and were generically termed "drusen" when observed by ophthalmologists upon clinical examination of the retina [28]. Histopathological examination defines three main types of subRPE deposits on the basis of thickness, content, and locationt: a) basal laminar deposits (BLD), b) basal linear deposits (BLinD), and c) nodular drusen [14,29,30]. BLD and BLinD are both diffuse deposits that accumulate on opposite sides of the basal lamina of the RPE (Fig. 2); therefore, the RPE basement membrane is the crucial dividing line that demarcates the location of BLD from BLinD [14]. BLD is seen as amorphous material of intermediate electron density between the plasma membrane and the basement membrane of the RPE, often containing wide-spaced collagen, patches of electron-dense fibrillar or granular material, and occasionally, membranous debris [31]. They are distributed throughout the retina, including the periphery as well as the macula, underlying not only cones but rods as well. BLinD are diffuse, amorphous accumulations within the inner collagenous zone of BrM, external to RPE basement membrane (Fig. 2), with similar content variations [14]. BLinD are characterized by coated and non-coated vesicles as well as some membranous and empty profiles [14]. Biochemically, deposits contain phospholipids, triglycerides, cholesterol, cholesterol esters, unsaturated fatty acids, peroxidized lipids, and apolipoproteins [24-26].

Nodular drusen are discrete, dome-shaped deposits within the inner collagenous zone of BrM (i.e., external to the RPE basal lamina), which are often contiguous with BLinD, and can be difficult to distinguish from BLinD without electron microscopy [5]. Nodular drusen may also specifically contain vitronectin, immunoglobulins, amyloid, complement, and proteins 
associated with RPE cell function [32] as well as other poorly characterized components [24-27]. Further, low-grade monocyte infiltration within the choriocapillaris is often present underlying areas of deposits $[25,27,33]$.

Clinically, deposits of AMD are classified on fundoscopic features of morphology and size [24]. Although multiple classifications exist, most clinicians use size to classify drusen: small or "hard" ( $<63 \mu \mathrm{m})$ and soft, intermediate $(>63$ to $<125 \mu \mathrm{m})$ and large $(>125 \mu \mathrm{m})$ drusen [24]. When hard or soft drusen coalesce to the point of losing their boundaries they are then classified as "diffuse." Although diagnosis of AMD is typically made when intermediate or large drusen are present, the diagnosis can be also be made in the absence of drusen based on the presence of pigmentary changes indicative of RPE degeneration $[3,29,30]$. The specific contribution of drusen to AMD complications and progression are not well characterized, but the presence of macular drusen is considered a strong risk factor for the development of both forms of late AMD, geographic atrophy and neovascular AMD [3,34,35]. In general, eyes with clinical AMD have been found to express all three deposit subtypes $[14,25,36]$. Furthermore, histological, immunohistochemical, and ultrastructural studies of surgically-excised choroidal neovascular (CNV) membranes have shown that the cellular and extracellular constituents of CNV are the same regardless of the underlying disease, with the exception of the amount of BLD and the presence of BLinD, which is virtually exclusively found in CNV specimens from patients with AMD [29,37].

The cellular and molecular events involved in drusen formation have not been fully elucidated. Lack of scientific consensus exists regarding the origin of drusen, but at least five different paradigms are currently proposed to explain deposit formation in AMD; a) genetic hypothesis, b) lysosomal failure/lipofuscin hypothesis, c) choroidal hypoperfusion hypothesis, d) barrier hypothesis, and e) RPE injury hypothesis. Because our research is based on the RPE injury hypothesis, in this section this theory is reviewed in light of the more recent finding.

There are a number of direct and/or indirect lines of evidence supporting a role for the RPE in drusen biogenesis. According to traditional models of drusen formation, any cellular material residing within drusen is predicted to be of RPE origin. Indeed, RPE-derived basal laminae, organelles and cellular fragments, and even entire cells can be detected in early "drusen". Some authors have described the appearance of RPE "debris" blebbing into drusen or pre-drusen sites [38]. RPE constituents, such as basal laminae, as well as lipofuscin and melanin granules, are observed within early drusen, where they likely contribute to drusen volume and formation.

The theory that drusen were derived from damaged RPE was originally postulated by Donders, who first described drusen in a post-mortem eye, believed that drusen were derived from RPE nuclei, based on the supposition that the latter are relatively resistant to degradation [39]. Donders' theory was later modified by De Vicentis (1887) who proposed that degenerative change in the RPE cytoplasm, rather than in the nucleus, was the precipitating event. On the other hand, Muller (1856) proposed that drusen result from aberrant secretion of basement membrane components by the aged RPE [40].With the advent of electron microscopy, the substructural features of drusen were revealed, and new variants of the earlier theories were advanced. Some investigators have concluded, that drusen are formed when the RPE expels 
portions of its basal cytoplasm into BrM [38], possibly as a mechanism for removing damaged cytosol [41] or as a byproduct of phagocytic degradation [19]. Others have postulated that drusen are formed by autolysis of the RPE, due to aberrant lysosomal enzyme activity [42], although enzyme histochemical studies failed to demonstrate the presence of lysosomal enzymes in drusen [43]. Additional mechanisms for drusen formation, including lipoidal degeneration of the RPE, have been proposed [44,45].

In the modern version, the RPE injury hypothesis proposes that deposit formation is secondary to chronic, repetitive but nonlethal RPE injury [46, 47]. Two separate phenomena must be distinguished: the injury stimulus and the cellular response. The most widely implicated injury stimuli are various oxidants, especially those induced by RPE exposure to visible light or those derived from endogenous metabolism [48,49]. More recently, inflammatory-derived injury stimuli have also become implicated, including oxidants, complement, immune complexes and factors produced by macrophages or monocyte [50-52]. Inflammatory cells might be responsible for drusen progression into CNV by secretion of growth factors and cytokines that will damage the choriocapillaris and stimulate the invasion of neovessels into the subretinal space $[37,51,52]$.

Irrespective of the injury, this model proposes that all stimuli result in a final common pathway of cellular responses that cause the actual deposits. Cellular responses that can lead to deposit formation include RPE cell membrane blebbing and dysregulation of extracellular matrix (ECM) production and breakdown. Accumulation of sub-RPE blebbed material in the setting of imbalanced breakdown and resynthesis of basement membrane and BrM ECM is proposed to produce the various deposits of AMD. Repetitive injury ultimately can kill RPE, leading to late dry AMD [6].

\section{Hypothetical model for dry AMD and its progression to wet AMD}

Our research is based on the RPE injury hypothesis (Fig. 4). Oxidative injury-mediated non lethal RPE membrane blebbing, dysregulation of ECM turnover, inflammation, and angiogenesis appear to be key cellular processes that play a central role in the formation and progression of sub-RPE deposits. We postulate that the pathogenesis and progression of dry AMD is characterized by the following stages: (A) Initial RPE oxidant injury causes extrusion of cell membrane "blebs," together with decreased activity of matrix metalloproteinases (MMPs), promoting bleb accumulation under the RPE as BLD. Numerous endogenous or exogenous oxidants can induce blebbing; (B) RPE cells are subsequently stimulated to increase synthesis of MMPs and other molecules responsible for extracellular matrix turnover (i.e., producing decreased laminin and collagen), affecting both RPE basement membrane and BrM $[46,53,54]$. This process leads to progression of BLD into BLinD and drusen by admixture of blebs into BrM, followed by the formation of new basement membrane under the RPE to trap these deposits within BrM [55,56]. We postulate that various hormones and other plasmaderived molecules related to systemic health cofactors are implicated in this stage [57-60]. (C) Altered macrophages recruitment to sites of RPE injury and deposit formation. Macrophage 
recruitment may be beneficial or harmful depending upon their activation status at the time of recruitment [50,61]. Nonactivated or scavenging macrophages may remove deposits without further injury. Activated or reparative macrophages, through the release of inflammatory mediators, growth factors, or other substances, may promote complications and progression to the late forms of the disease [37,50,62,37]. As discussed below, the effect of cigarette smoking and Ang II in the mentioned stages will be reviewed in depth.

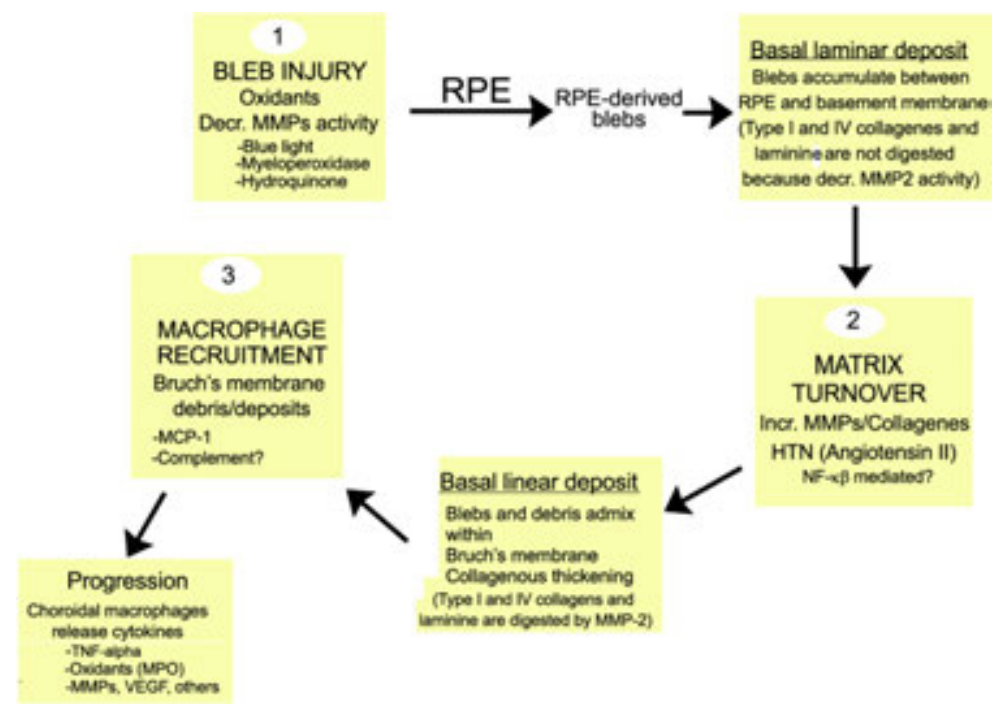

Figure 4. Schematic drawing of the early stages of age-related macular degeneration (AMD). First stage: Oxidant injury at the retinal pigment epithelium (RPE) causes bleb formation and decreased matrix metalloproteinases (MMPs). Blebs than accumulate between the RPE and the basement membrane as basal laminar deposits (BLDs). Second stage: Increased matrix turnover characterized by increased MMPs and decreased collagens. BLDs progress into basal linear deposits (BLinDs) and drusen and are located within the inner collagenous layer of Bruchs membrane. Third stage: Macrophages recruited to the site of injury by chemotactic factors are responsible for release of cytokines, angiogenic factors, and oxidants that perpetuate RPE injury and lead to late stages of AMD. Abbreviations: MPO = myeloperoxidase; NF-KB = nuclear factor kappa-light-chain-enhancer of activated B cells; TNF-a: tumor necrosis factor-alpha; MCP-1: monocyte chemotactic protein-1; VEGF: vascular endothelial growth factor.

\section{Smoking and age-related macular degeneration}

It has been postulated that environmental oxidants are frequently implicated in RPE injury and may contribute to deposit formation. Cigarette smoking is the strongest environmental risk factor for all forms of AMD, even in people exposed to passive smoking [63-66]. People who have smoked at least 100 cigarettes (lifetime) have approximately triple risk of developing AMD compared to individuals who have never smoked. Current smokers and heavy smokers have even higher AMD risk. 
Cigarette smoke is comprised of a gas and tar phase. Each phase contains both inorganic and organic free radicals, including ROS, epoxides, peroxides, $\mathrm{NO}$, nitrogen dioxide, peroxynitrite, peroxynitrates and various other free radicals [67]. Moreover, cigarette smoke contains a high concentration of potent oxidants such as acrolein [68-70], dioxin [71], Benzo(a)Pyrene [72], cadmium, [73-75] quinones, nicotine, and NO [76-79]. Many of them demonstrated to be toxic to ocular tissue affecting the eye through oxidative damage and abnormal vascularization. Although the pathogenesis of AMD and the mechanism of action of smoking on the eye are not fully understood [80], the risk of developing AMD is likely to involve more than one mechanism.

Smoking habit appears to be related to the long-term incidence and progression of AMD [81]. Plausible biological mechanisms such as direct oxidation, depletion of antioxidant protection (e.g. decreases plasma vitamin C and carotenoids), immune system activation, atherosclerotic vascular changes, induction of hypoxia and alteration of choroidal blood flow $[82,83]$, support the involvement of smoking in the etiology of AMD [84]. Interestingly, the Age-related Eye Disease Study (AREDS) [85] found that reduction in plasma glutathione and cysteine oxidation correlated with benefit from anti-oxidant treatment for intermediate AMD [86]. Collectively, these studies, along with the studies on cigarette smoking, implicate oxidative stress as a mechanism of AMD. Genetic variations such as a susceptibility locus in or near the hypothetical LOC387715 gene were associated with AMD [87,88]. It has been reported that this locus encodes a mitochondrial protein, raising suspicion for a role of the oxidative defense response in this disease. This locus is associated with smoking, and the combination of the LOC387715 polymorphism and smoking confers a higher risk for AMD than either factor alone [89,90]. Moreover, chemical in cigarette smoke modifies oxidatively docosohexanoic acid (DHA), the most abundant fatty acid in photoreceptor tips, to carboxyethylpyrrole (CEP) [91] and other lipids which have been identified which "tag" oxidatively oxidized damaged photoreceptors in AMD [92]. In the RPE, multiple proteins isolated from lipofuscin are also oxidatively damaged by cigarette smoke compounds including malondialdehyde, 4-hydroxynonenal and advanced glycation end products (AGE) $[93,94]$. Interestingly, AGEs accumulate in BrM including basal deposits and drusen, and CEP adducts appear in drusen isolated from AMD samples [95,96].The ability to defend against oxidative stress by upregulating the anti-oxidant defense response is likely to be a pivotal event that mediates the initiation and progression of AMD. The molecular damage from oxidative modification illustrated here, suggests that the anti-oxidant response in the macula at some point, becomes unable to neutralize oxidative stress.

In addition to direct oxidative damage to tissue, oxidative free radicals from cigarette smoke can modulate the immune-inflammatory system in part, through enhanced expression of proinflammatory genes, as reviewed in Biswas and Rahman (2009) [97]. The discovery of polymorphisms in several complement factors with AMD susceptibility points toward a specific role for complement mediated inflammation in the pathophysiology of AMD [98,99]. AMD has been associated with local inflammatory responses in the RPE/choroid [100]. In previous works, it was demonstrated that the aged RPE/choroid becomes immunologically active [101] due to increased expression of complement components. Smoking also influences the function 
of the alternative pathway of complement activation [121]. Smoking seems to alter the C3 component of the complement and to reduce the efficacy by which it binds to complement factor $\mathrm{H}(\mathrm{CFH})$.

The association between smoke and ApoE has also been investigated. Smokers are known to have higher serum cholesterol and LDL levels, a possible risk factor for AMD development [102]. Impaired cholesterol metabolism in particular ApoE isoforms carriers could be further enhanced among smokers. Moreover, smoking is associated with decreased endothelial NO production, while ApoE-4 genotype has been reported to increase NO synthesis, relative to ApoE2 and ApoE3 [103]. Thus, the presence of the ApoE2 protein in smokers may reduce endothelial NO levels in cell tissues. Given that the normal function of NO in the retina is to neutralize circulating oxidized lipids, its decreased availability may promote oxidative damage to the RPE cells.

As mentioned above, quinones, acrolein, BenzoPyrenes, and cadmium can damage the eye through oxidative processes. It has been demonstrated that hydroquinone the most abundant quinone in cigarette smoke causes oxidative damage, apoptosis, increases lipid peroxidation and mitochondrial superoxide production, and decreases intracellular glutathione in the RPE cells [104]. Acrolein, a product of lipid peroxidation in vivo, is a mitochondrial toxicant in RPE cells, which induces oxidative mitochondrial dysfunction and oxidative damage to proteins and DNA causing loss of cell viability [70-72]. Whereas Benzo(a)Pyrene causes mtDNA damage, alteration in the lysosomal activity, complement activation in the aged RPE, and upregulates expression of complement pathway components such as $\mathrm{C} 3 \mathrm{a}, \mathrm{C} 5, \mathrm{C} 5 \mathrm{~b}-9$, and $\mathrm{CFH}$ in the RPE/choroid contributing to drusen formation [105,106]. Cadmium (Cd), is another toxic which is concentrated in the body through cigarette smoke. Cd has been demonstrated to be a potent inflammatory, an oxidant agent, and accumulates with aging, effects which are linked to AMD [77, 107]. In vitro studies have revealed Cd as an important potential factor in RPE cell death associated retinal disease [76].

Cigarette smoke also induces angiogenesis promoting $\mathrm{CNV}$ and progression to neovascular AMD. Nicotine is one of the major components of the cigarette and has been demonstrated to enhance the generation of radical oxygen species producing oxidative stress [108-110] and promote the generation of pro-inflammatory responses leading to chronic inflammation in smokers [111]. Futhermore, nicotine is responsible for the mitogenesis of endothelial and smooth muscle cells [112] regulating abnormal responses to vascular injury [113] and endothelial functions [114]. We and other previously showed that nicotine by its direct action on nicotinic receptors promoted angiogenesis and increased size and severity of CNV in a mouse model $[112,114]$. Moreover, it has been shown that nicotine targets the retinal microvasculature by reducing the apoptotic rate of vascular endothelial cells and inducing the formation of new capillarity, mediated at least in part by release of vascular endothelial growth factor (VEGF) [113], which is one of the key growth factors involved in neovascularization and implicated in the most severe form of AMD [115-118]. Nicotine has also the ability to stimulate the growth of smooth muscle cells after oxidative injury, leading to the development of $\mathrm{CNV}$ in the retina. Moreover other cigarette smoke components such as dioxin induce expression and release of VEGF by RPE cells promoting CNV [104, 119]. 


\section{Hypertension and age-related macular degeneration}

Even though age is the major determinant for developing AMD, clinical and epidemiologic studies have suggested systemic vascular disease, especially hypertension, as an important risk factor for AMD $[3,119]$ and a correlation between AMD and aging and hypertension $[3,120]$. Aging is the risk factor with the greatest correlation with incidence, prevalence and severity of AMD, but the age-related susceptibility factors remain completely unknown $[3,120]$. However, increased sensitivity to the injurious effects of hypertension and to oxidantinjury are all more severe in the elderly than in the young [121-123]. For exemple, the interaction of Angiotensin II (Ang II) (the most important hormone associated with hypertension) with AT1 receptors, produces ROS, and with advancing age, oxidative alterations accumulate in cellular components, including those in the antioxidative defense systems, due to disrupted redox regulation during aging can influence the gene transcription and signal transduction pathways.

Hypertension is of particular interest among the systemic risk factors, due to its increasing incidence in Western societies. In several cross sectional and case control studies, systemic hypertension was associated with increased prevalence and progression of the severity and incidence of drusen [124] and with the development of wet AMD [125-127]. Interestingly, a recent study provides a strong association between hypertension and the development of wet AMD in the presence of early AMD [128]. Despite of the apparent link between AMD and hypertension, these studies make no mention of the mechanism(s) by which hypertension may induce or contribute to the pathogenesis of dry AMD and its progression from early AMD to CNV.

Traditionally, hypertension is believed to contribute to chronic diseases by at least two distinct mechanisms: hemodynamic injury and humoral factors [129-131]. Hemodynamic injury refers to mechanical damage induced by flow turbulence in large vessels or stretching of capillaries induced by increased blood pressure. Humoral factors refer to cellular activities induced by hormones or growth factors associated with hypertension $[129,130]$ shuch as Ang II, which is upregulated in hypertension, present in the blood of many hypertensive patients and has been demonstrated to activate specific receptors to induce various cellular functions. Ang II as the molecular surrogate for the effects of hypertension in AMD, and its properties will be described below.

The classical view of the renin-angiotensin system (RAS) as a systemic regulator of blood pressure has been extended, and a substantial number of studies have highlighted the importance of local RAS in a variety of extra-renal tissues, including adrenal glands [132], thymus [133] and recently in the eye [134,135]. In the eye, Ang II, and Ang II type 1 and type 2 receptors (AT1R, AT2R) have been found in the retina, particularly in the retinal pigment epithelium (RPE) [59,60,136-139]. Similarly, studies in rat retinal tissues also suggested local synthesis of both renin and angiotensin convertingenzyme (ACE) [140]. Along this line, Milenkovic et al. (2010) demonstrated that the RPE expresses renin and secretes it towards the retinal side. The presence of the most important RAS components in the retina implies a physiological function of RAS within the eye. However, despite the considerable evidence for 
local RAS in the retina, its exact role and its possible relationship with the systemic RAS remain poorly understood. The fact that AT1R is localized at the basolateral membrane of the RPE, which faces the blood side of the epithelium, suggests that the activity of the systemic RAS is a part of that signaling. Interestingly, it has been shown that modulation of the systemic RAS (e.g. by systemic application of ACE inhibitors) changes neuronal activity within the retina, mainly of bipolar cells and amacrine cells as monitored by electroretinography [139,141,142]. Moreover, modulators of the systemic RAS alter renin expression in the RPE [138] and plasma Ang II can not cross the intraocular space [143] suggesting that the systemic RAS most likely influences the intraocular RAS through the RPE.

Ang II mediates its biological effects through the activation of AT1R and AT2R receptors. It is, however, through AT1R activation that Ang II elicits most of its well known effects, including vasoconstriction, electrolyte homeostasis, fibrosis, inflammation and proliferation. In the eye, AT1R activation has been implicated in the pathogenesis of many ocular disorders such as diabetic retinopathy $[144,145]$, neovascularization in hypoxic-induced retinopathies [146-148] and age-related macular degeneration [59,60,149]. We postulate that the interaction of Ang II with AT1R, one of the most important oxidative stress inducer: a) induces blebs formation through reactive oxygen intermediate (ROS) production by activation of NADPH promoting bleb accumulation under the RPE as BLD and b) increases MMP-2 activity, MMP-14, and basigin, major mediator of ECM turnover through MAPK phosphorylation, and pro-inflammatory monocyte chemoattractant protein-1 (MCP-1) production through NF-kB activation by RPE stimulating RPE basement membrane breakdown and infiltration of pro-inflammatory macrophages to sub-RPE deposit areas, where they will scavenge, release inflammatory mediators, growth factors or other substances, which may promote complications and progression to CNV [37,51,62]. Moreover, we propose that Ang II decreases TNFSF15, an antiangiogenic cytokine expressed in inflammatory diseases, altering the balance between TNFSF15 and VEGF required for normal angiogenesis.

\section{Oxidative injury to the RPE}

As mentioned previously, a substantial body of literature suggests a role for oxidant injury to the RPE as a putative mechanism in the pathogenesis of AMD and addresses the protective actions of anti-oxidant. Although intuitively obvious, oxidant injury can induce either lethal responses, leading to cell death, or nonlethal responses inducing a functional change from baseline compatible with continued life of the cell but leading to dysfunction of the tissue or organ. Most studies focus on oxidant-mediated death of RPE [150-153]. Yet, RPE death (socalled geographic atrophy) is a very late stage of dry AMD, resulting from a very chronic and progressive process. Subretinal deposits and thickening of BrM, the hallmarks of early AMD, develop decades before the RPE cells actually die. Therefore, nonlethal cellular responses to RPE oxidant injury must contribute to early AMD.

Oxidative modifications in key cellular molecules such as DNA, carbohydrates, cellular proteins and cell membranes can often produce a cytotoxic chain reaction that contributes to 
the pathogenesis of many diseases [154-156]. However, we believe that oxidative damage to cell membranes and cellular proteins is more important in AMD.

RPE cell membranes are highly susceptible to lipid peroxidation. Phospholipids in RPE and photoreceptor membranes are especially rich in polyunsaturated fatty acid (PUFAs), including the $\omega-3$ fatty acid docosahexanoic acid and the $\omega-6$ fatty acid arachadonic acid. The presence of both types of PUFAs in phagocytosed photoreceptor outer segments renders the RPE cell membrane especially susceptible to lipid peroxidation and blebbing [157,158]. Cellular proteins are also important targets of oxidant-induced modification. Typical chemical modifications include breakdown of disulfide bonds, tyrosylation, acetylation and many other biochemical changes that can alter function of the molecule [159]. Accordingly, several welldescribed pathways exist to remove these damage biomolecules [160]. Although any cellular protein is potentially susceptible, the actin cytoskeleton is especially vulnerable to oxidantinduced damage.

Although oxidants derived from blue-light exposure, inflammation, or endogenous metabolism are more frequently implicated in RPE injury, we have also hypothesized that environmental toxicants and various hormones and other plasma-derived molecules related to systemic health cofactors serve as oxidants to contribute to deposit formation. We embrace the pathogenic paradigm based on the response-to-injury hypothesis which proposes that subRPE deposits originate from RPE-derived cell membrane blebs and dysregulation of ECM turnover induced by chronic nonlethal injury to the RPE in response to oxidative damage and propose that cigarette smoking-related hydroquinone and Ang II-induced hypertension contributes to the pathogeneis of AMD by causing oxidative damage to the RPE.

\subsection{Nonlethal cell derived microparticles}

Cell derived microparticles are considered to be microvesicles released through the process of exocytic budding of the plasma membrane following stimulation of different cell types [161, 162]. There are two well-known cellular processes that can lead to the formation of microparticles: chemicals and physical cell activation, and apoptosis [163,164]. Mild injuries inflected to the retina elicit a cellular response in the RPE consisting in pinching off small areas of the plasma membrane, which renders small microvesicles called blebs [165] (Fig. 5). The reason(s) behind membrane blebbing remains unknown, although it has been postulated to be an attempt to discard damaged cellular constituents by the RPE cell [14]. Nonlethal cell membrane blebbing was first introduced 30 years ago as a possible pathogenic mechanism in drusen formation [38, 166,167]. Blebbing is an early morphologic sign of cell injury which occurs immediately after exposure to a wide variety of toxic agents. However this process is different from lethal blebbing and apoptosis [168-170]. As mentioned previously, under prolonged injury, blebs may accumulate between the RPE and the basal lamina underneath this cell monolayer. Based on this concept, a plausible role for blebs in the pathogenesis of dry AMD has been suggested as a likely contributor to build-up of the sub-RPE deposits, which are characteristic of the early stages of this disorder [14]. 


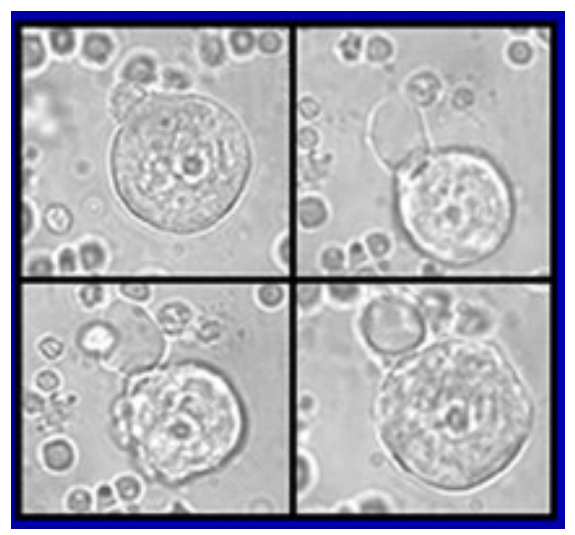

Figure 5. Plasma membrane microvesicles (blebs).

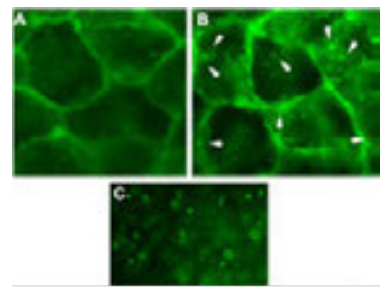

(a)
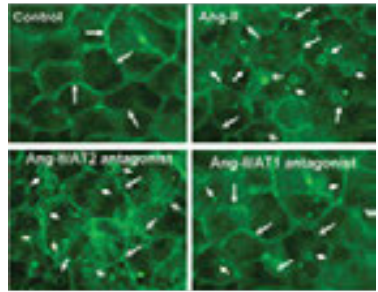

(b)

Figure 6. (a) Induction of membrane blebs in ARPE-19 cells by hydroquinone-induced cellular stress. ARPE-19 cells expressing GFP at the plasma membrane (A) were exposed to HQ $(100 \mu \mathrm{M})$ for $6 \mathrm{~h}$ (B). Cells were observed immediately under epifluorescence microscope (magnification, $\times 40$ ). The figure shows GFP localized to the membrane and the presence of membrane blebs (white arrowheads) after HQ treatment. A detailed view of the blebs that accumulated in the conditioned medium after HQ treatment is shown (C). (b) Induction of cellular changes in ARPE-19 cells by Ang II. Fluorescent GFP-ARPE-19 derived blebs before and after exposure to Ang II (100 nM) alone or in combination with a specific Ang II receptor antagonists AT1 (CD, 100 nM) or AT2 (PD 123319, 100 nM) for 24 hours. Cells were treated and observed immediately under epifluorescent microscope. White arrows show GFP localized to the membrane. White arrowheads show the presence of membrane blebs. 
Using a genetically modified human RPE cell line containing fluorescent protein anchored to the inner leaflet of the plasma membrane, we demonstrated nonlethal blebbing in response to oxidative stress. Bebbing can be induced by oxidant injury with blue light, myeloperoxidase (MPO), hydroquinone (Monroy D., et al., IOVS, 2001, 42(4), ARVO Abstract, 4060; Suner I.J., et al. IOVS 2004; ARVO E-Abstract 1810) [56,171], or Ang II (Fig. 6). Today, however, RPE bleb composition and potential functions remain largely unexplored.

Membrane bleb or microvesicle production stimulated by a variety of stress has been extensively described in many different cell types [172-178]. To gain a better understanding of the functional relevance of blebs in general and the pathogenic mechanism(s) involved in early AMD in particular, we investigated the identity of proteins carried by human RPE blebs. In our study, we showed the proteomics characterization of stress-induced blebs in RPE cells from human retina. We report identification of several proteins, some of them potentially involved in MMP activation, membrane lipid raft formation, and immunogenic processes (Fig. 7) [179]. In our study, we intended to gain some insight into the functional characterization of blebs to unravel some of the biological consequences of cell membrane blebbing in disease.
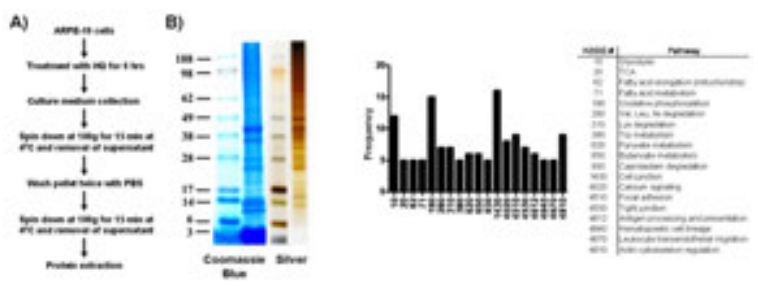

Figure 7. Isolation of blebs (left). A, scheme for bleb isolation. ARPE-19 cells were treated with HQ (100 $\mu \mathrm{M})$ for $6 \mathrm{~h}$. Culture medium was collected and centrifuged at $100 \times \mathrm{g}$ for $15 \mathrm{~min}$ at $4{ }^{\circ} \mathrm{C}$. The resulting pellet was washed twice with PBS and resuspended. The resuspended pellet was centrifuged at $100 \times \mathrm{g}$ for $15 \mathrm{~min}$ at $4{ }^{\circ} \mathrm{C}$, and the supernatant was removed. Blebs were collected and used for protein extraction. $B$, representative one-dimensional gel showing the Coomassie Blue and silver stainings of resolved proteins present in ARPE-19 blebs. Functional characterization of proteins identified in hydroquinone-induced blebs (right). The distribution profile of the proteins identified in hydroquinone-induced blebs is depicted according to functional categories. The KEGG database number and its corresponding metabolic pathway are shown. TCA, tricarboxylic acid cycle.

Blebbing are closely interrelated with the actin cytoskeleton [180-188]. The cytoskeleton is a dynamic structure undergoing continuous turnover by disassembly and reassembly of G-actin

monomers, which are added to the active edge of a growing filament. Cytoskeletal turnover is mediated by actin polymerizing protein system (APP), which is a large system of interacting proteins. The identity of these proteins is a rapidly growing field, and includes kinases, phosphatases, cleavage proteins, and elongating proteins. Their individual specific function and regulatory interactions remain essentially unknown. However, in general, the APP functions as a coordinated system such that individual molecular regulators of cytoskeleton dynamics exert their actions on the entire APP in coordinated fashion [180-188].

Very little information is available regarding the molecules that regulate the APP system and disease pathogenesis. Interestingly, oxidant injury is an effective activator of increased 
cytoskeleton turnover, presumably secondary to direct oxidative changes of disulfide bonds within actin filaments [180, 189-192]. The best characterized inhibitor/ stabilizer of cytoskeleton turnover is heat shock protein 25/27 (Hsp25/27). This molecule belongs to the family of small heat shock proteins (which includes $\alpha-\beta$ crystallins) and serves a dual role as cytoskeleton stabilizer and chaperone protein [191-193].

Oxidant injury can induce a rapid upregulation of Hsp25/27 protein through the activation of presynthesized heat shock factors (hsf-1,-2,-3) which upon oxidation form trimers that become very potent transcription factors [184-189]. Upon phosphorylation, Hsp25/27 acts as an F-actin cap-binding protein, binding to the active edge of a growing microfilament, causing a transient delay in actin cytoskeleton reassembly and repair [180,181,194,195]. Transient delay in reassembly allows the unsupported plasma membrane to be forced outward by the hydrostatic forces of the cytoplasm, and a vesicle or bleb forms if cortical cytoskeleton and microfilaments do not completely reform within the outpouched membrane. Phosphorylation of Hsp25/27 is mediated through the MAP kinase cascade, but is directly phosphorylated by MAPKAP 2 kinase (MK2), which in turn is phosphorylated by p38 kinase (Figure 4) [180, 196]. Thus, oxidative stress induces profound rearrangements of the actin cytoskeleton [197, 189, 198] leading to membrane blebbing through the activation of p38 mitogen activated protein kinase (MAPK)//Heat shock protein 27 (Hsp27) pathway [190,198].

In response to stress, phosphorylated Hsp27 undergoes conformational changes and reorganizes into dimeric units [198-202]. Phosphorylated Hsp27 regulates actin filaments dynamics by repressing the ability of Hsp27 to block actin polymerization [201]. Hsp27 phosphorylation has been abundantly described in several human diseases [203]. Yet, there is a complete lack of information regarding the possible association between phosphorylated Hsp27 and AMD. Increased Hsp27 protein content along with evidence of cellular oxidative stress was reported in human eyes with AMD, but Hsp27 phosphorylation was not investigated [204]. Therefore, we believe that Hsp27 is an important mediator of RPE response to hydroquinone-induced oxidative damage, which may contribute to injury-induced actin rearrangement and blebbing. We studied the phosphorylation of Hsp27 in RPE from human eye donors and found that the RPE constitutively express phosphorylated Hsp27, and that its expression is increased in patients with dry AMD (Fig. 8) [205] providing novel evidence that phosphorylated Hsp27 may play a major role in the pathogenesis of AMD.

We reported that human RPE cells constitutively express high levels of Hsp27 which were regulated by oxidative-mediated injury and that Hsp27 is expressed in extruded blebs confirming that Hsp27 plays a role in actin filaments dynamics [205, 206]. We also addressed the question whether hydroquinone-induced oxidative injury can activate different MAPK pathways of any posttranslational modifications such as dimerization or phosphorylation of Hsp27 known to regulate F-actin polymerization. Our previous observations were extended by showing that exposure of RPE cells to cigarette smoke-derived hydroquinone non lethal injury induces the transcriptional activation of Hsp27, accumulation of Hsp27 dimers and a rapid phosphorylation of Hsp27 as well as actin rearrangements inton aggregates and membrane blebbing (Fig. 9) [205]. These results together with the observation that SB203580, a specific pharmacologic inhibitor of p38 kinase activity [207], efficiently blocked Hsp27 
A
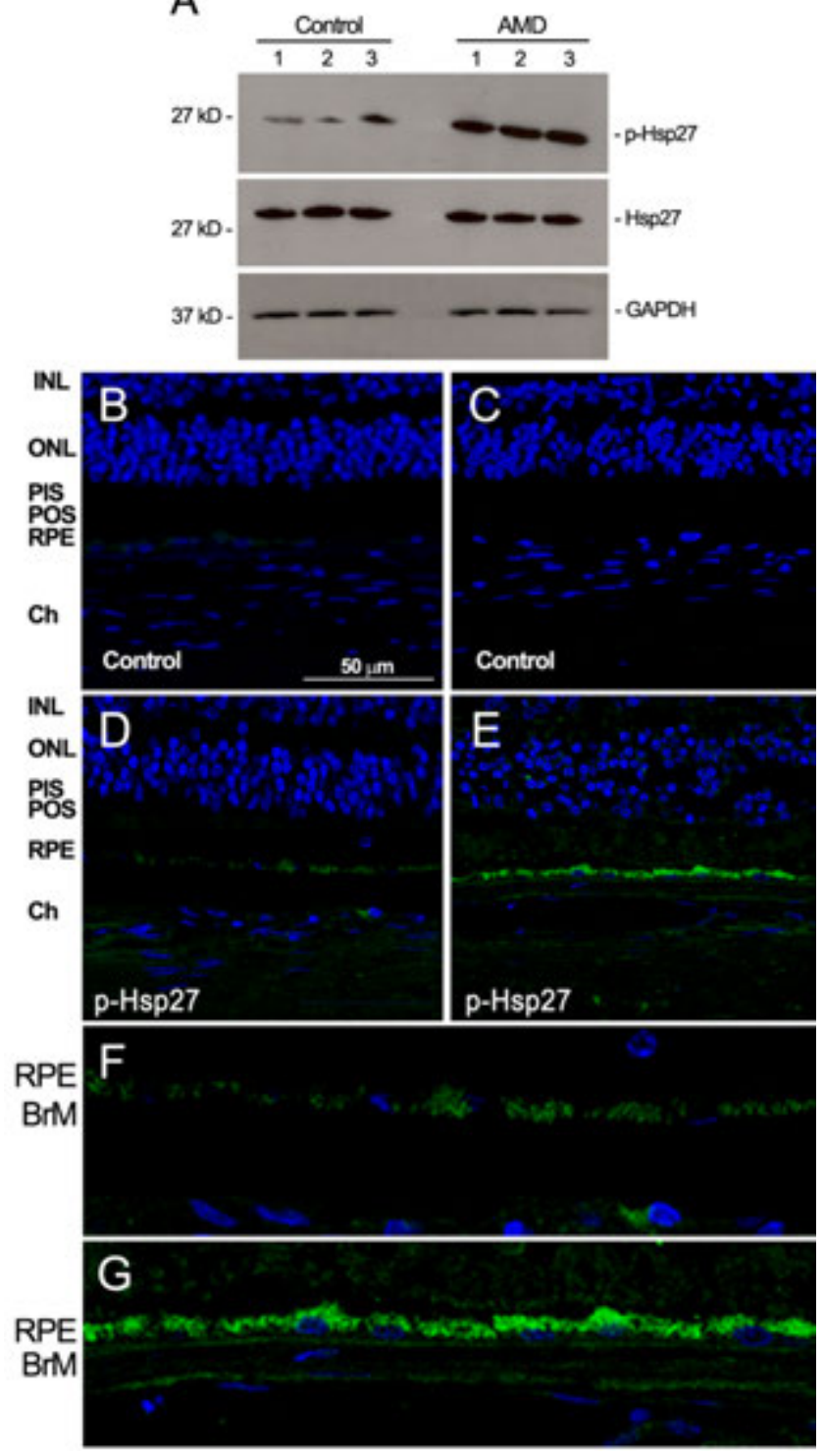

Figure 8. Increased phosphorylated Hsp27 ( $\mathrm{p}-\mathrm{Hsp} 27$ ) expression in human RPE from patient donors with dry AMD. A: Representative Western blot for p-Hsp27, total Hsp27 and GAPDH on RPE lysates from 3 donors with dry AMD and 3 controls with no known history of eye disease. B-G: Representative immunofluorescent double staining of p-Hsp27 (green) and nuclei (bleu) in retina sections from human donor eyes with no known eye disease (D), and human donor eyes with dry AMD (E). Negative controls were generated by omission of the primary antibody (B, C). Higher magnification showing RPE and BrM in control $(F)$ and $A M D(G)$ patients. Sections were analyzed using confocal microscopy (magnification x40 and x400). INL, inner nuclear layer; ONL, outer nuclear layer; PIS, photoreceptor inner segments; POS, photoreceptor outer segments; RPE, retinal pigment epithelium; Ch, choroid; BrM, Bruch's membrane. 
phosphorylation as well as actin cytoskeleton remodeling and blebs formation in response to hydroquinone in RPE cells, strongly suggest that p38 MAPK pathways activation by hydroquinone modulates F-actin aggregates formation and membrane blebbing through Hsp27 phosphorylation. Our findings are in agreement with prior studies reporting p38 MAPK signaling pathway as an upstream mediator in oxidative stress-induced actin reorganization and Hsp27 phosphorylation [190, 198-200, 208].

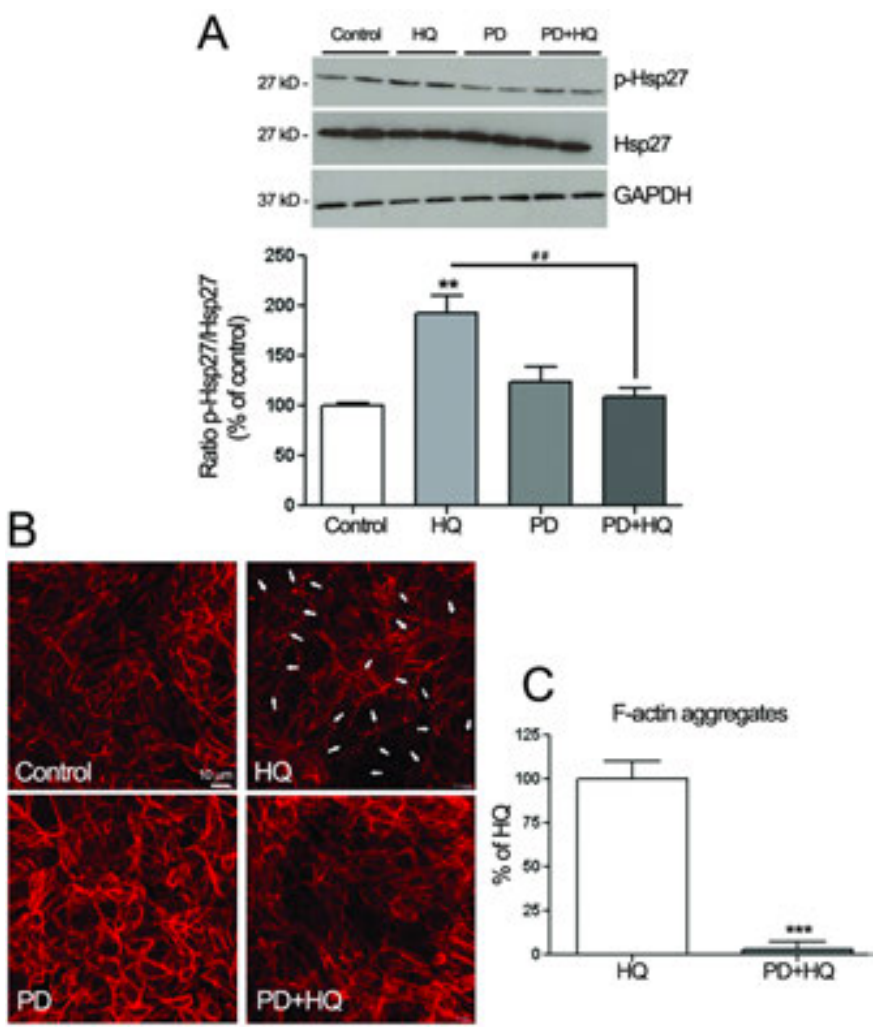

Figure 9. Inhibition of ERK MAPK pathway blocks hydroquinone (HQ)-induced Hsp27 phosphorylation and focal aggregates formation. A: Abrogation of HQ-induced Hsp27 phosphorylation by PD98059. Confluent serum-starved

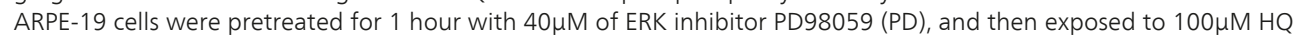
for $5 \mathrm{~min}$. Total Hsp27, p-Hsp27 and GAPDH protein expression was evaluated by Western blot analysis. Top: Western blot from a representative experiment. Numbers on the left represent protein molecular mass in kilodaltons (kD). $p$ Hsp27 protein expression was normalized to total Hsp27 protein. Bottom: average densitometry results of three independent experiments run in duplicate. Data are expressed as percentage of control and are means $\pm \mathrm{SE}$. ${ }^{* *} \mathrm{p}<0.01$ versus control; \#\#p<0.01 versus HQ alone. B: Decreased formation of F-actin aggregates showed by staining for $\mathrm{F}$ actin in ARPE-19 cells pretreated for 1 hour with or without $40 \mu \mathrm{M}$ of PD and then exposed to $100 \mu \mathrm{M}$ HQ for 6 hours. Cells were stained with rhodamine-phalloidin and examined by confocal microscopy using magnification $\times 40$. White arrowheads show formation of focal aggregates. C: Quantification of F-acting aggregates from three independent experiments run in duplicate. Data are expressed as percentage of HQ-treated cells and are means $\pm \mathrm{SE} .{ }^{* \star *} \mathrm{p}<0.001$ versus HQ-treated cells. 
Several reports have shown that PP2A is involved in Hsp27 dephosphorylation $[209,210]$ and that oxidative stress causes extracellular-signal-regulated kinases (ERK) phosphorylation and reorganization of actin cytoskeleton in RPE cells [211]. Using okadaic acid as an inhibitor of Hsp27 dephosphorylation by PP1 and 2A, we observed an increase in Hsp27 phosphorylation in hydroquinone-stimulated RPE cells as well as F-actin reorganization and blebs formation [205]. Moreover, we demonstrate that Hsp27 phosphorylation and F-actin aggregates formation is almost completely abolished in cells transfected with siRNA against Hsp27 following treatment with hydroquinone [205].

As mentioned above ERK cascade participates in numerous intracellular signaling pathways in response to environmental stimuli, such as oxidative stress [211]. Our study also show that treatment with hydroquinone led to a robust activation of ERK signaling pathway in ARPE-19 cells as well as in mice. These results together with the observation that PD98059, a specific pharmacologic inhibitor of MEK, completely abolished Hsp27 phosphorylation as well as actin cytoskeleton remodeling in response to hydroquinone, strongly suggest that ERK is also a key upstream activator of hydroquinone-induced Hsp27 phosphorylation in RPE cells [205] (Fig 9). Our results not only showed that kinetics of p38 and ERK phosphorylation correlated well with that of Hsp27, but also that Hsp27 phosphorylation and F-actin aggregates formation were decreased after inhibition of either p38 or ERK signaling cascades. These observations suggest that p38 as well as ERK MAPK pathways are required for the optimal activation of Hsp27 leading to F-actin rearrangement and bleb formation in RPE cells in response to hydroquinone. Taken together,these data establish; a) a direct correlation between levels of phosphorylated Hsp27 and actin cytoskeleton reorganization in response to hydroquinoneinduced oxidative injury in human RPE cells; b) present ERK as a novel upstream positive regulator of Hsp27 and actin aggregates formation in response to hydroquinone-induced oxidative injury in RPE cells; and c) give support to a key role of phosphorylated Hsp27 in the regulation of F-actin filaments dynamics and blebs formation following hydroquinoneinduced oxidative stress in RPE cells. Given that there is no effective treatment for dry AMD, this study highlights Hsp27 as a potential, disease-related protein as well as biochemical pathways for potential therapeutic strategies.

In addition to Hsp27/Hsp25, other important molecules such as small GTPases protein superfamily (RAS and Ral) have been involved in the regulation of the actin polymerizing protein system and oxidative stress [212,213]. Membrane blebbing is RhoA-, Rho kinase (ROCK)-, and myosin light chain kinase (MLCK)-dependent, and blebs are devoid of actin, mDia1 and Arp2/3 [214]. Rals are small G proteins that cycle between an active GTP-bound state and an inactive GDP-bound state [215]. Ral GDP dissociation stimulator (RalGDS) was found to be an effector of Ras [216-218] and highly specific for RalA and RalB, whereby it facilitates the exchange of GDP for GTP on Rals $[216,219,220]$. Moreover, it has been demonstrated that RalGDS forms a cytosolic complex with $\beta$-arrestin, and that in response to formylMet-Leu-Phe (fMLP) receptor stimulation, RalGDS is released from $\beta$-arrestin and translocates to the plasma membrane.

RhoA is an additional small G protein that is implicated in regulating plasma membrane dynamics. RhoA is activated by Ang II and is necessary for AT1 receptor-induced stress fiber formation [221]. The proteins ROCK and mDia1 are both RhoA effectors and have been shown 
to play a role in changes in actin cytoskeletal reorganization. RhoA acts through ROCK to form stress fibers [240], and ROCK has been shown to be involved in cell contraction induced by Ang II [222]. mDia1 is a member of the ubiquitous formin protein family. These proteins are activated by interaction with Rho GTPases and are then able to mediate actin polymerization [223]. Overexpression of the GTP-Rho binding domain of mDia1 causes spontaneous membrane blebbing [224].

Ang II-stimulated membrane bleb formation involves RhoA. Furthermore, membrane blebbing activated by Ang II through AT1 receptor activation is attenuated in the presence of the $\beta$-arrestin amino-terminal domain, Ral GDP dissociation stimulator (RalGDS) $\beta$-arrestin binding domain, and short interfering RNA (siRNA) depletion of $\beta$-arrestin2 [225]. In addition, the inhibition of the downstream RhoA effectors ROCK and MLCK effectively attenuated AT1 receptor-mediated membrane blebbing. Thus, membrane blebbing in response to AT1 receptor signaling was dependent on $\beta$-arrestin 2 and was mediated by a RhoA/ROCK/MLCK-dependent pathway providing evidence that agonist stimulation of AT1 receptor leads to plasma membrane blebbing responses by activation of RhoA and subsequent coupling to the ROCK/ MLCK pathway [225].

Cytoplasmic actin aggregates were observed after nonlethal blebbing, but not with lethal oxidant injury. Interestingly, activation of the AT1 receptor with Ang II resulted in the rapid formation of ROS and membrane blebs at early time points of Ang II stimulation that cease within 60 min of Ang II stimulation (Marin-Castano., et al., IOVS, 2001, 42(4), ARVO Abstract, 4060). Further, Ang II-enhanced ROS production and blebbing was prevented by pre-treatment of RPE with the AT1 receptor blocker, which attenuates oxidative stress [226]. However, RPE derived blebs after Ang II were bigger than those seem when RPE cells were exposed to blue light, MPO, or hydroquinone. Moreover, formation of RPE-membrane blebs induced by Ang II occurred earlier than with the other oxidants we studied. Therefore, we believe that Rho-kinase pathway could be implicated as an important mediator of RPE response to Ang II-induced oxidative damage instead of Hsp27/Hsp25/p38/ERK pathway.

In conclusion, characterization of the molecular mechanism(s) by which hydroquinone and the AT1 receptor regulates the actin cytoskeleton and plasma membrane dynamics will be essential for modulating the degree of blebbing in vitro and deposit formation in vivo for potential therapeutic strategies.

Another injury response relevant to early AMD is imbalance in ECM turnover. The normal anatomy and physiology of ECM in most tissues requires continuous turnover of matrix components by a tightly regulated balance in the production of matrix molecules like collagen, laminin, matrix metalloproteinases (MMPs), and tissue inhibitors of metalloproteinases (TIMPs) [227,228]. Matrix metalloproteinases (MMPs) are a family of at least 20 zinc endopeptidases that take part in the regulation of cell matrix composition by cleaving basal lamina and ECM proteins. MMPs can be secretory or cell surface bound. Under normal conditions, MMP activity is required for tissue remodeling, but altered MMP activity has been reported in disease. Most MMPs are secreted as inactive pro-proteins but get activated when cleaved by extracellular proteinases. Interestingly, one of the targets of MMP activity is the ECM molecules in BrM. 
It has been shown that relatively small dysregulation in the relative production of MMPs, TIMPs, and collagen types I and IV $[227,228]$ may lead to net changes in the ECM, including thickening and deposit formation $[228,231]$. Accordingly, dysregulated turnover of ECM is a major mechanism of disease pathogenesis in many tissue sites, including renal disease, atherosclerosis, lung disease, and others [228-231]. Unfortunately, minimal information is available concerning normal turnover in healthy BrM or imbalanced turnover in AMD.

Ample evidence supports the idea that MMPs and their tissue inhibitors TIMPs play an important role in AMD. The RPE is capable of producing many ECM components such as MMP-2, MMP-14, Basigin, also known as EMMPRIN (extracellular matrix metalloproteinase inducer) or CD147, collagen, and TIMP-2 [56,171,232, 233]. MMP-2 and MMP-14 are the major RPE enzymes synthesized for the degradation of matrix type IV and I collagens, laminin, and fibronectin, which are components found in BrM [232,233]. MMP-2 is the key enzyme for ECM turnover in BrM and is synthesized as an inactive zymogen pro form (pro-MMP-2) [227]. The transmembrane metalloproteinase MMP-14 is well known to activate MMP-2 in a specific manner [233]. On the other hand, TIMP-2 may inhibit the cleavage of pro-MMP-2 into MMP-2 [228]. Based on these data our research focuses on MMP-2, MMP-14, basigin, and TIMP-2 and propose that dysregulation of MMP-2 is the primary cause for the accumulation of sub-RPE deposits that become BLD and drusen. Thus, preservation of RPE-derived MMP-2 function will prevent these events.

As mentioned before, oxidative injury to the RPE may not only produce blebbing but also dysregulated ECM turnover $[5,46,47,206,234,235]$. Our group has demonstrated that nonlethal oxidant injury to the RPE with hydroquinone induces a wide range of changes in gene expression, especially for those genes involved in regulation of ECM [47], and that blebs form and accumulate in the absence of activated MMP-2, which otherwise induce breakdown of types I and IV collagen present in the basement membrane of the RPE [235]. Sustained oxidant injury with hydroquinone is capable of downregulating MMP-2 activity in an in vitro system of RPE cells, correlating with an increase in bleb levels [56,171]. Also, type IV collagen accumulation, the main component of the RPE basement membrane, correlated with the absence of MMP-2 activity [56]. Accordingly, we have shown in vivo [235] that reducing MMP-2 activity leads to an increase in deposit formation by RPE cells. This allows the blebs to become trapped between the RPE cell membrane and the basement membrane to form BLD.

For the BLD deposits to progress into linear deposits ECM upregulation with MMP-2 activation is necessary for collagen and BLD deposit degradation. This will ultimately displace subRPE deposits into the inner layer of BrM where BLinD and drusen are histologically found. As proposed in our hypothetical model fro dry AMD, RPE-derived blebs accumulated as BLD could stimulate RPE basement membrane breakdown allowing the migration of BLD and buildup of BLiD or drusen. We postulate that various plasma-derived molecules related to systemic health cofactors (i.e., Ang II) are implicated in this stage.

As an attempt to better understand the mechanisms involved in early AMD, we investigated the proteomic profile of RPE-derived blebs induced by hydroquinone. Interestingly MMP-14 and basigin were identified in the RPE blebs [236]. Both proteins are of special relevance to the AMD pathology as they promote MMP-2 activation. Basigin, is a pleiotropic transmembrane 
glycoprotein [236,239]. The basigin gene (BSG) encodes for a $29 \mathrm{kDa}$ protein which is prone to glycosylation increasing its molecular weight between 35 and $65 \mathrm{kDa}$ [238-240]. Induction of matrix MMPs constitutes the most relevant function of basigin [240, 242-244]. A clear requirement for basigin to be glycosylated exists for MMP induction [245-247]. The fact that basigin is a prominent MMP inducer provides this protein with a putative role in normal tissue remodeling physiology and ECM pathologies other than cancer. In particular, glycosylated basigin has been reported to be necessary for maturation of the retina photoreceptor cells [248]. Within the mature eye, basigin is expressed in the RPE, Mueller cells, and in endothelial cells of blood vessels [249-252]. A known mechanism by which basigin increases the MMPs occurs at transcriptional level $[253,254]$. However, shedding of basigin from the plasma membrane constitutes an additional regulatory mechanism recently proposed where basigin is transported in microvesicles which are later on degraded, releasing soluble, active basigin [255]. This proposed mechanism may permit basigin to exert its actions at distant sites. MMP-14 is an interesting candidate responsible for the basigin shedding [256-258]. Based on the cited evidence, we hypothesize a mechanistic model by which basigin and MMP-14 are carried to distal sites from the RPE where they exert their actions promoting MMP-2 activity. In addition, MMP-14 may interact with basigin releasing fully functional "soluble" basigin (Fig. 10).

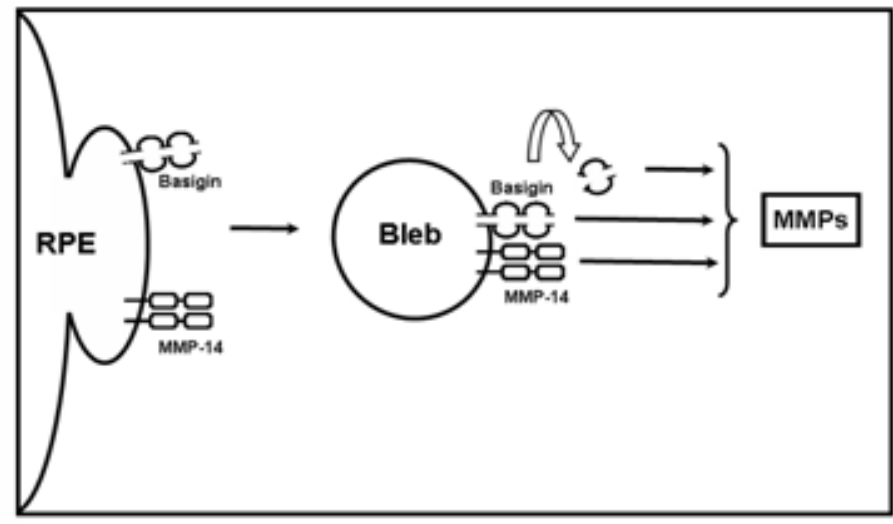

Figure 10. Mechanistic model by which basigin and MMP-14 are carried to distal sites from RPE where they exert their actions promoting MMP-2 activity.

We reported the presence of glycosylated basigin and MMP-14 in blebs, which was confirmed by Western blot and immunofluorescence staining in human control and AMD retinas (Fig. 11) [179]. Basigin and MMP-14 were confined to the RPE in normal retina, while it was widely expressed in AMD retina. In addition, our data showed that RPE cells incubated with blebs exhibit increased active MMP-2. MMP-2 activity returned to basal levels after incubation with anti-basigin and MMP-14 antibodies (Figure 10), suggesting that both proteins may play a pivotal role determining MMP-2 activity [179]. Thus, blebs accumulated under the RPE will stimulate ECM turnover increasing active MMP-2 through the action of two bleb- 
carried proteins, basigin and MMP-14. Therefore, we speculate that blebs may play an important role for sub-RPE to traverse RPE basement membrane. RPE are subsequently stimulated to increase synthesis of collagens and other molecules responsible for ECM turnover, affecting both RPE basement membrane and BrM. This process leads to the formation of new basement membrane under the RPE to trap these deposits within BrM. We postulate that various hormones and other plasma-derived molecules related to systemic health cofactors are implicated in this stage.
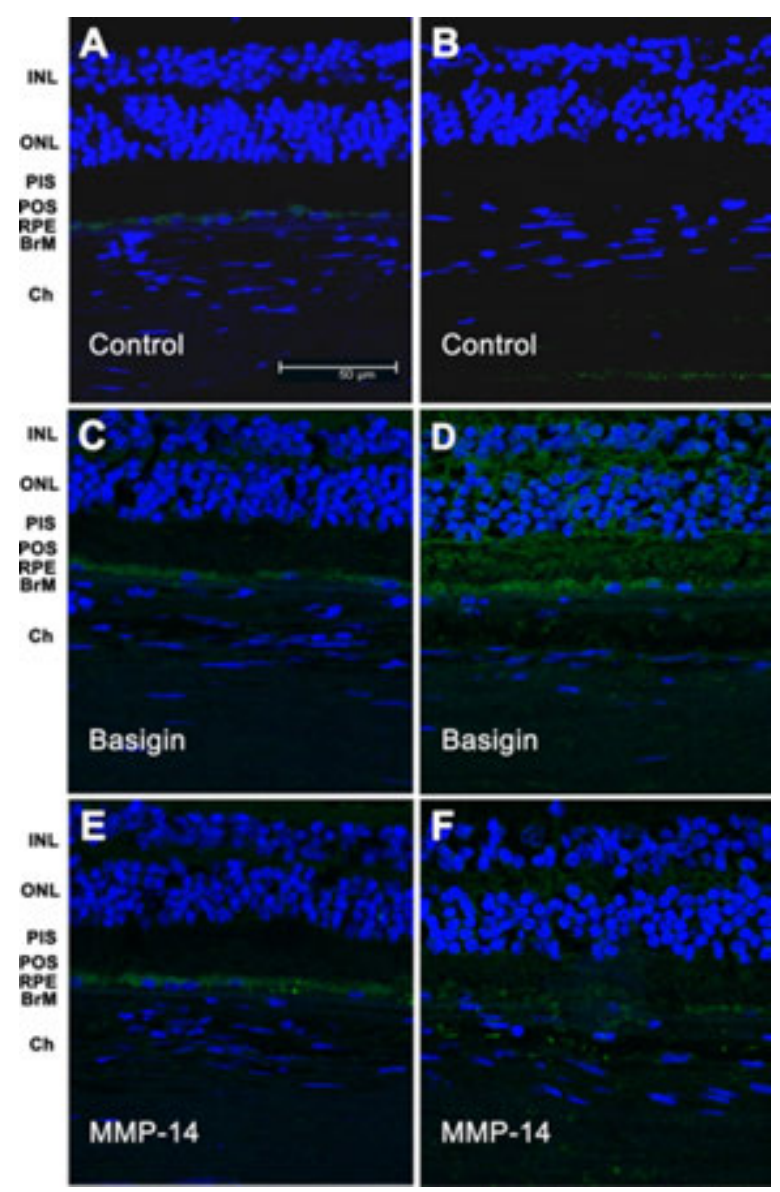

Figure 11. Immunohistochemical analysis of basigin and MMP-14 in human retina. Retina sections from human donor eyes with no known eye disease ( $A, C$, and $E$ ) or from human donor eyes with dry $A M D(B, C$, and $F)$ were stained with either mouse polyclonal anti-basigin ( $C$ and $D)$ or mouse monoclonal anti-MMP-14 (E and F) as indicated. Negative controls were generated by omission of the primary antibody (A and B). Secondary antibodies were coupled to Alexa Fluor 488. Nuclei were stained with 4,6-diamidino-2-phenylindole dihydrochloride. Sections were analyzed under a confocal microscope. INL, inner nuclear layer; ONL, outer nuclear layer; PIS, photoreceptor inner segments; POS, photoreceptor outer segments; Ch, choroi. 


\section{Inflammation and angiogenesis}

\subsection{Inflammation: Role of cigarette smoke and angiotensin II}

Another potential oxidative injury stimulus in AMD may occur during inflammation. Histopathology of AMD demonstrates that all stages of the disease, including drusen, geographic atrophy and $\mathrm{CNV}$, are associated with inflammatory cells, especially macrophages $[24,25,37,259,260]$. One well-characterized inflammatory oxidant is myeloperoxidase (MPO), a heme protein secreted by neutrophils and macrophages that converts its substrate hydrogen peroxide into an active oxidant [206]. RPE metabolism results in high quantities of hydrogen peroxide synthesis, which by itself is a weak oxidant and is neutralized by catalase and other anti-oxidant enzyme systems [261-263]. However, in the setting of MPO release, RPE-derived hydrogen peroxide can become a powerful oxidant [171]. Macrophage-derived MPO will remain extracellular, but may initiate or potentiate the RPE injury response by catalyzing hydrogen peroxide into the formation of powerful oxidants such as hydroxyl radicals, hydroperoxides, hypochlorous acid, and tyrosyl radicals [50,264]. Among their actions, MPOderived oxidants induce injury to the cell membrane and modify cell surface proteins and receptors [50,265,266].

Data from a number of laboratories provide compelling evidence that inflammatory and/or immune-mediated events may participate in the development of sub-RPE deposits formation and/or progression to CNV [12,24, 267-269]. Based upon available data, a new paradigm has been introduced for sub-RPE formation and its relationship to AMD. This integrated hypothesis is based largely upon the dynamic interactions between those factors that induce and sustain chronic local inflammation at the level of the RPE-BrM-choroidal interface, and those mechanisms that attenuate it. Complement and immune complexes have been identified in drusen, but their pathogenic role has not been defined. This information has been recently reviewed [24-27]. Other investigators have observed that choroidal monocytes/ macrophages are present in human specimens of both early and late AMD [24,25,27,37,259,270]. Macrophages have been detected along the choriocapillaris-side of BrM underlying areas of thick drusen or other deposits [10, 260-273] and processes from choroidal monocytes have been noted to insert into BrM deposits [260] Moreover, dentritic cells are often observed in the subRPE space in association with whole, or portions of, RPE cells that have been shunted into $\mathrm{BrM}$, prior to the time that drusen are detectable. Therefore, macrophages and choroidal dentritic cells may be activated and recruited by locally damaged and/or sublethaly injured RPE cells. This idea is consistent with the data showing that macrophages and/or dentritic cells, and thus the innate immune system, can be activated by microenvironmental tissue damage $[14,274,275]$. However it remains to be determined whether drusen-associated macrophages and dentriric cells initiate a classical immune response involving $\mathrm{T}$ helper cells, secreted cytokines, elicit an inflammatory or complement-mediated response, or play some other role in the generation of drusen.

While it is largely recognized that macrophages accumulate in AMD lesions, there is ambiguity surrounding their role in the disease process with conflicting evidence regarding whether they might be helpful by scavenging accumulated debris and therefore protecting against CNV or harmful by stimulating CNV [100]. This might be due to the largely observational nature of 
human samples but also probably reflects different functions macrophages serve during distinct phases of the disease.

Inflammation is a complex process that involves local secretion of pro-inflammatory cytokines (leukocyte adhesion molecules, ICAM-1 and VCAM-1) [276,277], MCP-1 [278-282] NFkB [283-285], and growth factors (tumour necrosis factor, TNF- $\alpha$, TGF- $\beta$ ). The key inflammatory molecule in initiating inflammatory responses may be MCP-1 [278-284] a powerful chemokine, expressed at sites of injury. Indeed, the importance of MCP-1 in inflammatory diseases is highlighted by a careful MEDLINE search for MCP-1, which readily returns more than 3000 citations following its characterization in the late 1980s. NFKB appears to control expression of MCP-1 [283-285]. After release, it activates the CCR2 chemotactic receptor to induce chemotactic responses that mediate monocyte and macrophage migration into sites of active inflammation in various diseases [286,287].

Based upon the assumption that injured RPE may serve as stimulatory factors that initiate macrophages recruitment and activation, it was determined if monocyte populations from individual AMD patients exhibited heterogeneity in terms of cytokine production in culture or in mRNA expression of freshly isolated cells, and if high levels served as a biomarker of risk for progression into neovascular AMD [51]. TNF- $\alpha$ expression, a potent cytotoxic and proangiogenic cytokine for wet AMD. Typically human macrophages in culture, after stimulation with RPE derived blebs produced an increase in TNF- $\alpha$. However, extremely high variability in baseline TNF- $\alpha$ expression from isolated macrophages was observed among different subjects [51]. These results are consistent with the hypothesis that the pre-existing macrophage activation state, defined as level of cytokine or mediator expression of the circulating monocyte, might determine the negative or positive consequence of macrophage recruitment as a disease modifier. Macrophages with low expression might remove deposits safely whereas macrophages with high expression might produce mediators that contribute to disease progression.

As mentioned above, aberrant expression of chemokines occurs in a variety of diseases that have an inflammatory component. Highly specialized RPE cells play a pivotal role in the maintenance of the outer retina by secreting several cytokines including monocyte chemoattractant protein-1 (MCP-1) [288,289] which has been suggested to be implicated in the pathogenesis of AMD [290,291]. RPE cells can secrete MCP-1 in the direction of choroidal blood vessels during inflammatory responses therefore suggesting that RPE cells might promote macrophage recruitment to the choroid from circulating monocytes [292]. It was reported that MCP-1 is regulated in injured ARPE-19 cells and that free radicals might be immunostimulatory [293] providing support for the notion that injured RPE cells may induce monocyte migration.

We have investigated MCP-1 expression in RPE from patients with AMD as well as the regulation of RPE-derived MCP-1 expression following cigarette hydroquinone-mediated oxidative injury. Our data report for the first time that MCP-1 expression is markedly decreased in RPE from smoker patients with AMD [294] thereby pointing to a critical role for MCP-1 in the pathogenesis of the disease. We acknowledge that due to the nature of our study, it cannot be determined whether the altered expression of MCP-1 in human RPE lysates is a cause or consequence of the disease. However, our current findings suggest that declining 
MCP-1 production by aging RPE cells may impair recruitment of macrophages/dentritic cells essential for scavenging debris which may lead to drusen formation and accumulation in AMD patients. It can be speculated that declining RPE-derived MCP-1 production resulting from cumulative exposure to oxidative damage may be an important factor that could accelerate and promote the formation of sub-RPE deposits in smokers. This theory is put forth bearing in mind the complexity of underlying cellular and molecular mechanisms involved in the inflammatory response and with the acknowledgment that numerous AMD genotypes may exist. Therefore, we fully recognize that only some aspects of the proposed hypothesis may be involved in any given AMD genotype.

Based on the above hypothesis, we have evaluated the possibility that hydroquinone-induced oxidative stress might regulate MCP-1 expression in the RPE. We showed that prolonged exposure to hydroquinone-induced oxidative injury downregulated MCP-1 production by ARPE-19 cells and RPE/choroids from C57BL/6 mice [294]. An earlier study by Joly et al is in line with our observations showing a decline in $\mathrm{MCP}-1$ gene expression in retinas of mice exposed to light-induced oxidative damage for several days [294]. Our observations suggest that sustained exposure to hydroquinone might impair RPE-derived MCP-1-mediated scavenging macrophages and dentritic cells recruitment and phagocytosis which might lead to incomplete clearance of proinflammatory debris trapped between the RPE and its BrM. On the other hand, our preliminary date show that RPE-derived blebs activate RPE MCP-1 production (unpublished data), suggesting that when significant BLD will have already formed, RPE-blebs and other debris will activate MCP-1 secretion by RPE leading to infiltration of proangiogenic macrophages to sub-RPE deposit areas, where they will scavenge, relate more cytokines and mediators, and amplify the process leading to progression of drusen to CNV in smoker patients with AMD.

Angiotensin II is not only a potent vasoconstrictor which elevates arterial blood pressure, but also a powerful pro-inflammatory cytokine, chemokine and growth factor [276, 283-285,295], which mediates the activation of inflammatory mechanisms involved in age-related diseases [296,297]. There is accumulating evidence that Ang II can cause target organ damage by facilitating inflammatory and growth responses through activation of NFkB [276, 283-285], the key nuclear transcription factor in inflammatory and fibrotic diseases. Activation of $\mathrm{NF} \kappa \mathrm{B}$ by Ang II may stimulate transcription of numerous inflammatory genes, including MCP-1, RANTES (Regulated on Active Normal T cell Expressed and Secreted) and interleukin (IL)-6, TNF- $\alpha$ and TGF- $\beta$ [276,283-285]. The view that MCP- 1 is one of the most important chemokines in Ang II-induced inflammatory responses is supported by numerous studies, although the mechanisms by which Ang II increases MCP-1 expression and production are still not well understood [279,283-285]. In a rabbit model of atherosclerosis, ACE1 inhibitor quinapril inhibited NFkB activity, expression and production of MCP-1 and neointimal macrophage infiltration at the injured sites [283]. In Ang II-induced hypertensive rats, vascular MCP-1 mRNA expression increased almost four-fold, which was significantly reduced by normalization of hypertension by the non-specific vasodilator hydralazine, but the effects of AT1 receptor blockade were not studied [301]. However, in a different study, Ang II enhanced expression of MCP-1 mRNA and protein production in rat vascular smooth muscle cells in a dose- and time-dependent fashion, and these effects were mediated by AT1 receptors involving the Rho-kinase pathway [298]. In mice, Wu et al. [299] showed that the AT1 receptor 
antagonist valsartan, at a dose that did not influence systolic blood pressure, significantly reduced the expression of MCP-1 along with other inflammatory genes such as TNF- $\alpha$, IL-6, IL-1 $\beta$ and monocyte/macrophage infiltration in injured vessels. Interestingly, the effects of valsartan on MCP-1 expression were attenuated in AT2 receptor-deficient mice, suggesting that both AT1 and AT2 receptors are involved.The advantage of using a lower dose of AT1 receptor blockers is that the treatment does not reduce systolic blood pressure to the normotensive level, but retains clinical efficacy in inhibiting MCP-1 expression and improving cardiac function and mortality. Accordingly, the beneficial effects of the AT1 receptor blockers may be explained by a mechanism other than high blood pressure. A direct effect of Ang II on MCP-1 expression and production may be implicated [295].

Finally, the signalling mechanisms by which Ang II increases MCP-1 expression and production and induces end-organ damage remain to be elucidated. As mentioned previously, there is mounting evidence that $\mathrm{NF} \kappa \mathrm{B}$ may be one of the most important nuclear transcription factors that mediates Ang II-stimulated MCP-1 expression and production [276,283-285]. However, the signalling pathways by which Ang II directly or indirectly activates NFkB, which is then translocated into the nucleus to mediate $\mathrm{MCP}-1$ transcription and synthesis, remain largely unknown. A local RAS may be activated in most, if not all, diseases with consequently increased tissue or intracellular Ang II. Binding of extracellular Ang II to cell surface AT1 receptors may stimulate $\mathrm{MCP}-1 \mathrm{mRNA}$ expression through activation of different intracellular signalling cascades, likely involving protein kinase $\mathrm{C}$-activated intracellular calcium mobilization [300], tyrosine kinase and mitogen-activated protein kinase [301], phospholipase $\mathrm{A}_{2}$ [302] and redox-sensitive NADH/NAD $(\mathrm{P}) \mathrm{H}$ oxidase [301]. Future studies further addressing these important issues could improve our understanding of the potential role of pro-inflammatory cytokines and chemokines in mediating Ang II-induced target organ damage and assist in further development of novel drugs to prevent and treat these diseases.

Even if it has been suggested that increased MCP-1 expression may be a key mediator between Ang II and retinal damage in hypertensive patients, MCP-1 expression has not been investigated in RPE from hypertensive patients with AMD nor has been the regulation of RPE-derived MCP-1 expression following Ang II-mediated injury.

On the basis of our preliminary data and those of others, we have proposed a molecular inflammatory hypothesis for AMD that describes a central role for the redox-sensitive NF- $\kappa \mathrm{B}$ in modulating the gene expression of MCP-1. Many studies have provided experimental evidence indicating that NF- $\mathrm{BB}$ can be activated by oxidative stress [303-305] and that the antioxidant may have beneficial effects on vascular inflammation that occurs in other age-related diseases [306,307]. Thus, we proposed that Ang II will active RPE MCP-1 production leading to recruitment of macrophages to sub-RPE deposit areas, where they will scavenge, release more cytokines and mediators, and amplify the process promoting complications, especially $\mathrm{CNV}$ formation. Our preliminary data indicate that expression of MCP-1, key mediators pertinent to inflammation is markedly increased in cultured human RPE cells in response to Ang II (Fig. 12). Moreover, our data indicate that the increase in MCP-1 mRNA and protein secretion by RPE was through AT1 receptors activation (Fig. 12), highlighting such proinflammatory role of Ang II and their mechanism. These observations may have strong implications for the drusen progression to $\mathrm{CNV}$ in hypertensive patients with dry AMD. 
Future studies addressing whether or not Ang II directly or indirectly activates NFkB and the signalling pathways could improve our understanding of the potential role of Ang II in the progression of dry AMD to CNV.
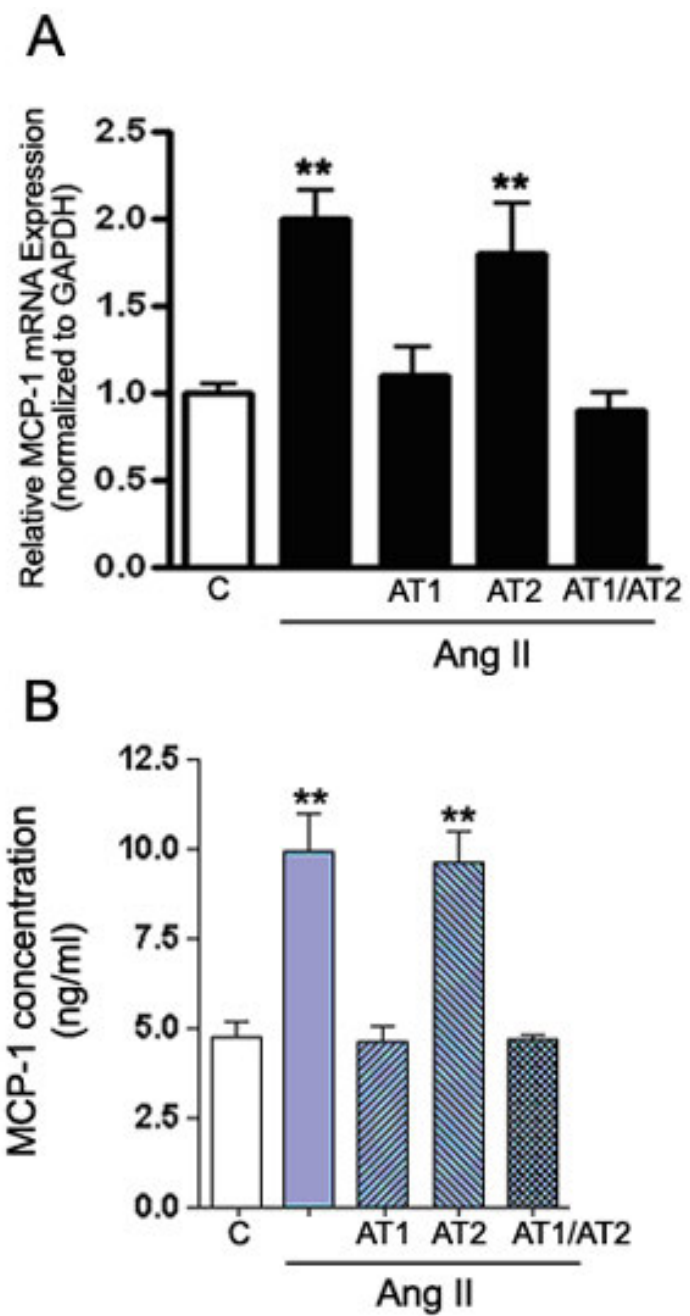

Figure 12. Ang II upregulated MCP-1 protein expression (A) and secretion (B) through Ang II receptor 1 (AT1) activation in RPE cells. Human ARPE-19 cells were incubated with Ang II alone (100 nM) for 24 hours or in combination with candesartan (CD, $100 \mathrm{nM}$ ), an AT1 receptor antagonist, or PD123319 (PD, $100 \mathrm{nM})$ an Ang II type 2 receptor antagonist for 30 min before Ang II stimulation, then washed with PBS and incubated in assay medium (0.1\% FBS) for 24 hours. Supernatants and cell homogenates were collected to assess MCP-1 mRNA expression by real-time PCR and protein secretion by ELISA. Results are expressed as mean \pm SEM. ${ }^{* *} \mathrm{P}<0.01$, statistically significant difference compared with the control 
Because hypertension has been unequivocally linked to the pathogenesis of AMD, it can be speculated that increase in RPE-derived MCP-1 production resulting from exposure to Ang II may be an important factor that could accelerate and promote the progression of early AMD to CNV. This theory is put forth bearing in mind the complexity of underlying cellular and molecular mechanisms involved in the inflammatory response.

\subsection{Angiogenesis: Role of cigarette smoke and angiotensin II}

Angiogenesis is a highly complex biological process that involves a delicate balance between numerous stimulators and inhibitors, each regulated by multiple control systems. CNV-related angiogenesis requires an alteration in the concentration of molecules that stimulate or inhibit growth of new blood vessels [308,309]. Vascular endothelial growth factor (VEGF) constitutively produced and secreted by RPE in culture [310-318], is a major angiogenic cytokine central to the development of wet AMD [312-315].VEGF regulates endothelial cells proliferation, migration and survival [315]. Interestingly, secretion of VEGF by RPE cells is polarized towards BrM [250]. There is ample clinical evidence that VEGF expression is increased in surgically excised AMD-associated choroidal neovascular membranes [315-317]. Eyes with early forms of AMD have increased expression of VEGF in the RPE and the vitreous of eyes with CNV have increased concentration of VEGF [315]. Similar observations have been made in animal models of CNV [311,320]. Furthermore, Reich et al reported that subretinal injection of VEGF siRNA significantly inhibited the growth of laser-induced CNV in a mouse model [318]. PEDF, a potent angiogenic inhibitor [321] secreted by RPE cells [322-324], counterbalances the effects of VEGF and modulates the formation of CNV [322,323]. A decrease in PEDF expression has been reported in eyes with AMD, therefore disrupting the critical balance between VEGF and PEDF that may lead to pathological angiogenesis and be permissive for the development of CNV [322]. PEDF levels decline in the vitreous of patients with CNV [324].

Interestinly, TNFSF15, a cytokine that belongs to the TNF superfamily, which originally was reported to be expressed exclusively in endothelial cells, and more recently in other several cell types in inflammatory diseases [325-328], could be implicated in the development of CNV. TNFSF15 is a potent inhibitor of endothelial cell proliferation, angiogenesis, and tumor growth [329] which has been involved in atherogenesis and neovascularization. Our preliminary data has shown constitutive TNFSF15 production and secretion by RPE in vitro and in vivo (MarinCastano, unpublished results). Moreover, there is recent evidence showing down-regulation of TNFSF15 by VEGF in endothelial cells, therefore disrupting the critical balance between TNFSF15 and VEGF and leading to development of neovascularization [330]. Based on this recent evidence, it is conceivable that the balance between TNFSF15 and VEGF could be of great importance in $\mathrm{CNV}$ development. However, until now, there is no report in the literature examining VEGF, PEDF, and TNFSF15 expression in RPE from AMD patients or evaluating whether or not cigarette smoke-related hydroquinone and nicotine and Ang II have the potential to dysregulate the VEGF/PEDF and VEGF/TNFSF15 balance in RPE cells.

Given the critical role of VEGF and PEDF in AMD and that oxidative damage to the RPE and angiogenesis appear to be central in the pathogenesis of the disease; we studied the expression of these chemokines in RPE from smoker patients diagnosed with AMD and whether cigarette 
smoke-derived hydroquinone and nicotine might also regulate VEGF and PEDF expression in RPE cells.

We report that VEGF expression is increased and PEDF expression is decreased in RPE from smoker patients with AMD resulting in an increased VEGF-to-PEDF ratio [282]. A disruption in the critical balance of these opposing stimuli may be permissive for the development of wet AMD. Our findings are consistent with clinical observations describing dysregulated expression of VEGF and PEDF [315-317,321,322,324] in eyes with AMD. Oxidant-mediated RPE damage might promote abnormal angiogenesis [309]. In vitro, although oxidative injury declined the production of PEDF without significantly changing VEGF expression in ARPE-19 cells regardless of dose and duration of exposure to hydroquinone, we observed an increased VEGF-to-PEDF ratio which may favor angiogenesis [282]. These results suggest that cigarette smoke-related HQ-induced oxidative stress might impair the delicate balance between VEGF and PEDF that controls angiogenic homeostasis in the retina. Other previous reports showed that cigarette smoke extract induces VEGF expression in ARPE-19 cells [104] and that $\mathrm{H}_{2} \mathrm{O}_{2}$ induced oxidative stress increased the production of VEGF in human RPE cells [309]. The discrepancy between our in vitro findings and those earlier observations with regards to VEGF might reflect differences in cellular responses in the setting of different types of oxidantmediated injury.

The endogenous angiogenic inhibitors are believed to be essential for maintaining the homeostasis of angiogenesis in the retina. Given the evidence that PEDF is an important negative regulator of angiogenesis, lower levels of PEDF is strongly suggestive of a decreased anti-angiogenic activity that may lead to the initiation of angiogenesis in response to hydroquinone-induced oxidative stress. However, we do not rule out the possibility that a decreased level of inhibitory factor PEDF by itself may not be sufficient for inducing the angiogenic switch leading to CNV. Reciprocal increase in stimulatory VEGF might also be needed. In fact, a longer more sustained exposure to hydroquinone might be necessary to induce VEGF expression in ARPE-19 cells. Furthermore, angiogenesis is a highly complex and tightly orchestrated multistep process involving extensive interplay between multiple angiogenic factors. It is therefore possible that several other molecules besides VEGF and PEDF regulated by hydroquinone might permit the development of abnormal angiogenesis. In vivo, we observed elevated expression of VEGF and PEDF protein in RPE/choroids from HQ-treated mice which translated into an enhanced VEGF-to-PEDF ratio. As stated earlier, important species-specific differences may also account for the discrepancy between human cells and mice results. In addition, one has to keep in mind that inherent in vitro and in vivo differences might explain this disparity. PEDF has multiple dose-dependent biological functions. Interestingly, it has been reported that low doses of PEDF are inhibitory but high doses can increase the development of CNV induced by laser in mice [331]. In addition, a study showed that RPE-derived VEGF upregulates PEDF expression via VEGF receptor-1 in an autocrine manner [332], therefore highlighting regulatory interactions between these two counterbalancing systems of angiogenic stimulators and inhibitors. In any case, our in vivo findings confirm that hydroquinone-induced oxidative damage is unequivocally associated with an imbalance between VEGF and PEDF in the RPE. 
We also studied whether Nicotine (NT), a potent angiogenic agent abundant in second hand smoke, play a major role in the pathogenesis of wet AMD. The purpose of this study was to evaluate the expression of nicotinic acetylcholine receptors (nAchR) in the RPE and determine the effects of NT on RPE-derived VEGF and PEDF expression in the context of passive smoking. We demonstrated that cultured RPE cells constitutively expressed nAchR $\alpha 3, \alpha 10$ and $\beta 1$ subunits, $\beta 1$ being most prevalent (Fig. 13). nAchR $\alpha 4, \alpha 5, \alpha 7$ and $\beta 2$ subunits were detected in RPE sheets from rats, among which $\alpha 4$ is the predominant subtype (Fig. 14). NT which did not, induced $\beta 1 \mathrm{nAchR}$, upregulated VEGF and downregulated PEDF expression through $\mathrm{nAChR}$ in ARPE-19 cells (Fig. 15). Moreover, transcriptional activation of $\mathrm{nAchR} \alpha 4$ subunit and nAChR-mediated upregulation of VEGF and PEDF were observed in RPE from rats exposed to NT [333]. Our findings confirm that NT is associated with an increased VEGF-toPEDF ratio in RPE through $n A c h R$ in vitro and in vivo which may play a key role in the progression to wet AMD in passive smokers [333].Taken together, these data provide strong support for a key role played by hydroquinone and NT-injured RPE cells in the progression of dry AMD to CNV. We demonstrated that RPE dysfunction might lead to dysregulation of macrophage clearance function and angiogenic homeostasis as a result of oxidative damage which may trigger progression towards CNV in smoker patients with dry AMD.

As mentined previously, hypertension has been associated with the development of wet AMD in the presence of early AMD [128]. These studies make no mention of the mechanism(s) by which hypertension may induce or contribute to the progression from early AMD to CNV. Some investigators have shown that Ang II contributes to to pathological conditions such as neovascularization, atherosclerosis, and tumor [334-340]. Moreover, it has been shown that Ang II-induced angiogenesis is mediated by VEGF receptor-1 [341] and that Ang II type 2 receptor inhibits VEGF-induced migration and in vitro tube formation of human endothelial cells [342]. However, nothing is known about the regulation of TNFSF15 by Ang II in any of the tissues where it is expressed. Therefore, investigating the regulation of TNFSF15 by Ang II helped us to understand how regulation of this cytokine by Ang II could participate in the development of neovascularization in wet AMD patients with HTN. We hypothesize that hypertension through Ang II will alter the secretion of TNFSF15 release by the RPE, which may contribute to an imbalance between VEGF and TNFSF15 leading to CNV development. Our preliminary data showed that Ang II diminishes release of TNFSF15 by RPE cells through activation of both Ang II receptor subtypes and increases release of VEGF by RPE cells through activation of the AT2 Ang II receptor subtype (Marin-Castano, unpublished data), which might permit the development of abnormal angiogenesis contributing to CNV. Our study may result in the identification of TNFSF-15 as an important target to inhibit the initiation of CNV and in Ang II receptors blockade as therapeutic preventive strategy

\section{Animal model for dry AMD}

Animal models are extremely useful in preclinical testing of theories of disease pathogenesis and can serve to question current hypotheses and predict outcomes of therapeutic interventions. Our laboratory and others have used the C57BL/6 mouse model to evaluate mechanisms 
A
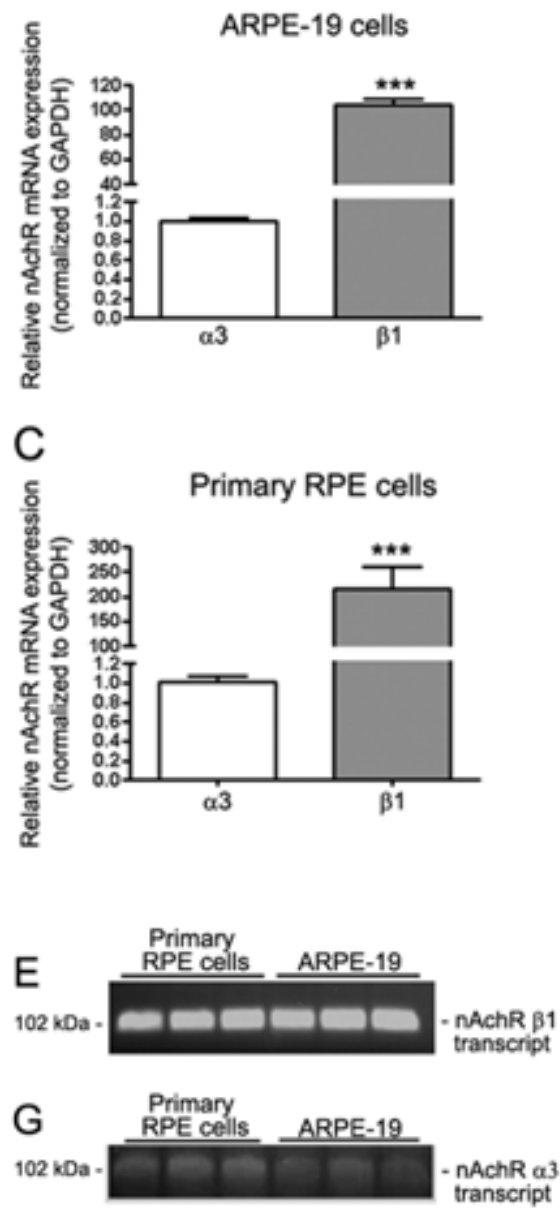

B

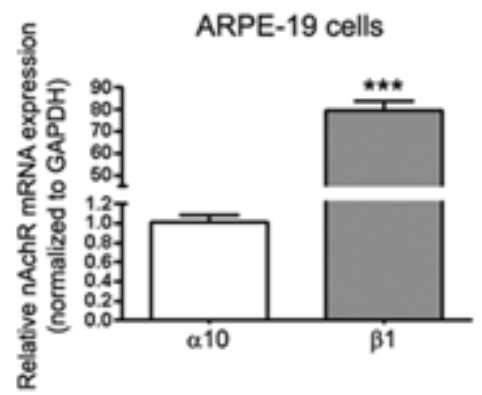

D
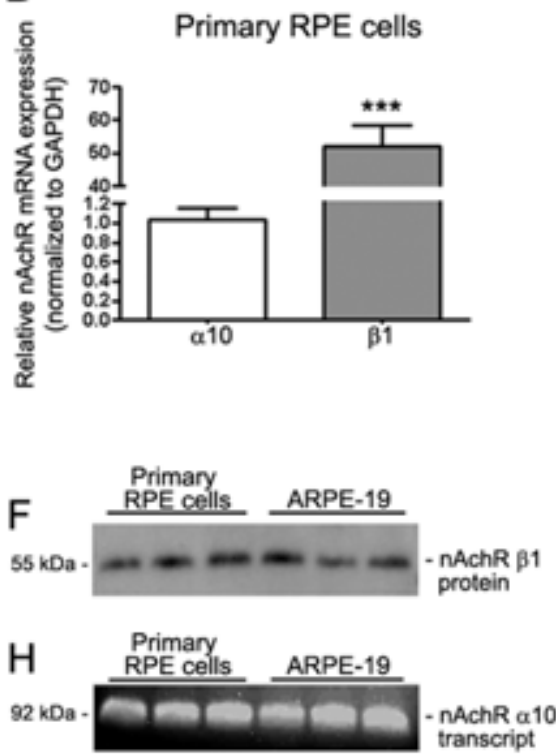

Figure 13. Human RPE cells constitutively express $a 3, a 10$ and $\beta 1$ nAchR subunits. Real-time PCR demonstrated the presence of $n A c h R$ a3, a10 and $\beta 1$ subunits transcripts and the prevalence of $\beta 1$ subtype in confluent serum-starved $(A, B, E, G, H)$ ARPE-19 and $(C, D, E, G, H)$ human primary RPE cells. GAPDH was used as housekeeping gene. Real-time $P C R$ for (E) $\beta 1,(G)$ a3 and $(H)$ a10 nAchR was followed by ethidium bromide-stained agarose gel electrophoresis to visualize the products in ARPE-19 and primary RPE cells. Shown is a representative gel. Number on the left represents size of transcript in base pairs (bp). (F) Western blot analysis demonstrated the expression of the most prevalent $n A c h R \beta 1$ subunits in confluent serum-starved ARPE-19 and primary RPE cells. Shown is a representative gel. Number on the left represents protein molecular weight in kilodaltons $(\mathrm{kDa})$.

for age, gender, diet, environmental toxins, and to text hypothesis [46,55,60,343]. Until recently, no animal models for dry AMD were available. The only available model for dry AMD and hypertension was reported by Jonas et al in 2003 [124]. 

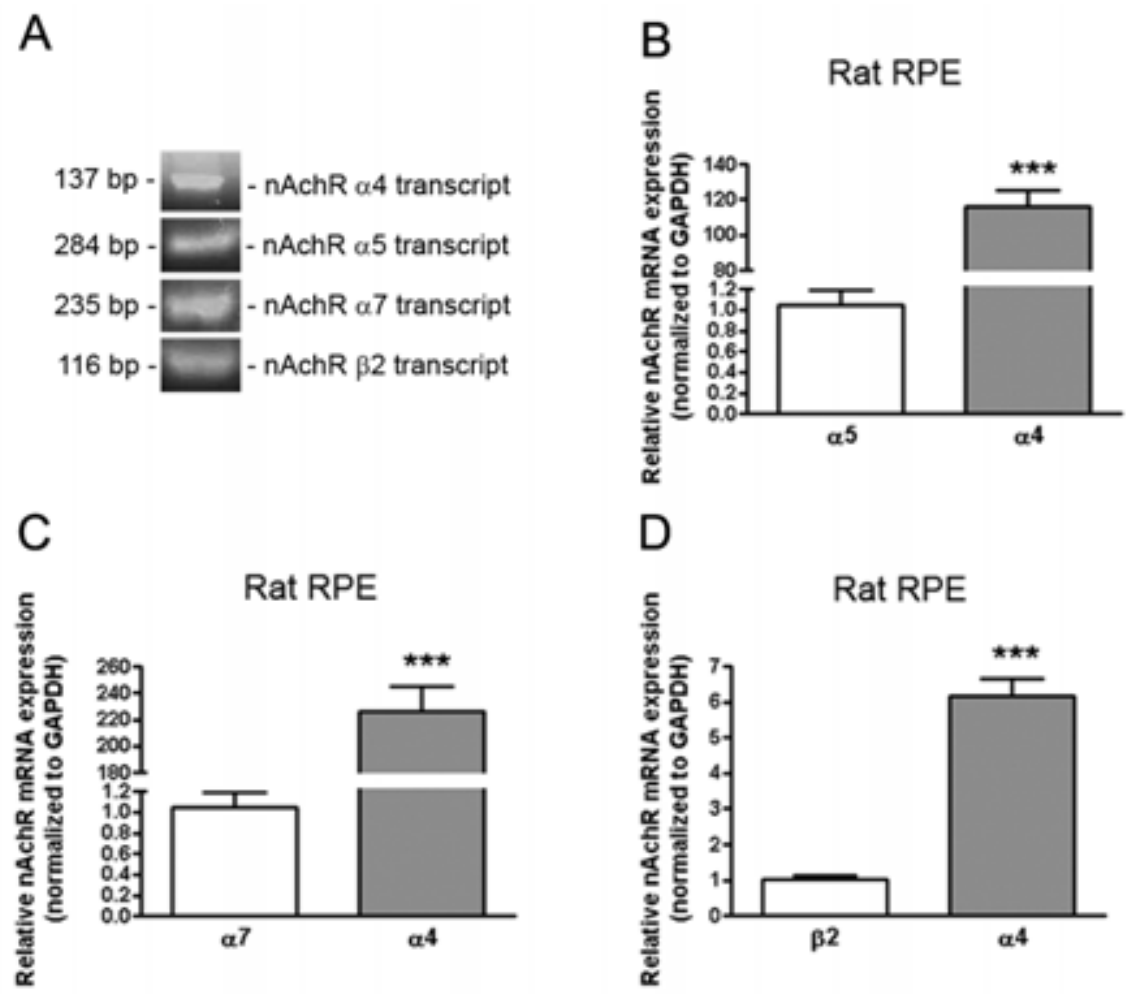

Figure 14. RPE from rats constitutively express $a 4, a 5, a 7$ and $\beta 2 \mathrm{nAchR}$ subunits. Real-time PCR demonstrated the presence of $n A c h R a 4, a 5, a 7$ and $\beta 2$ subunits transcripts (A-D) and the prevalence of a4 subtype (B-D) in RPE from Sprague-Dawley rats (pooled RNA from 5 rats/lane). Real-time PCR for $a 4, a 5, a 7$ and $\beta 2$ nAchR isoforms was followed by ethidium bromide-stained agarose gel electrophoresis to visualize the products (A). Shown are a representative gels. Number on the left represents size of transcript in base pairs (bp). ${ }^{* * *}$ is $p<0.0001$.

Based on the idea that hydroquinone and arterial hypertension might influence the development and severity of drusen, we extended our in vitro data to a more physiological environment using; a) the 16-month-old or b) the 9-month-old C57BL/6 mouse model for dry AMD published by our laboratory $[46,55,60,343]$, but providing an alternative source of oxidant stimulus by replacing exposure to blue light with exposure to hydroquinone in food [55] or drinking water [56] for 4.5 months or with Ang II alone or in combination with the AT1 receptor antagonist (candesartan) or the AT2 receptor antagonist (PD123319) for 4 weeks or 3.5 months. In addition, all mice received a regular fat diet instead of high-fat diet. We evaluated the impact of these compounds on the development of sub-RPE deposits, by using TEM.

As published previuosly, hydroquinone-treated mice had increased blood levels of hydroquinone relative to control mice that showed non detectable levels [56]. Mice not exposed to hydroquinone showed normal morphology of the RPE, BrM, and choriocapillaris endothelium (Fig. 16A). Some specimens demonstrated mild frequency of any BLD. None of the eyes in this 

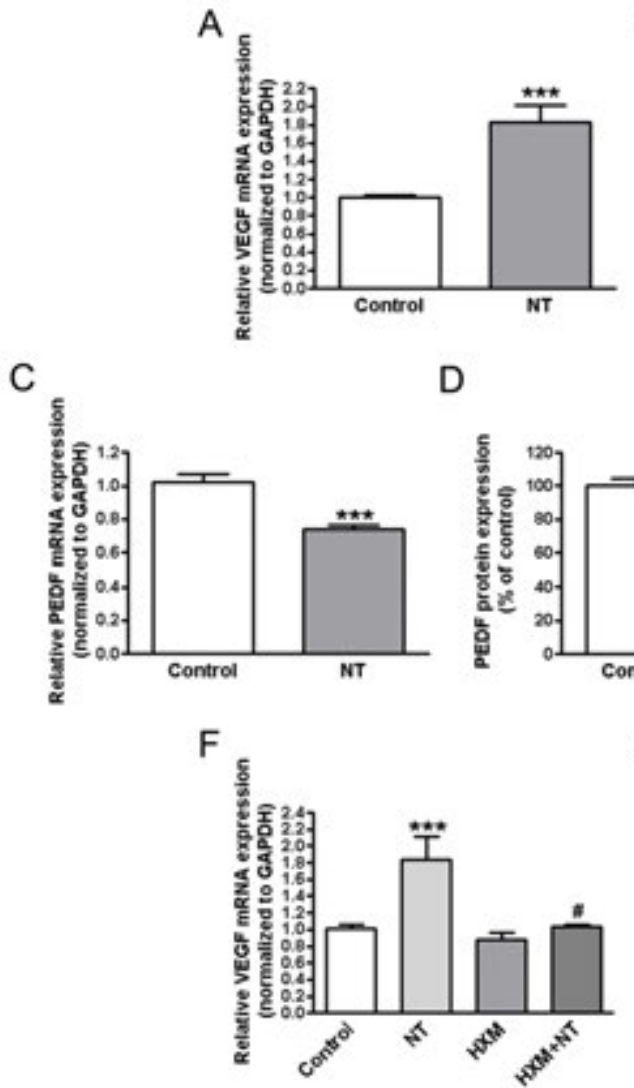

B

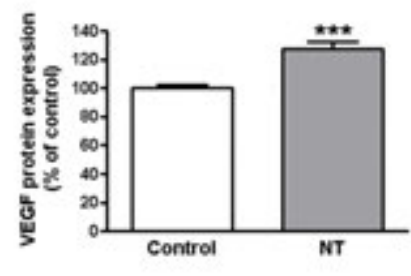

E
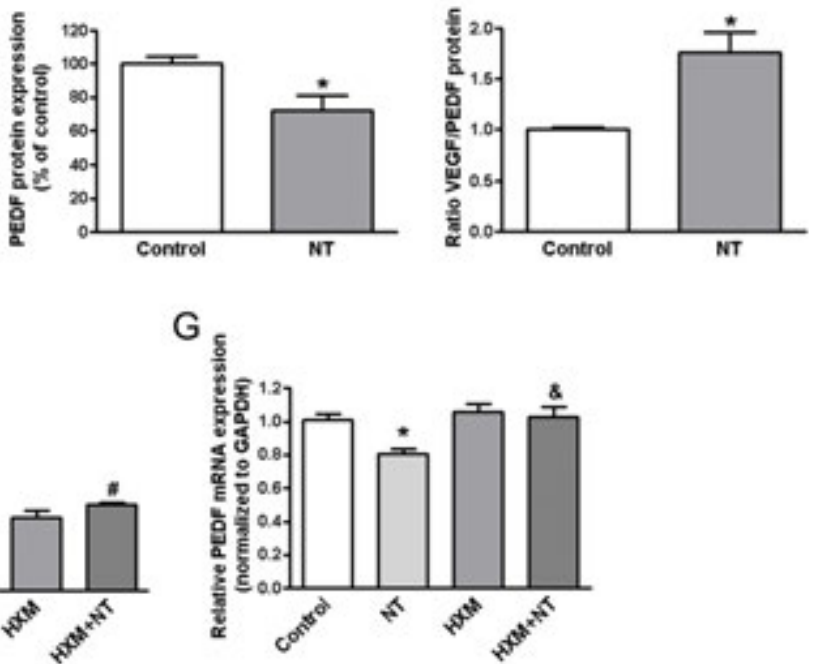

Figure 15. NT increased VEGF expression and decreased PEDF expression through nAchR in ARPE-19 cells. NT (A) increased VEGF and (C) decreased PEDF mRNA expression in ARPE-19 cells. Confluent serum-starved ARPE-19 cells were treated with NT $10^{-8} \mathrm{M}$ for 72 hours. Total RNA was extracted to assess VEGF and PEDF mRNA expression by real-time PCR. GAPDH was used as housekeeping gene. NT (B) increased VEGF and (D) decreased PEDF protein expression. Concentration of VEGF and PEDF secreted in supernatants of confluent serum-starved ARPE-19 cells treated with NT $10^{-8} \mathrm{M}$ for 72 hours was assessed by ELISA. (E) NT increased VEGF/PEDF protein ratio. NT-induced (F) upregulation of VEGF and $(G)$ downregulation of PEDF mRNA expression was abolished by hexamethonium (HXM). Confluent serumstarved ARPE-19 cells were pre-incubated with HXM 10-5 M for 1 hour then exposed to NT $10^{-8} \mathrm{M}$ for 72 hours. Total RNA was extracted to assess VEGF and PEDF mRNA expression by real-time PCR. GAPDH was used as housekeeping gene. Data are expressed as means \pm SE and represent the average results of 3 to 4 independent experiments run in duplicate. ${ }^{*}$ is $p<0.05$ and ${ }^{* * *}$ is $p<0.0001$ versus control; $\#$ is $p<0.01$ and $\&$ is $p<0.05$ versus NT alone.

group demonstrated moderate BLD. Animals exposed to hydroquinone showed pathologic changes in the RPE and BrM characterized by moderate BLD [56]. Approximately a 83\% of eyes exhibited moderate BLD. The BrM was thickened, with coated vesicles, membranous profiles, and banded structures, Figs. 16B, 16C ), typical of those described in some human AMD specimens [46]. Findings were of a magnitude similar to those previously observed in mice exposed to high-fat diet plus blue green light [62]. Interestingly, animals showed blebs 
(Fig. 16C). In preliminary experiments, we have also demonstrated that mice receiving subconjunctival injections of hydroquinone exhibeted a rudimentary form of BLD, often demonstrating small vesicular vesicles bleblike structures (Reinoso, et al. IOVS 2005;46:ARVO E-Abstract 3010). In addition, RPE from mice exposed to hydroquinone in drinking water showed increased levels of phosphorylated Hsp25, p38 and ERK [205], suggesting that phosphorylated Hsp25 might be a key mediator in early cellular events associated with actin reorganization and bleb formation involved in sub-RPE deposits formation.

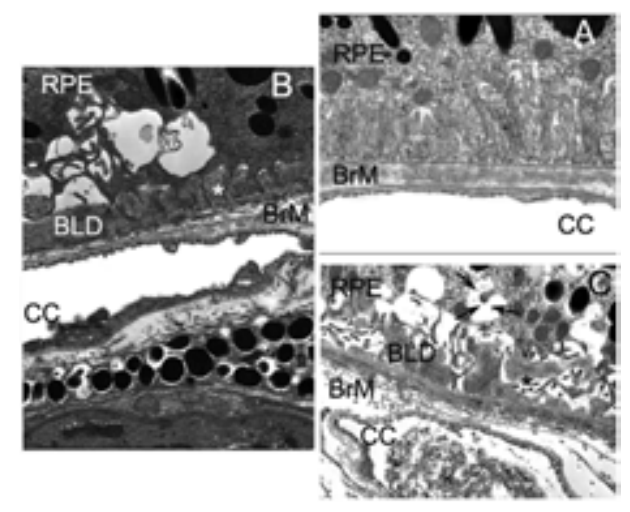

Figure 16. Transmission electron microscopy of the outer retina and choroid from a 16-month-old female mouse fed with a regular fat diet for 4 months. (A) Outer retina and choroid of a mouse fed a regular diet without oxidant showed a normal RPE, BrM, and choriocapillaris. (B) Outer retina and choroid of a mouse fed a regular diet and exposed to HQ ( $0.8 \%$ for 4 months) in drinking water revealed sub-RPE deposits characterized by accumulation of moderately severe BLD with dense granular material between the RPE and its basement membrane $\left(^{*}\right)$, compatible with a high mean severity score. The specimen, also, shows the abnormal choriocapillaris endothelium with increased thickening and loss of fenestration. (C) TEM of the outer retina and choroids from another 16-month-old female mouse fed a regular diet and exposed to $\mathrm{HQ}$. The specimen shows moderately thick BLD with bandes structures $\left({ }^{*}\right)$ and occasional blebs (black arrows). CC, choriocapillaris, Magnification: (A, C) x25,000; (B) x7,200.

We used Ang II to determine whether hypertension-associated Ang II was important for ECM regulation in RPE and the development of sub-RPE deposits. We reported that Ang II-treated mice had increased blood pressure as well as plasma and ocular levels of Ang II relative to control mice [60]. Ang II also regulated AT1a and AT1b receptor mRNA expression, and the intracellular concentration of calcium $\left[\mathrm{Ca}^{2+}\right]_{\mathrm{J}}$, showing that Ang II AT1 receptor is functional. In addition, MMP-2 activity, and type IV collagen accumulation were regulated by Ang II. Concurrent administration of Ang II with the AT1 receptor blocker prevented the increase in blood pressure and rise in ocular Ang II levels, as well as the calcium and MMP-2 responses. In contrast, the type IV collagen response to Ang II was prevented by blockade of AT2 receptors, but not AT1 receptors. Plasma Ang II levels were not modified by the AT1 or AT2 receptor blockade. In addition, Ang II stimulates MMP-14, basigin, and phosphorylation of ERK, p38, and JNK in RPE sheets from mice. These effects were mediated by Ang II type 1 receptors [344]. 
Animals exposed to Ang II for 3.5 months revealed moderate BLD deposits. Sub-RPE changes were characterized by accumulation of moderately dense homogeneous material between the RPE and its basement membrane (Marin-Castano, unpublished data). Given that the Ang II receptors in rodents are similar to human Ang II receptors, our study help to elucidate the mechanism(s) by which Ang II receptor blockers may prevent these ECM changes important for early AMD development and provide a potential future clinical tool for the prevention of AMD. Moreover, our observations indicate that Ang II may induce the development of BLD. Thus, the results suggest the role for Ang II in ECM turnover and sub-RPE formation and propose Ang II-induced hypertension as an injury stimulus to the RPE, which may serve to explain the mechanisms that underlie pathologic BLD deposits in early AMD.

Taken together, these observations indicate that different oxidant stimuli (i.e., blue light, hydroquinone, and Ang II) may induce a common response in the RPE and that a high-fat diet is not an absolute requirement for the development of BLD. Thus, the results suggest the role for blebs in sub-RPE formation and propose hydroquinone and Ang II another oxidative injury stimulus to the RPE, which may serve to explain the mechanisms that underlie pathologic BLD deposits in early AMD.

\section{Conclusions}

In summary, we postulate that cigarette smoke-related and Ang II play a role in the development of dry AMD and its progression to wet AMD. Although our hypothesis remains to be proven, we have proposed new ideas and suggested different mechanisms highlighting Hsp27, MMP-2, basigin, MMP-14, MCP-1, MAPK, and TNFSF15 as potential disease-related proteins as well as biochemical pathways for potential therapeutic strategies, which might result in prevention of more severe and irreversible late stages of this dreadful disease. Our goal is to intervene promptly in the early stages of the disease so that progression to the more severe late forms of AMD can be prevented. In this respect, RPE-derived MMPs and blebs formation are potential target due to their pivotal role in stimulating drusen formation and progression into CNV. Levels of phosphorylated Hsp27, glycosilated basigin and MMP-14, as well as, MCP-1 and TNFSF15 could be markers, which may contribute and aid to the ophthalmologic community in the management of the drusen. Moreover, AT1 receptor antagonists and p38/ERK1/2 MAPK blockers could be used successfully on the prevention of sub-RPE deposits formation in selected high-risk AMD patients.

\section{Author details}

Maria E. Marin-Castaño

Department of Ophthalmology, Bascom Palmer Eye institute, University of Miami, Miami, FL, USA 


\section{References}

[1] Fine, SL, \& Berger, .. Age-related macular degeneration. The New England journal of medicine. 2000; 342 (7);483-492.

[2] Klein, R, Chou, C. F, Klein, B. E, Zhang, X, Meuer, S. M, \& Saaddine, J. B. Prevalence of age-related macular degeneration in the US population. Archives of Ophthalmology. (2011). , 129(1), 75-80.

[3] Klein, R, Peto, T, Bird, A, \& Vannewkirk, M. R. The epidemiology of age-related macular degeneration. American Journal of Ophthalmology. (2004). , 137(3), 486-495.

[4] Rein, D. B, Wittenborn, J. S, Zhang, X, Honeycutt, A. A, Lesesne, S. B, \& Saaddine, J. Forecasting age-related macular degeneration through the year 2050: the potential impact of new treatments.Archives of Ophthalmology. (2009). , 127(4), 533-540.

[5] Abdelsalam, A. Del Priore L, Zarbin MA. Drusen in age-related macular degeneration: pathogenesis, natural course, and laser photocoagulation-induced regression. Survey of Ophthalmology. (1999). , 44(1), 1-29.

[6] Zarbin, M. A. Current concepts in the pathogenesis of age-related macular degeneration. Archives of Ophthalmology. (2004). , 122(4), 598-614.

[7] Abecasis, G. R, Yashar, B. M, Zhao, Y, Ghiasvand, N. M, Zareparsi, S, \& Branham, K. E. Age-related macular degeneration: a high-resolution genome scan for susceptibility loci in a population enriched for late-stage disease. Am J Hum Genet. (2004). , 74, 482-494.

[8] Tuo, J, Bojanowski, C. M, \& Chan, C. C. Genetic factors of age-related macular degeneration. Prog Retin Eye Res. (2004). , 23, 229-249.

[9] Rodrigues, E. B. Inflammation in dry age-related macular degeneration. Ophthalmologica. (2007). , 143-152.

[10] Oh, H, Takagi, H, \& Takagi, C. The potential angiogenic role of macrophages in the formation of choroidal neovascular membranes. Invest Ophthalmol Vis Sci. (1999). , 40, 1891-1898.

[11] Liang, F. Q, \& Godley, B. F. Oxidative stress-induced mitochondrial DNA damage in human retinal pigment epithelial cells: a possible mechanism for RPE aging and agerelated macular degeneration. Exp Eye Res. (2003). , 76, 397-403.

[12] Donoso, L. A, Kim, D, Frost, A, Callahan, A, \& Hageman, G. The role of inflammation in the pathogenesis of age-related macular degeneration. Surv Ophthalmol. (2006). , 51, 137-152.

[13] Berger, J. W, Fine, S. L, \& Maguire, M. G. Age-related macular degeneration. St. Louis: Mosby, (1999). 
[14] Grenn, W. R. Histopathology of age-related macular degeneration. (1999). Molecular vision, $5,27$.

[15] Bird, A. C, Bressler, N. M, Bressler, S. B, Chisholm, I. H, Coscas, G, Davis, M. D, De Jong, P. T, Klaver, C. C, Klein, B. E, Klein, R, et al. An international classification and grading system for age-related maculopathy and age-related macular degeneration. The International ARM Epidemiological Study Group. Surv Ophthalmol. (1995). Review., 39(5), 367-74.

[16] Gass, J. D. Drusen and disciform macular detachment and degeneration. Trans Am Ophthalmol Soc. (1972). , 70, 409-36.

[17] Guymer, R, Luthert, P, \& Bird, A. Changes in Bruch's membrane and related structures with age. Progress in retinal and eye research. (1999). , 18(1), 59-90.

[18] Hiscott, P, Sheridan, C, Magee, R. M, \& Grierson, I. Matrix and the retinal pigment epithelium in proliferative retinal disease. Progress in retinal and eye research. (1999). , 18(2), 167-190.

[19] Young, R. W. Pathophysiology of age-related macular degeneration. Survey of Ophthalmology. (1987). , 31(5), 291-306.

[20] Strauss, O. The retinal pigment epithelium in visual function. Physiol Rev. (2005). , $85,845-881$.

[21] Sheridan, C, Williams, R, \& Grierson, i. Basement membranes and artificial substrates in cell transplantation. Graefe's archive for clinical and experimental ophthalmology = Albrecht von Graefes Archiv fur klinische und experimentelle Ophthalmologie. (2004). , 242(1), 68-75.

[22] Hewitt, A. T, Nakazawa, K, \& Newsome, D. A. Analysis of newly synthesized Bruch's membrane proteoglycans. Investigative Ophthalmology \& Visual Science. (1989). , 30(3), 478-486.

[23] Inatani, M, \& Tanihara, H. Proteoglycans in retina. Progress in retinal and eye research. (2002). , 21(5), 429-447.

[24] Hageman, G. S, \& Luthert, P. J. Victor Chong NH, Johnson LV, Anderson DH, Mullins RF. An integrated hypothesis that considers drusen as biomarkers of immunemediated processes at the RPE-Bruch's membrane interface in aging and age-related macular degeneration. Prog Retin Eye Res. (2001). , 20(6), 705-732.

[25] Penfold, P. L, Madigan, M. C, Gillies, M. C, \& Provis, J. M. Immunological and aetiological aspects of macular degeneration. Prog Retin Eye Res. (2001). , 20(3), 385-414.

[26] Hageman, G. S, \& Mullins, R. F. Molecular composition of drusen as related to substructural phenotype. Mol Vis. (1999). Review. 
[27] Anderson, D. H, Mullins, R. F, Hageman, G. S, \& Johnson, L. V. A role for local inflammation in the formation of drusen in the aging eye. Am J Ophthalmol. (2002). , 134(3), 411-431.

[28] Zarbin, M. A. Age-related macular degeneration: review of pathogenesis European Journal of Ophthalmology. (1998). , 8(4), 199-206.

[29] Sarks, S, Cherepanoff, S, Killingsworth, M, \& Sarks, J. Relationship of Basal laminar deposit and membranous debris to the clinical presentation of early age-related macular degeneration. Investigative Ophthalmology \& Visual Science. (2007). , 48(3), 968-977.

[30] Van Der Schaft, T. L, Mooy, C. M, De Bruijn, W. C, Oron, F. G, Mulder, P. G, \& De Jong, P. T. Histologic features of the early stages of age-related macular degeneration. A statistical analysis Ophthalmology. (1992). , 99(2), 278-286.

[31] Kliffen, M, Van Der Schaft, T. L, Mooy, C. M, \& De Jong, P. T. Morphologic changes in age-related maculopathy. Microscopy Research and Technique.(1997). , 36(2), 106-122.

[32] Wang, L, Clark, M. E, Crossman, D. K, Kojima, K, Messinger, J. D, Mobley, J. A, \& Curcio, C. A. Abundant lipid and protein components of drusen. PLoS ONE.(2010). , e10329.

[33] 33-Cherepanoff S, McMenamin P, Gillies MC, Kettle E, Sarks SH. Bruch's membrane and choroidal macrophages in early and advanced age-related macular degeneration. British Journal of Ophthalmology. 2010;94(7):918-925.

[34] la Cour MKiilgaard JF, Nissen MH. Age-related macular degeneration: epidemiology and optimal treatment. Drugs and Aging.(2002). , 19(2), 101-133.

[35] Wang, J. J, Foran, S, Smith, W, \& Mitchell, P. Risk of age-related macular degeneration in eyes with macular drusen or hyperpigmentation: the Blue Mountains Eye Study cohort Archives of Ophthalmology. (2003). , 121(5), 658-663.

[36] Green, W. R, \& Enger, C. Age-related macular degeneration histopathologic studies. The 1992 Lorenz E. Zimmerman Lecture. Ophthalmology. (1993). , 100(10), 1519-1535.

[37] Grossniklaus, H. E, Ling, J. X, Wallace, T. M, Dithmar, S, Lawson, D. H, Cohen, C, Elner, V. M, \& Elner, S. G. Sternberg Jr P. Macrophage and retinal pigment epithelium expression of angiogenic cytokines in choroidal neovascularization. Molecular vision. (2002). , 119-126.

[38] IshibashiT; Patterson, R; Ohnishi, Y; Inomata, H; Ryan, S. Formation of drusen in the human eye. Am. J. Ophthalmol, (1986). , 101, 342-353.

[39] Donders, F. Beitrage zur pathologischen Anatomie des Auges. Graefe's Arch. Clin. Exp. Ophthalmol, (1854). , 1, 106-118. 
[40] Muller, H. Anatomische beitrage zur ophthalmologie. Albrecht von Graefe Arch Ophthalmol, (1856). , 2, 1-69.

[41] Young, R. W. Pathophysiology of age-related macular degeneration. Surv Ophthalmol. (1987). , 31(5), 291-306.

[42] Farkas, T, Sylvester, V, \& Archer, D. The ultrastructure of drusen. Am J Ophthalmol. (1971). , 71, 1196-1205.

[43] Feeney-burns, L, Gao, C, \& Tidwell, M. Lysosomal enzyme cytochemistry of human RPE, Bruch's membrane and drusen. Invest. Ophthalmol Visual Sci. (1987). , 28, 1138-1147.

[44] El Baba, F, Green, W, Fleischmann, J, Finkelstein, D, \& De La Cruz, Z. Clinicopathologic correlation of lipidization and detachment of the retinal pigment epithelium. Am J Ophthalmol. (1986). , 101, 576-583.

[45] Charras, G. T. A short history of blebbing. J Microsc. (2008). , 231, 466-478.

[46] Cousins, S. W, Espinosa-heidmann, D. G, Alexandridou, A, Sall, J, Dubovy, S, \& Csa$\mathrm{ky}, \mathrm{K}$. The role of aging, high fat diet and blue light exposure in an experimental mouse model for basal laminar deposit formation. Exp Eye Res, (2002). , 75(5), 543-553.

[47] Strunnikova, N, Zhang, C, Teichberg, D, Cousins, S. W, Baffi, J, Becker, K. G, \& Csaky, K. G. Survival of retinal pigment epithelium after exposure to prolonged oxidative injury: a detailed gene expression and cellular analysis. Invest Ophthalmol Vis Sci. (2004). , 45(10), 3767-3777.

[48] Beatty, S, Koh, H, Phil, M, Henson, D, \& Boulton, M. The role of oxidative stress in the pathogenesis of age-related macular degeneration. Surv Ophthalmol. (2000). , 45(2), 115-134.

[49] Winkler, B. S, Boulton, M. E, Gottsch, J. D, \& Sternberg, P. Oxidative damage and age-related macular degeneration. Mol Vis. (1999).

[50] Chisolm GM IIIHazen SL, Fox PL, Cathcart MK. The oxidation of lipoproteins by monocytes-macrophages. Biochemical and biological mechanisms. J Biol Chem. (1999). , 274(37), 25959-25962.

[51] Cousins, S. W, Espinosa-heidmann, D. G, \& Csaky, K. G. Monocyte activation in patients with age-related macular degeneration: a biomarker of risk for choroidal neovascularization? Arch Ophthalmol. (2004). , 122(7), 1013-1018.

[52] Espinosa-heidmann, D. G, Suner, I. J, Hernandez, E. P, Monroy, D, Csaky, K. G, \& Cousins, S. W. Macrophage depletion diminishes lesion size and severity in experimental choroidal neovascularization. Invest Ophthalmol Vis Sci. (2003). , 44(8), 3586-3592. 
[53] Marin-castano, M. E. Angiotensin II receptor expression and function in retinal pigment epithelium. Investigative Ophthalmology \& Visual Science. (2004). ARVO EAbstract)., 1811.

[54] Striker, G. E, Praddaude, F, Alcazar, O, Cousins, S. W, \& Marin-castaño, M. E. Regulation of angiotensin II receptors and extracellular matrix turnover in human retinal pigment epithelium: role of angiotensin II. Am J Physiol Cell Physiol. (2008). C , 1633-46.

[55] Espinosa-heidmann, D. G, Suner, I. J, Catanuto, P, Hernandez, E. P, Marin-castano, M. E, \& Cousins, S. W. Cigarette smoke-related oxidants and the development of sub-RPE deposits in an experimental animal model of dry AMD. Investigative Ophthalmology \& Visual Science. (2006). , 47(2), 729-737.

[56] Marin-castano, M. E, Striker, G. E, Alcazar, O, Catanuto, P, Espinosa-heidmann, D. G, \& Cousins, S. W. Repetitive nonlethal oxidant injury to retinal pigment epithelium decreased extracellular matrix turnover in vitro and induced sub-RPE deposits in vivo. Investigative Ophthalmology \& Visual Science. (2006). , 47(9), 4098-4112.

[57] Elliot, S, Catanuto, P, Fernandez, P, Espinosa-heidmann, D, Korach, K. K, \& Cousins, S. W. Subtype specific estrogen receptor action protects against changes in MMP-2 activation in mouse retinal pigmented epithelial cells. Experimental Eye Research. (2008). , 86(4), 653-660.

[58] Elliot, S, Catanuto, P, Espinosa-heidmann, D. G, Fernandez, P, Hernandez, E, Saloupis, P, Korach, K, \& Cousins, S. W. Estrogen receptor beta protects against in vivo injury in RPE cells Experimental Eye Research.(2010). , 90(1), 10-16.

[59] Striker, G. E, Praddaude, F, Alcazar, O, Cousins, S. W, \& Marin-castano, M. E. Regulation of angiotensin II receptors and extracellular matrix turnover in human retinal pigment epithelium: role of angiotensin II. American Journal of Physiology. Cell Physiology. (2008). C , 1633-1646.

[60] Praddaude, F, Cousins, S. W, Pecher, C, \& Marin-castano, M. E. Angiotensin II-induced hypertension regulates AT1 receptor subtypes and extracellular matrix turnover in mouse retinal pigment epithelium. Experimental Eye Research (2009). , 89(1), 109-118.

[61] Cousins, S. W, \& Csaky, K. Immunology of Age-Related Macular Degeneration J.I. Lim (Ed.), Age-Related Macular Degeneration, Marcel Dekker, Inc., New York. (2002). , 27-65.

[62] Espinosa-heidmann, D. G, Suner, I. J, Hernandez, E. P, Monroy, D, Csaky, K. G, \& Cousins, S. W. Macrophage depletion diminishes lesion size and severity in experimental choroidal neovascularization. Investigative Ophthalmology \& Visual Science. (2003). 
[63] Esfandiary, H, Chakravarthy, U, Patterson, C, Young, I, \& Hughes, A. E. Association study of detoxification genes in age related macular degeneration. Br. J. Ophthalmol. (2005). , 89, 470-474.

[64] Clemons, T. E, Milton, R. C, Klein, R, Seddon, J. M, \& Ferris, F. L. Age-Related Eye Disease Study Research Group. Risk factors for the incidence of Advanced Age-Related Macular Degeneration in the Age-Related Eye Disease Study (AREDS). Ophthalmology. (2005). , 112, 533-539.

[65] Seddon, J. M, Willett, W. C, Speizer, F. E, \& Hankinson, S. E. A prospective study of cigarette smoking and age-related macular degeneration in women. JAMA. (1996). , $276,1141-1146$.

[66] Tomany, SC, Wang, JJ, Van Leeuwen, R, Klein, R, Mitchell, P, Vingerling, JR, Klein, $\mathrm{BE}$, \& Smith, . . Risk factors for incident age-related macular degeneration: pooled findings from 3 continents. Ophthalmology. 2004;111:1280-1287.

[67] Rahman, I. MacNee W. Role of oxidants/antioxidants in smoking-induced lung diseases. Free Radical Biology and Medicine. (1996). , 21(5), 669-681.

[68] Rahman, I. MacNee W. Role of oxidants/antioxidants in smoking-induced lung diseases. Free Radical Biology and Medicine. (1996). , 21(5), 669-681.

[69] Feng, Z, Liu, Z, Li, X, Jia, H, \& Sun, L. Tian C; Jia L, Liu J. Alpha-Tocopherol is an effective Phase II enzyme inducer: protective effects on acrolein-induced oxidative stress and mitochondrial dysfunction in human retinal pigment epithelial cells. J Nutr Biochem. (2010). , 21(12), 1222-1231.

[70] Jia, L, Liu, Z, Sun, L, Miller, S. S, Ames, B. N, Cotman, C. W, \& Liu, J. Acrolein, a toxicant in cigarette smoke, causes oxidative damage and mitochondrial dysfunction in RPE cells: protection by (R)-alpha-lipoic acid. Invest Ophthalmol Vis Sci. (2007). , 48(1), 339-48.

[71] Takeuchi, A, Takeuchi, M, Oikawa, K, Sonoda, K. H, Usui, Y, Okunuki, Y, Takeda, A, Oshima, Y, Yoshida, K, Usui, M, Goto, H, \& Kuroda, M. Effects of dioxin on vascular endothelial growth factor (VEGF) production in the retina associated with choroidal neovascularization. Invest Ophthalmol Vis Sci. (2009). , 50(7), 3410-34166.

[72] Sharma, A, Neekhra, A, Gramajo, A. L, Patil, J, Chwa, M, Kuppermann, B. D, \& Kenney, M. C. Effects of Benzo(e)Pyrene, a toxic component of cigarette smoke, on human retinal pigment epithelial cells in vitro. Invest Ophthalmol Vis Sci. (2008). , 49(11), 5111-5117.

[73] Wills, N. K, \& Kalariya, N. Sadagopa Ramanujam VM, Lewis JR, Haji Abdollahi S, Husain A, van Kuijk FJ. Human retinal cadmium accumulation as a factor in the etiology of age-related macular degeneration. Exp Eye Re. (2009). , 89, 79-87. 
[74] Kalariya, N. M, Wills, N. K, Ramana, K. V, Srivastava, S. K, \& Van Kuijk, F. J. Cadmium-induced apoptotic death of human retinal pigment epithelial cells is mediated by MAPK pathway. Exp Eye Res. (2009). , 89(4), 494-502.

[75] Wills, N. K. Sadagopa Ramanujam VM, Chang-Strepka J, Kalariya N, Lewis JR, van Kuijk, FJ. Cadmium accumulation in the aging human retina. Exp. Eye Res. (2008). , 86(1), 41-51.

[76] Pryor, W. A. Cigarette smoke radicals and the role of free radicals in chemical carcinogenicity. Environ Health Perspect. (1997). , 105(4), 875-882.

[77] Halliwell, B. Free radicals and vascular disease: how much do we know? BMJ. (1993). , 307(6909), 885-886.

[78] Winston, G. W, Church, D. F, Cueto, R, \& Pryor, W. A. Oxygen consumption and oxyradical production from microsomal reduction of aqueous extracts of cigarette tar. Arch Biochem Biophys. (1993). , 304(2), 371-378.

[79] Niki, E, Minamisawa, S, Oikawa, M, \& Komuro, E. Membrane damage from lipid oxidation induced by free radicals and cigarette smoke. Ann N Y Acad Sci. (1993). , 686, 29-37.

[80] Klein, R, Knudtson, M. D, Cruickshanks, K. J, \& Klein, B. E. Further observations on the association between smoking and the long-term incidence and progression of age-related macular degeneration: The Beaver Dam Eye Study. Archives of Ophthalmology. (2008). , 126(1), 115-121.

[81] Solberg, Y, Rosner, M, \& Belkin, M. The association between cigarette smoking and ocular diseases. Surv Ophthalmol. (1998). , 42, 535-547.

[82] Chow, C. K, Thacker, R. R, Chow, C. K, Thacker, R. R, Changchit, C, Bridges, R. B, Rehm, S. R, Humble, J, \& Turbek, J. Lower levels of vitamin C and carotenes in plasma of cigarette smokers. J Am Coll Nutr. (1986). , 5(3), 305-312.

[83] Church, D. F, \& Pryor, W. A. Free-radical chemistry of cigarette smoke and its toxicological implications. Environ Health Perspect. (1985). , 64, 111-126.

[84] Rahman, I. MacNee W. Role of oxidants/antioxidants in smoking-induced lung diseases. Free Radical Biology and Medicine. (1996). , 21(5), 669-681.

[85] AREDSA randomized, placebo-controlled, clinical trial of high-dose supplementation with vitamins $\mathrm{C}$ and $\mathrm{E}$, beta carotene, and zinc for age-related macular degeneration and vision loss: AREDS report Archives of Ophthalmology. (2001). , 119(8), 1417-1436.

[86] Moriarty-craige, S. E, Adkison, J, Lynn, M, Gensler, G, Bressler, S, \& Jones, D. P. Sternberg P Jr. Antioxidant supplements prevent oxidation of cysteine/cystine redox in patients with age-related macular degeneration. Am J Ophthalmol. (2005). , 140, 1020-1026. 
[87] Jakobsdottir, J, Conley, Y. P, Weeks, D. E, Mah, T. S, Ferrell, R. E, \& Gorin, M. B. Susceptibility genes for age-related maculopathy on chromosome 10q26. Am J of Human Genetics. (2005). , 77(3), 389-407.

[88] Rivera, A, Fisher, S. A, Fritsche, L. G, Keilhauer, C. N, Lichtner, P, Meitinger, T, \& Weber, B. H. Hypothetical LOC387715 is a second major susceptibility gene for agerelated macular degeneration, contributing independently of complement factor $\mathrm{H}$ to disease risk. Human Molecular Genetics. (2005). , 14(21), 3227-3236.

[89] Schmidt, S, Hauser, M. A, Scott, W. K, Postel, E. A, Agarwal, A, Gallins, P, Wong, F, Chen, Y. S, Spencer, K, Schnetz-boutaud, N, Haines, J. L, \& Pericak-vance, M. A. Cigarette smoking strongly modifies the association of LOC387715 and age-related macular degeneration. Am J of Human Genetics. (2006). , 78(5), 852-864.

[90] Kanda, A, Chen, W, Othman, M, Branham, K. E, Brooks, M, Khanna, R, He, S, Lyons, R, Abecasis, G. R, \& Swaroop, A. A variant of mitochondrial protein LOC387715/ ARMS2, not HTRA1, is strongly associated with age-related macular degeneration. Proceedings of the National Academy of Sciences USA, (2007). , 41, 16227-16232.

[91] Gu, X, Meer, S. G, Miyagi, M, Rayborn, M. E, Hollyfield, J. G, Crabb, J. W, \& Salomon, R. G. Carboxyethylpyrrole protein adducts and autoantibodies, biomarkers for age-related macular degeneration. Jl of Biol Chem. (2003). , 43, 42027-42035.

[92] SunML; Finnemann,SC; Febbraio, M; Shan, L; Annangudi, SP; Podrez, EA; Hoppe, G; Darrow, R; Organisciak, DT; Salomon, RG; Silverstein, RL; Hazen, S. Light-induced oxidation of photoreceptor outer segment phospholipids generates ligands for CD36mediated phagocytosis by retinal pigment epithelium: A potential mechanism for modulating outer segment phagocytosis under oxidant stress conditions. J Biol Chem. (2006). , 281(7), 4222-4230.

[93] Schutt, F, Bergmann, M, Holz, F. G, \& Kopitz, J. Proteins modified by malondialdehyde, 4-hydroxynonenal, or advanced glycation end products in lipofuscin of human retinal pigment epithelium. Invest Ophthalmol Vis Sci. (2003). , 44(8), 3663-3668.

[94] Schutt, F, Ueberle, B, Schnölzer, M, Holz, F. G, \& Kopitz, J. Proteome analysis of lipofuscin in human retinal pigment epithelial cells. FEBS Letters. (2002). , 528, 217-221.

[95] Crabb, J. W, Miyagi, M, Gu, X, Shadrach, K, West, K. A, Sakaguchi, H, Kamei, M, Hasan, A, Yan, L, Rayborn, M. E, Salomon, R. G, \& Hollyfield, J. G. Drusen proteome analysis: An approach to the etiology of age-related macular degeneration. Proc Natl Acad Sci U SA. (2002). , 99(23), 14682-14687.

[96] Farboud, B, Aotaki-keen, A, Miyata, T, Hjelmeland, L. M, \& Handa, J. T. Development of a polyclonal antibody with broad epitope specificity for advanced glycation endproducts and localization of these epitopes in Bruch's membrane of the aging eye. Molecular Vision. (1999). 
[97] Biswas, S. K, \& Rahman, I. Environmental toxicity, redox signaling and lung inflammation: The role of glutathione. Molecular Aspects of Medicine. (2009).

[98] Edwards, A. O, \& Ritter, R. ${ }^{\text {rd }}$, Abel KJ, Manning A, Panhuysen C, Farrer LA.Complement factor $\mathrm{H}$ polymorphism and age-related macular degeneration. Science. (2005). , 308(5720), 421-424.

[99] Zareparsi, S, Branham, K. E, Li, M, Shah, S, Klein, R. J, Ott, J, Hoh, J, Abecasis, G. R, \& Swaroop, A. Strong association of the $\mathrm{Y} 402 \mathrm{H}$ variant in complement factor $\mathrm{H}$ at 1q32 with susceptibility to age-related macular degeneration. Am J of Hum Gen. (2005). , 77(1), 149-153.

[100] Ding, X, Patel, M, \& Chan, C. C. Molecular pathology of age-related macular degeneration. Prog Retin Eye Res. (2009). , 28(1), 1-18.

[101] Chen, H, Liu, B, Lukas, T. J, \& Neufeld, A. H. The aged retinal pigment epithelium/ choroid: a potential substratum for the pathogenesis of age-related macular degeneration. PLoS One, (2008). Jun 4;3(6):e2339.

[102] Scott, W. K, Schmidt, S, Hauser, M. A, Gallins, P, Schnetz-boutaud, N, Spencer, K. L, Gilbert, J. R, Agarwal, A, \& Postel, E. A. Haines Jl, Pericak-Vance MA. Independent effects of complement factor $\mathrm{H} Y 402 \mathrm{H}$ polymorphism and cigarette smoking on risk of age-related macular degeneration. Ophthalmology. (2007). , 114, 1151-1156.

[103] Schmidt, S, Haines, J. L, Postel, E. A, \& Agarwal, A. Kwan SY; Gilbert JR, PericakVance MA, Scott WK. Joint effects of smoking history and APOE genotypes in agerelated macular degeneration. Mol Vis, (2005). , 11, 941-949.

[104] Bertram, K. M, Baglole, C. J, Phipps, R. P, \& Libby, R. T. Molecular regulation of cigarette smoke induced-oxidative stress in human retinal pigment epithelial cells: implications for age-related macular degeneration. Am J Physiol Cell Physiol. (2009). C , $1200-1210$.

[105] Wang, A. L, Lukas, T. J, Yuan, M, Du, N, Handa, J. T, \& Neufeld, A. H. Changes in retinal pigment epithelium related to cigarette smoke: possible relevance to smoking as a risk factor for age-related macular degeneration. PLoS One. (2009). e5304.

[106] Hollyfield, J. G, Bonilha, V. L, Rayborn, M. E, Yang, X, Shadrach, K. G, Lu, L, Ugret, R. L, Salomon, R. G, \& Perez, V. L. Oxidative damage-induced inflammation initiates age related macular degeneration. Nat. Med. (2008).

[107] Mahapatra, S. K, Das, S, Bhattacharjee, S, Gautam, N, Majumdar, S, \& Roy, S. Toxicol Mech Methods. (2009). , 19(2), 100-108.

[108] Maritz, G. S. Nicotine and lung development. Birth Defects Res C Embryo Today. (2008). , 84(1), 45-53. 
[109] Das, S, Neogy, S, Gautan, N, \& Roy, S. In vitro nicotine induced superoxide mediated DNA fragmentation in lymphocytes: protective role of Andrographis paniculata Nees. Toxicology in Vitro. (2009). , 23, 909-998.

[110] Vassallo, R, Kroening, P. R, Parambil, J, \& Kita, H. Nicotine and cigarette smoke constituents induce-immune-modulatory and pro-inflammatory dendritic cell responses. Mol Immunol. (2008). , 45(12), 3321-3329.

[111] Pestana, I. A, Vazquez-padron, R. I, Aitouche, A, \& Pham, S. M. Nicotine and PDGFreceptor function are essential for nicotine-stimulated mitogenesis in human vascular smooth muscle cells. J Cell Biochem. (2005). , 965, 986-995.

[112] Suner, I, Espinosa-heidmann, D. G, Marin-castano, M. E, \& Hernandez, E. Pereira-Simon S Cousins SW. Nicotine increase size and severity of experimental choroidal neovascularization. Invest. Ophthalmol. Vis. Sci. (2004). , 451, 311-317.

[113] Villablanca, A. C. Nicotine stimulates DNA synthesis and proliferation in vascular endothelial cell in vitro. J. Appl. Physiol. (1998). , 846, 2086-2098.

[114] Kiuchi, K, Matsuoka, M, \& Wu, J. C. Lima e Silva R, Kengatharan M, Verghese M, Ueno S, Yokoi K, Khu NH, Cooke JP, Campochiaro PA. Mecamylamine suppresses basal and nicotine-stimulated choroidal neovascularization. Invest Ophthalmol Vis Sci. (2008). , 49(4), 1705-11.

[115] KandaY; Watanabe, Y. Nicotine-induced vascular endothelial growth factor release via the EGFR-ERK pathway in rat vascular smooth muscle cells. Life Sci, (2007). , 8015, 1409-1414.

[116] Ishibashi, T, Hata, Y, Yosikawa, H, Nakagawa, K, Sueishi, K, \& Inomata, H. Expression of vascular endothelial growth factor in experimental choroidal neovascularization. Graefes Arch Clin Exp Ophthalmol. (1997). , 2353, 159-167.

[117] Kliffen, M, Sharma, H. S, Mooy, C. M, Kerkvliet, S, \& De Jong, P. T. Increased expression of angiogenic growth factor in age-related maculopathy. Br J Ophthalmology. (1997). , 812, 154-162.

[118] Kvanta, A. Ocular angiogenesis: the role of growth factors. Acta Ophthalmol. (2006). , $843,282-288$.

[119] Hyman, L, \& Neborsky, R. Risk factors for age-related macular degeneration: an update Current Opinion in Ophthalmology. (2002). , 13(3), 171-175.

[120] Vingerling, J. R, Klaver, C. C, \& Hofman, A. Epidemiology of age-related maculopathy. Epidemiol.Rev. (1995). , 17, 347-360.

[121] Bilato, C, \& Crow, M. T. Atherosclerosis and the vascular biology of aging. Aging (Milano), (1996). , 8, 221-234. 
[122] Hariri, R. J, Alonso, D. R, \& Hajjar, D. P. Aging and arteriosclerosis. I. Development of myointimal hyperplasia after endothelial injury. J Exp.Med, (1986). , 164, 1171-1178.

[123] Spagnoli, L. G, Sambuy, Y, \& Palmieri, G. Age-related modulation of vascular smooth muscle cells proliferation following arterial wall damage. Artery, (1985). , 13, 187-198.

[124] Jonas, J. B, Hayreh, S. S, \& Martus, P. Influence of arterial hypertension and diet-induced atherosclerosis on macular drusen. Graefe's archive for clinical and experimental ophthalmology $=$ Albrecht von Graefes Archiv fur klinische und experimentelle Ophthalmologie. (2003). , 241(2), 125-134.

[125] Olea, J. L, \& Tuñón, J. Patients with neovascular age-related macular degeneration in Spain display a high cardiovascular risk. Eur J Ophthalmol. (2012). , 22(3), 404-11.

[126] Hogg, R. E, Woodside, J. V, Gilchrist, S. E, Graydon, R, Fletcher, A. E, Chan, W, Knox, A, Cartmill, B, \& Chakravarthy, U. Cardiovascular disease and hypertension are strong risk factors for choroidal neovascularization. Ophthalmology. (2008). , 115(6), 1046-1052.

[127] Thapa, R, Paudyal, G, Shrestha, M. K, Gurung, R, \& Ruit, S. Age-related macular degeneration in Nepal. Kathmandu Univ Med J (KUMJ). (2011). , 9(35), 165-9.

[128] Hogg, R. E, Mckay, G. J, Hughes, A. E, Muldrew, K. A, \& Chakravarthy, U. GENOTYPE-PHENOTYPE ASSOCIATIONS IN NEOVASCULAR AGE-RELATED MACULAR DEGENERATION. Retina. (2012). Apr 5. (Epub ahead of print).

[129] Ruiz-OrtegaM; Ruperez, M; Esteban, V. Molecular Mechanisms of Angiotensin II-induced Vascular Injury. Curr Hypertens.Rep, (2003). , 5, 73-79.

[130] Taylor, W. R. Hypertensive vascular disease and inflammation: mechanical and humoral mechanisms. Curr Hypertens.Rep, (1999). , 1, 96-101.

[131] DoreyCK; Wu, G; Ebenstein, D. Cell loss in the aging retina. Relationship to lipofuscin accumulation and macular degeneration. Invest Ophthalmol Vis Sci,(1989). , 30, 1691-1699.

[132] Rong, P, Wilkinson-berka, J. L, \& Skinner, S. L. Control of renin secretion from adrenal gland in transgenic Ren-2 and normal rats. Mol Cell Endocrinol. (2001). , 173, 203-212.

[133] Wilkinson-berka, J. L, Kelly, D. J, Rong, P, Campbell, D. J, \& Skinner, S. L. Characterisation of a thymic renin-angiotensin system in the transgenic $\mathrm{m}($ Ren-2)27 rat. Mol Cell Endocrinol. (2002). , 194, 201-209.

[134] Berka, J. L, Stubbs, A. J, \& Wang, D. Z. DiNicolantonio R, Alcorn D, Campbell DJ, Skinner SL (1995). Renin-containing Muller cells of the retina display endocrine features. Invest Ophthalmol Vis Sci. (1995). , 36, 1450-1458. 
[135] Sarlos, S, Rizkalla, B, Moravski, C. J, Cao, Z, Cooper, M. E, \& Wilkinson-berka, J. L. Retinal angiogenesis is mediated by an interaction between the angiotensin type 2 receptor, VEGF, and angiopoietin. Am J Pathol. (2003). , 163, 879-887.

[136] Senanayake, P, Drazba, J, Shadrach, K, Milsted, A, Rungger-brandle, E, Nishiyama, K, Miura, S, Karnik, S, Sears, J. E, Hollyfield, J. G, \& Angiotensin, I. I. and its receptor subtypes in the human retina. Invest Ophthalmol Vis Sci. (2007). , 48, 3301-3311.

[137] Downie, L. E, Vessey, K, Miller, A, Ward, M. M, Pianta, M. J, Vingrys, A. J, Wilkinson-berka, J. L, \& Fletcher, E. L. Neuronal and glial cell expression of angiotensin II type 1 (AT1) and type 2 (AT2) receptors in the rat retina. Neuroscience. (2009). , 161, 195-213.

[138] Milenkovic, V. M, Brockmann, M, Meyer, C, Desch, M, Schweda, F, Kurtz, A, Todorov, V, \& Strauss, O. Regulation of the renin expression in the retinal pigment epithelium by systemic stimuli. Am J Physiol Renal Physiol. (2010). FF403., 396.

[139] Fletcher, E. L, Phipps, J. A, Ward, M. M, Vessey, K. A, \& Wilkinson-berka, J. L. The renin-angiotensin system in retinal health and disease: Its influence on neurons, glia and the vasculature. Prog Retin Eye Res. (2010). , 29, 284-311.

[140] Wagner, J. Jan Danser AH, Derkx FH, de Jong TV, Paul M, Mullins JJ, Schalekamp MA, Ganten D. Demonstration of renin mRNA, angiotensinogen mRNA, and angiotensin convertingenzyme mRNA expression in the human eye: evidence for an intraocular renin-angiotensin system.Br J Ophthalmol. (1996). , 80, 159-163.

[141] Jacobi, P. C, Osswald, H, Jurklies, B, \& Zrenner, E. Neuromodulatory effects of the reninangiotensin system on the cat electroretinogram. Invest Ophthalmol Vis Sci. (1994). , 35, 973-980.

[142] Jurklies, B, Eckstein, A, Jacobi, P, Kohler, K, Risler, T, \& Zrenner, E. The renin-angiotensin system--a possible neuromodulator in the human retina? Ger J Ophthalmol. (1995). , 4, 144-150.

[143] Danser, A. H, Derkx, F. H, Admiraal, P. J, Deinum, J, De Jong, P. T, \& Schalekamp, M. A. (1994). Angiotensin levels in the eye. Invest Ophthalmol Vis Sci , 35, 1008-1018.

[144] Wilkinson-berka, J. L, Tan, G, Jaworski, K, \& Ninkovic, S. Valsartan but not atenolol improves vascular pathology in diabetic Ren-2 rat retina. Am J Hypertens. (2007). , 20, 423-430.

[145] Mauer, M, Zinman, B, Gardiner, R, Suissa, S, Sinaiko, A, Strand, T, Drummond, K, Donnelly, S, Goodyer, P, Gubler, M. C, \& Klein, R. Renal and retinal effects of enalapril and losartan in type 1 diabetes. N Engl J Med. (2009). , 361, 40-51.

[146] Moravski, C. J, Kelly, D. J, Cooper, M. E, Gilbert, R. E, Bertram, J. F, Shahinfar, S, Skinner, S. L, \& Wilkinson-berka, J. L. Retinal neovascularization is prevented by blockade of the renin-angiotensin system. Hypertension. (2000). , 36, 1099-1104. 
[147] Nagai, N, Noda, K, Urano, T, Kubota, Y, Shinoda, H, Koto, T, Shinoda, K, Inoue, M, Shiomi, T, Ikeda, E, Tsubota, K, Suda, T, Oike, Y, \& Ishida, S. Selective suppression of pathologic, but not physiologic, retinal neovascularization by blocking the angiotensin II type 1 receptor. Invest Ophthalmol Vis Sci. (2005). , 46, 1078-1084.

[148] Downie, L. E, Pianta, M. J, Vingrys, A. J, Wilkinson-berka, J. L, \& Fletcher, E. L. AT1 receptor inhibition prevents astrocyte degeneration and restores vascular growth in oxygen-induced retinopathy. Glia. (2008). , 56, 1076-1090.

[149] Nagai, N, Oike, Y, Izumi-nagai, K, Koto, T, Satofuka, S, Shinoda, H, Noda, K, Ozawa, Y, Inoue, M, Tsubota, K, \& Ishida, S. Suppression of choroidal neovascularization by inhibiting angiotensinconverting enzyme: minimal role of bradykinin. Invest Ophthalmol Vis Sci. (2007). , 48, 2321-2326.

[150] Jin, G. F, \& Hurst, J. S. Godley BF cultured human retinal pigment epithelial cells. Curr Eye Res. (2001). , 22, 165-173.

[151] Yamada, H, Yamada, E, Hackett, S. F, Ozaki, H, Okamoto, N, \& Campochiaro, P. A. Hyperoxia causes decreased expression of vascular endothelial growth factor and endothelial cell apoptosis in adult retina. J Cell Physiol. (1999). , 179, 149-156.

[152] Hecquet, C, Lefevre, G, Valtink, M, Engelmann, K, \& Mascarelli, F. Activation and role of MAP kinase-dependent pathways in retinal pigment epithelium cells: JNK1, kinase, and cell death. Invest Ophthalmol Vis Sci. (2003). , 38.

[153] Dunaief, J. L, Dentchev, T, Ying, G. S, \& Milam, A. H. The role of apoptosis in agerelated macular degeneration. Arch Ophthalmol. (2002). , 120, 1435-1442.

[154] Florence, T. M. The role of free radicals in disease. Australian and New Zealand Journal of Ophthalmology. (1995). , 23(1), 3-7.

[155] Machlin, L. J, \& Bendich, A. Free radical tissue damage: protective role of antioxidant nutrients The FASEB journal : official publication of the Federation of American Societies for Experimental Biology. (1987). , 1(6), 441-445.

[156] Stohs, S. J. The role of free radicals in toxicity and disease. Journal of Basic and Clinical Physiology and Pharmacology. (1995).

[157] Beatty, S, Koh, H, Phil, M, Henson, D, \& Boulton, M. The role of oxidative stress in the pathogenesis of age-related macular degeneration. Survey of Ophthalmology. (2000). , 45(2), 115-134.

[158] Wilhelm, J. Metabolic aspects of membrane lipid peroxidation. Acta Universitatis Carolinae. Medica. Monographia. (1990). , 137, 1-53.

[159] Blokhina, O, Virolainen, E, \& Fagerstedt, K. V. Antioxidants, oxidative damage and oxygen deprivation stress: a review. Annals of Botany. (2003). Spec (179-194), 179-194. 
[160] Iwai, K. An ubiquitin ligase recognizing a protein oxidized by iron: implications for the turnover of oxidatively damaged proteins. Journal of Biochemistry. (2003). , 134(2), 175-182.

[161] Hugel, B. Martinez mC, Kunzelmann C, Freyssinet JM. Membrane microparticles: two sides of the coin. Physiology. (2005). , 20, 22-27.

[162] Nomura, S, Ozaki, Y, \& Ikeda, Y. Function and role of microparticles in various clinical setting. Thromb Res. (2008). , 123, 8-23.

[163] Mostefai, H. A, Andriantsitohaina, R, \& Martinez, M. C. Plasma membrane microparticles in angiogenesis: role in ischemic diseases and cancer. Physiol Res. (2008). , $57,311-320$.

[164] Van Wijk, D, \& Simons, M. Microparticles in cardiovascular diseases. Cardiovasc Res. (2003). , 59, 1121-1132.

[165] Negi, A, \& Marmor, M. F. Experimental serous retinal detachment and focal pigment epithelial damage. Arch Ophthalmol. (1984). , 102(3), 445-9.

[166] Van Der Schaft, T. L, De Bruijn, B. C, \& Mooy, G. M. Ketelaars DAM, Jong PTVM. Is basal laminar deposit unique for age-related macular degeneration?. Arch Ophthalmol (1991). , 109, 420-425.

[167] Burns, R. Feeney Burns L. Clinico-morphologic correlations of drusen of Bruch's membrane. Trans Am Ophthalmol Soc. (1980). , 78, 206-225.

[168] Gerthoffer, W. T, \& Gunst, S. J. Invited review: focal adhesion and small heat shock proteins in the regulation of actin remodeling and contractility in smooth muscle. J Appl Physiol. (2001). , 91, 963-972.

[169] Zhu, Z. R, Goodnight, R, Nishimura, T, Sorgente, N, Ogden, T. E, \& Ryan, S. J. Experimental changes resembling the pathology of drusen in Bruch's membrane in the rabbit. Curr Eye Res.(1988). , 7, 581-592.

[170] Malorni, W, Iosi, F, Mirabelli, F, \& Bellomo, G. Cytoskeleton as a target in menadione-induced oxidative stress in cultured mammalian cells: alterations underlying surface bleb formation. Chem Biol Interact. (1991). , 80, 217-236.

[171] Marin-castaño, M. E, Csaky, K. G, \& Cousins, S. W. Nonlethal oxidant injury to human retinal pigment epithelium cells causes cell membrane blebbing but decreased MMP-2 activity. Invest Ophthalmol Vis Sci. (2005). , 46(9), 3331-3340.

[172] Stein, J. M, \& Luzio, J. P. complement attack on human neutrophils. The sorting of endogenous plasma-membrane proteins and lipids into shed vesicles. Biochem. J. (1991). , 274, 381-386.

[173] Combes, V, Simon, A. C, Grau, G. E, Arnoux, D, Camoin, L, Sabatier, F, Mutin, M, Sanmarco, M, Sampol, J, \& Dignat-george, F. In vitro generation of endothelial micro- 
particles and possible prothrombotic activity in patients with lupus anticoagulant. J. Clin. Investig. (1999). , 104, 93-102.

[174] Sims, P. J, Faioni, E. M, Wiedmer, T, \& Shattil, S. J. Complement proteins C5b-9 cause release of membrane vesicles from the platelet surface that are enriched in the membrane receptor for coagulation factor Va and express prothrombinase activity. J. Biol. Chem. (1988). , 263, 18205-18212.

[175] Iida, K, Whitlow, M. B, \& Nussenzweig, V. Membrane vesiculation protects erythrocytes from destruction by complement. J. Immunol. (1991). , 147, 2638-2642.

[176] Pascual, M, Steiger, G, Sadallah, S, Paccaud, J. P, Carpentier, J. L, James, R, \& Schifferli, J. A. Identification of membrane-bound CR1 (CD35) in human urine: evidence for its release by glomerular podocytes. J. Exp. Med. (1994). , 179, 889-899.

[177] Satta, N, Toti, F, Feugeas, O, Bohbot, A, Dachary-prigent, J, Eschwège, V, Hedman, $\mathrm{H}$, \& Freyssinet, J. M. Monocyte vesiculation is a possible mechanism for dissemination of membrane-associated procoagulant activities and adhesion molecules after stimulation by lipopolysaccharide. J. Immunol. (1994). , 153, 3245-3255.

[178] Bütikofer, P. Kuypers, Xu CM, Chiu DT, Lubin B. Enrichment of two glycosyl-phosphatidylinositol-anchored proteins, acetylcholinesterase and decay accelerating factor, in vesicles released from human red blood cells. Blood; , 74, 1481-1485.

[179] Alcazar, O, Collier, T. S, Cousins, S. W, Bhattacharya, S. K, Muddiman, D. C, \& Marin-castano, M. E. Proteomics Characterization of Cell Membrane Blebs in Human Retinal Pigment Epithelium Cells. Mol Cell Proteomics. (2009). , 8(10), 2201-2211.

[180] Dalle-donne, I, Rossi, R, \& Milzani, A. Di Simplicio P, Colombo R. The actin cytoskeleton response to oxidants: from small heat shock protein phosphorylation to changes in the redox state of actin itself. Free Radic Biol Med. (2001). , 31(12), 1624-1632.

[181] Lanzetti, L. Di Fiore PP, Scita G. Pathways linking endocytosis and actin cytoskeleton in mammalian cells. Exp Cell Res. (2001). , 271(1), 45-56.

[182] Taunton, J. Actin filament nucleation by endosomes, lysosomes and secretory vesicles. Curr Opin Cell Biol. (2001). , 13(1), 85-91.

[183] Rao, A, \& Craig, A. M. Signaling between the actin cytoskeleton and the postsynaptic density of dendritic spines. Hippocampus. (2000). , 10(5), 527-541.

[184] Kaibuchi, K, Kuroda, S, \& Amano, M. Regulation of the cytoskeleton and cell adhesion by the Rho family GTPases in mammalian cells. Annu Rev Biochem. (1999). , 68, 459-486.

[185] Valentijn, K, Valentijn, J. A, \& Jamieson, J. D. Role of actin in regulated exocytosis and compensatory membrane retrieval: insights from an old acquaintance. Biochem Biophys Res Commun.(1999). , 266(3), 652-661. 
[186] Downey, G. P. Mechanisms of leukocyte motility and chemotaxis. Curr Opin Immunol. (1994). , 6(1), 113-124.

[187] Hirokawa, N. Axonal transport and the cytoskeleton. Curr Opin Neurobiol. (1993). , 3(5), 724-731.

[188] Weed, S. A, \& Parsons, J. T. Cortactin: coupling membrane dynamics to cortical actin assembly. Oncogene. (2001). , 20(44), 6418-6434.

[189] Milzani, A. DalleDonne I, Colombo R, Rodriguez OC. Prolonged oxidative stress on actin. Arch Biochem Biophys. (1997). , 339(2), 267-274.

[190] Huot, J, Houle, F, Rousseau, S, Deschesnes, R. G, Shah, G. M, Landry, J, \& Sapk, p. dependent F-actin reorganization regulates early membrane blebbing during stressinduced apoptosis. J Cell Biol. (1998). , 143(5), 1361-1373.

[191] ConcannonCG; Gorman, AM; Samali, A. On the role of Hsp27 in regulating apoptosis. Apoptosis. (2003). , 8(1), 61-70.

[192] Delogu, G, Signore, M, Mechelli, A, \& Famularo, G. Heat shock proteins and their role in heart injury. Curr Opin Crit Care. (2002). , 8(5), 411-416.

[193] Ganea, E. Chaperone-like activity of alpha-crystallin and other small heat shock proteins. Curr Protein Pept Sci. (2001). , 2(3), 205-225.

[194] De Lanerolle, P, \& Cole, A. B. Cytoskeletal proteins and gene regulation: form, function, and signal transduction in the nucleus. Sci STKE. (2002). E30.

[195] Landry, J, \& Huot, J. Modulation of actin dynamics during stress and physiological stimulation by a signaling pathway involving MAP kinase and heat-shock protein 27. Biochem Cell Biol. (1995). , 38.

[196] Stokoe, D, Engel, K, Campbell, D. G, Cohen, P, \& Gaestel, M. Identification of MAPKAP kinase 2 as a major enzyme responsible for the phosphorylation of the small mammalian heat shock proteins. FEBS Lett. (1992). , 313(3), 307-313.

[197] Gerthoffer, W. T, \& Gunst, S. J. Invited review: focal adhesion and small heat shock proteins in the regulation of actin remodeling and contractility in smooth muscle. $\mathrm{J}$ Appl Physiol. (2001). , 91, 963-972.

[198] Huot, J, Houle, F, Marceau, F, \& Landry, J. Oxidative stress-induced actin reorganization mediated by the mitogen-activated protein kinase/heat shock protein 27 pathway in vascular endothelial cells. Circ Res. (1997). , 38.

[199] Lavoie, J. N, Lambert, H, Hickey, E, Weber, L. A, \& Landry, J. Modulation of cellular thermoresistance and actin filament stability accompanies phosphorylation-induced changes in the oligomeric structure of heat shock protein 27. Mol Cell Biol. (1995). , 15, 505-516. 
[200] GuayJ; Lambert, H; Gingras-Breton, G; Lavoie, JN; Huot, J; Landry, J. Regulation of actinfilament dynamics by map kinase-mediated phosphorylation of heat shock protein 27. J Cell Sci. (1997). , 38.

[201] ClerkA; Michael, A; Sugden, PH. Stimulation of multiple mitogen-activated protein kinase sub-families by oxidative stress and phosphorylation of the small heat shock protein, HSP25/27, in neonatal ventricular myocytes. Biochem J. (1998). , 333(3), 581-589.

[202] GusevNB; Bogatcheva, NV; Marston, SB. Structure and properties of small heat shock proteins (sHsp) and their interaction with cytoskeleton proteins. Biochemistry (Mosc). (2002). , 67, 511-519.

[203] Shi, B, Han, B, Schwab, I. R, \& Isseroff, R. R. UVB irradiation-induced changes in the 27-kd heat shock protein (HSP27) in human corneal epithelial cells. Cornea. (2006). , 25, 948-955.

[204] Decanini, A, Nordgaard, C. L, Feng, X, Ferrington, D. A, \& Olsen, T. W. Changes in select redox proteins of the retinal pigment epithelium in age-related macular degeneration. Am J Ophthalmol. (2007). , 143, 607-615.

[205] Pons, M, Cousins, S. W, Csaky, K. G, Striker, G, \& Marin-castaño, M. E. Cigarette smoke-related hydroquinone induces filamentous actin reorganization and heat shock protein 27 phosphorylation through and extracellular signal-regulated kinase $1 / 2$ in retinal pigment epithelium: implications for age-related macular degeneration. Am J Pathol. (2010). , 38.

[206] Strunnikova, N, Baffi, J, Gonzalez, A, Silk, W, Cousins, S. W, \& Csaky, K. G. Regulated heat shock protein 27 expression in human retinal pigment epithelium. Invest Ophthalmol Vis Sci. (2001). , 42, 2130-2138.

[207] Cuenda, A, Rouse, J, Doza, Y. N, Meier, R, Cohen, P, Gallagher, T. F, Young, P. R, Lee, J. C, \& Is, S. B. a specific inhibitor of a MAP kinase homologue which is stimulated by cellular stresses and interleukin-1. FEBS Lett. (1995). , 364, 229-233.

[208] Huot, J, Lambert, H, Lavoie, J. N, Guimond, A, Houle, F, \& Landry, J. Characterization of $45-\mathrm{kDa} / 54-\mathrm{kDa}$ HSP27 kinase, a stress-sensitive kinase which may activate the phosphorylationdependent protective function of mammalian 27-kDa heat-shock protein HSP27. Eur J Biochem. (1995). , 227, 416-427.

[209] Cairns, J, Qin, S, Philp, R, Tan, Y. H, \& Guy, G. R. Dephosphorylation of the small heat shock protein Hsp27 in vivo by protein phosphatase 2A. J Biol Chem, (1994). , $269,9176-9183$.

[210] Kostenko, S, \& Moens, U. Heat shock protein 27 phosphorylation: kinases, phosphatases,functions and pathology. Cell Mol Life Sci. (2009). , 66, 3289-3307. 
[211] Garg, T. K, \& Chang, J. Y. Oxidative stress causes ERK phosphorylation and cell death in cultured retinal pigment epithelium: prevention of cell death by AG126 and 15-deoxy-delta PGJ2. BMC Ophthalmol. (2003). , 12, 14.

[212] Chiang, J, \& Kowada, M. Ames III A, Wright RL, Majino G. Cerebral isquenia III. Vascular changes. Am. J. Path. (1968). , 52, 437-447.

[213] Feig, L. A. Ral-GTPases: approaching their 15 minutes of fame. Trends Cell Biol. (2003). , 13, 419-425.

[214] Charras, G. T. A short history of blebbing. J Microsc. (2008). , 231, 466-478.

[215] Takai, Y, Sasaki, T, \& Matozaki, T. Small GTP-binding proteins. Physiol Rev. (2001). , 81, 153-208.

[216] Albright, C. F, Giddings, B. W, Liu, J, Vito, M, \& Weinberg, R. A. Characterization of a guanine nucleotide dissociation stimulator for a ras-related GTPase. EMBO J. (1993). , 12, 339-347.

[217] Hofer, F, Fields, S, Schneider, C, \& Martin, G. S. Activated Ras interacts with the Ral guanine nucleotide dissociation stimulator. Proc Natl Acad Sci USA. (1994). , 91, 11089-11093.

[218] Kikuchi, A, \& Williams, L. T. Regulation of interaction of ras with RalGDS and Raf-1 by cyclic AMP-dependent protein kinase. J Biol Chem. (1996). , 21.

[219] Matsubara, K, Kishida, S, Matsuura, Y, Kitayama, H, Noda, M, \& Kikuchi, A. Plasma membrane recruitment of RalGDS is critical for Ras-dependent Ral activation. Oncogene. (1999). , 18, 1303-1312.

[220] Wolthuis, R. M, \& Bos, J. L. Ras caught in another affair: the exchange factors for Ral. Curr Opin Genet Dev. (1999). , 9, 112-117.

[221] Barnes, W. G, Reiter, E, Violin, J. D, Ren, X. R, Milligan, G, \& Lefkowitz, R. J. betaArrestin 1 and Galphaq/11 coordinately activate RhoA and stress fiber formation following receptor stimulation. J Biol Chem. (2005). , 280, 8041-8050.

[222] Matrougui, K, Tankó, L. B, Loufrani, L, Gorny, D, Levy, B. I, Tedgui, A, \& Henrion, D. Involvement of Rho-kinase and the actin filament network in angiotensin II-induced contraction and extracellular signal-regulated kinase activity in intact rat mesenteric resistance arteries. Arterioscler Thromb Vasc Biol. (2001). , 21, 1288-1293.

[223] Lammers, M, Meyer, S, Kühlmann, D, \& Wittinghofer, A. Specificity of interactions between mDia isoforms and Rho proteins. J Biol Chem. (2008). , 283, 35236-35246.

[224] Krebs, A, Rothkegel, M, Klar, M, \& Jockusch, B. M. Characterization of functional domains of mDia1, a link between the small GTPase Rho and the actin cytoskeleton. J Cell Sci. (2001). , 114, 3663-3672. 
[225] Godin, C. M, \& Ferguson, S. S. The angiotensin II type 1 receptor induces membrane blebbing by coupling to Rho A, Rho kinase, and myosin light chain kinase. Mol Pharmacol. (2010).

[226] Min Kim JUehara Y, Ja Choi Y, Mi Ha Y, Hyeok, Ye, B, Pal Yu B, Young Chung H. Mecahnism of attenuation of pro-inflammatory Ang II-induced NF-kB activation by genistein in the kidneys of male rats during aging. Biogerontology. (2011). DOIs10522-011-9345-4).

[227] Aumailley, M, \& Gayraud, B. Structure and biological activity of the extracellular matrix. J Mol Med. (1998). , 76, 253-265.

[228] Kugler, A. Matrix metalloproteinases and their inhibitors. Anticancer Res. (1999). , 19, 1589-1592.

[229] Jacot, T. A, Striker, G. E, \& Stetler-stevenson, M. Mesangial cells from transgenic mice with progressive glomerulosclerosis exhibit stable, phenotypic changes including undetectable MMP-9 and increased type IV collagen. Lab Invest. (1996). , 75, 791-799.

[230] Peten, E. P, Garcia-perez, A, \& Terada, Y. Age-related changes in alpha and alpha 2chain type IV collagen mRNAs in adult mouse glomeruli: competitive PCR. Am J Physiol. (1992). F951-F957., 1.

[231] Belkhiri, A, Richards, C, \& Whaley, M. Increased expression of activated matrix metalloproteinase-2 by human endothelial cells after sublethal H2O2 exposure. Lab Inves. (1997). , 77, 533-539.

[232] Alcazar, O, Cousins, S. W, \& Marin-castaño, M. E. MMP-14 and TIMP-2 overexpression protects against hydroquinone-induced oxidant injury in RPE: implications for extracellular matrix turnover. Invest Ophthalmol Vis Sci. (2007). , 48(12), 5662-70.

[233] Wiesner, C, Faix, J, Himmel, M, Bentzien, F, Linder, S, \& Kif, B. and KIF3A/KIF3B kinesins drive MT1-MMP surface exposure, CD44 shedding, and extracellular matrix degradation in primary macrophages. Blood. (2010). , 116(9), 1559-69.

[234] Zhang, C, Baffi, J, Cousins, S. W, \& Csaky, K. G. Oxidant-induced cell death in retinal pigment epithelium cells mediated through the release of apoptosis-inducing factor. J Cell Sci. (2003). , 116(10), 1915-1923.

[235] Cousins, S. W, Marin-castano, M. E, Espinosa-heidmann, D. G, Alexandridou, A, Striker, L, \& Elliot, S. Female gender, estrogen loss, and Sub-RPE deposit formation in aged mice. Invest Ophthalmol Vis Sci. (2003). , 44(3), 1221-1229.

[236] Fossum, S, Mallett, S, \& Barclay, A. N. The MRC OX-47 antigen is a member of the immunoglobulin superfamily with an unusual transmembrane sequence. Eur J Immunol. (1991). , 21, 671-679.

[237] Miyauchi, T, Masuzawa, Y, \& Muramatsu, T. The basigin group of the immunoglobulin superfamily: complete conservation of a segment in and around transmem- 
brane domains of human and mouse basigin and chicken HT7 antigen. J Biochem. (1991). , 110, 770-774.

[238] Kasinrerk, W, Fiebiger, E, Stefanová, I, Baumruker, T, Knapp, W, \& Stockinger, H. Human leukocyte activation antigen M6, a member of the Ig superfamily, is the species homologue of rat OX-47, mouse basigin, and chicken HT7 molecule. J Immunol. (1992). , 149, 847-854.

[239] Kasinrerk, W, Tokrasinwit, N, \& Phunpae, P. CD147 monoclonal antibodies induce homotypic cell aggregation of monocytic cell line U937 via LFA-1/ICAM-1 pathway. Immunology. (1999). , 96, 184-192.

[240] Biswas, C, Zhang, Y, Decastro, R, Guo, H, Nakamura, T, Kataoka, H, \& Nabeshima, $\mathrm{K}$. The human tumor cell-derived collagenase stimulatory factor (renamed EMMPRIN) is a member of the immunoglobulin superfamily. Cancer Res. (1995). , 55, 434-439.

[241] Biswas, C. Tumor cell stimulation of collagenase production by fibroblasts. Biochem Biophys Res Commun. (1982). , 109, 1026-1034.

[242] Kataoka, H, Decastro, R, Zucker, S, \& Biswas, C. Tumor cell-derived collagenasestimulatory factor increases expression of interstitial collagenase, stromelysin, and 72-kDa gelatinase. Cancer Res. (1993). , 53, 3154-3148.

[243] Guo, H, Zucker, S, Gordon, M. K, Toole, B. P, \& Biswas, C. Stimulation of matrix metalloproteinase production by recombinant extracellular matrix metalloproteinase inducer from transfected Chinese hamster ovary cells. J Biol Chem. (1997). , 272, 24-27.

[244] Sameshima, T, Nabeshima, K, Toole, B. P, Yokogami, K, Okada, Y, Goya, T, Koono, M, \& Wakisaka, S. Glioma cell extracellular matrix metalloproteinase inducer (EMMPRIN) (CD147)stimulates production of membrane-type matrix metalloproteinases and activated gelatinase A in co-cultures with brain-derived fibroblasts. Cancer Lett. (2000). , 157, 177-184.

[245] Hakomori, S. Tumor malignancy defined by aberrant glycosylation and sphingo(glyco)lipid metabolism. Cancer Res. (1996). , 56, 5309-5318.

[246] Sun, J, \& Hemler, M. E. Regulation of MMP-1 and MMP-2 production through CD147/extracellular matrix metalloproteinase inducer interactions. Cancer Res. (2001). , 61, 2276-2281.

[247] Tang, W, Chang, S. B, \& Hemler, M. E. Links between CD147 function, glycosylation, and caveolin-1. Mol Biol Cell. (2004). , 15, 4043-4050.

[248] Ochrietor, J. D, Moroz, T. P, Clamp, M. F, Timmers, A. M, Muramatsu, T, \& Linser, P. $\mathrm{J}$. Inactivation of the Basigin gene impairs normal retinal development and maturation. Vision Res. (2002). , 42, 447-453. 
[249] Ochrietor, J. D, Moroz, T. P, Van Ekeris, L, Clamp, M. F, Jefferson, S. C, Decarvalho, A. C, Fadool, J. M, Wistow, G, Muramatsu, T, \& Linser, P. J. Retina-specific expression of 5A11/Basigin-2, a member of the immunoglobulin gene superfamily. Invest Ophthalmol Vis Sci. (2003). , 44, 4086-4096.

[250] Hori, K, Katayama, N, Kachi, S, Kondo, M, Kadomatsu, K, Usukura, J, Muramatsu, T, Mori, S, \& Miyake, Y. Retinal dysfunction in basigin deficiency. Invest Ophthalmol Vis Sci. (2000). , 41, 3128-3133.

[251] Ochrietor, J. D, Moroz, T. M, Kadomatsu, K, Muramatsu, T, \& Linser, P. J. Retinal degeneration following failed photoreceptor maturation in 5A11/basigin null mice. Exp Eye Res. (2001). , 72, 467-477.

[252] Clamp, M. F, Ochrietor, J. D, Moroz, T. P, \& Linser, P. J. Developmental analyses of 5A11/Basigin, 5A11/Basigin-2 and their putative binding partner MCT1 in the mouse eye. Exp Eye Res. (2004). , 78, 777-789.

[253] Taylor, P. M, Woodfield, R. J, Hodgkin, M. N, Pettitt, T. R, Martin, A, Kerr, D. J, \& Wakelam, M. J. Breast cancer cell-derived EMMPRIN stimulates fibroblast MMP2 release through a phospholipase $\mathrm{A}(2)$ and 5-lipoxygenase catalyzed pathway. Oncogene. (2002). , 21, 5765-5772.

[254] Lim, M, Martinez, T, Jablons, D, Cameron, R, Guo, H, Toole, B, Li, J. D, \& Basbaum, C. Tumor-derived EMMPRIN (extracellular matrix metalloproteinase inducer) stimulates collagenase transcription through MAPK FEBS Lett. (1998). , 38.

[255] Sidhu, S. S, Mengistab, A. T, \& Tauscher, A. N. LaVail J, Basbaum C. The microvesicle as a vehicle for EMMPRIN in tumor-stromal interactions. Oncogene. (2004). , 23, 956-563.

[256] Seiki, M, Koshikawa, N, \& Yana, I. Role of pericellular proteolysis by membrane-type 1 matrix metalloproteinase in cancer invasion and angiogenesis. Cancer Metastasis Rev. (2003). , 22, 129-143.

[257] ItohY; Seiki, M. MT1-MMP: a potent modifier of pericellular microenvironment. J Cell Physiol. (2006). , 206, 1-8.

[258] Egawa, N, Koshikawa, N, Tomari, T, Nabeshima, K, Isobe, T, \& Seiki, M. Membrane type 1 matrix metalloproteinase (MT1-MMP/MMP-14) cleaves and releases a 22-kDa extracellular matrix metalloproteinase inducer (EMMPRIN) fragment from tumor cells. J Biol Chem. (2006). , 281, 37576-37585.

[259] Grossniklaus, H. E, Cingle, K. A, Yoon, I. D, Ketkar, N, Hernault, L, \& Brown, N. S. Correlation of histologic dimensional reconstruction and confocal scanning laser microscopic imaging of choroidal neovascularization in eyes with age-related maculopathy. Archives of Ophthalmology. (2000). , 2.

[260] Killingsworth, M. C, Sarks, J. P, \& Sarks, H. S. Macrophages related to Bruch's membrane in age-related macular degeneration. Eye. (1990). Pt 4):613-621. 
[261] Miceli, M. V, Liles, M. R, \& Newsome, D. A. Evaluation of oxidative processes in human pigment epithelial cells associated with retinal outer segment phagocytosis. Experimental Cell Research. (1994). , 214(1), 242-249.

[262] Tate Jr DJMiceli MV, Newsome DA. Phagocytosis and H2O2 induce catalase and metallothionein gene expression in human retinal pigment epithelial cells. Investigative Ophthalmology \& Visual Science. (1995). , 36(7), 1271-1279.

[263] Tate, D. J, Miceli, M. V, \& Newsome, D. A. Expression of metallothionein isoforms in human chorioretinal complex.Current Eye Research. (2002). , 24(1), 12-25.

[264] Parthasarathy, S, \& Santanam, N. Mechanisms of oxidation, antioxidants, and atherosclerosis.Current Opinion in Lipidology (1994). , 5(5), 371-375.

[265] Katsuda, S, \& Kaji, T. Atherosclerosis and extracellular matrix. Journal of atherosclerosis and thrombosis. (2003). , 10(5), 267-274.

[266] St-pierre, Y, Van Themsche, C, \& Esteve, P. O. Emerging features in the regulation of MMP-9 gene expression for the development of novel molecular targets and therapeutic strategies. Current Drug Targets: Inflammation \& Allergy. (2003). , 2(3), 206-215.

[267] Patel, M, \& Chan, C. C. Immunopathological aspects of age-related macular degeneration. Semin Immunopathol. (2008).

[268] Haines, J. L, Hauser, M. A, Schmidt, S, Scott, W. K, Olson, L. M, Gallins, P, Spencer, K. L, Kwan, S. Y, Noureddine, M, Gilbert, J. R, Schnetz-boutaud, N, Agarwal, A, Postel, E. A, \& Pericak-vance, M. A. Complement factor $\mathrm{H}$ variant increases the risk of age-related macular degeneration. Science. (2005). , 308, 419-421.

[269] Lommatzsch, A, Hermans, P, Muller, K. D, Bornfeld, N, \& Bird, A. C. Pauleikhoff. Are low inflammatory reactions involved in exudative age-related macular degeneration? Morphological and immunhistochemical analysis of AMD associated with basal deposits. Graefes Arch Clin Exp Ophthalmol. (2008). , 246(6), 803-810.

[270] Hinton, D. R, He, S, \& Lopez, P. F. Apoptosis in surgically excised choroidal neovascular membranes in age-related macular degeneration. Arch Ophthalmol. (1998). , 116(2), 203-209.

[271] Penfold, P. L, Killingsworth, M. C, \& Sarks, S. H. Senile macular degeneration: the involvement of immunocompetent cells. Graefes Arch Clin Exp Ophthalmol. (1985). , 223(2), 69-76.

[272] Penfold, P, Killingsworth, M, \& Sarks, S. An ultrastructural study of the role of leucocytes and fibroblasts in the breakdown of Bruch's membrane. Aust J Ophthalmol. (1984). , 12(1), 23-31.

[273] Lopez, P. F, Grossniklaus, H. E, Lambert, H. M, Aaberg, T. M, \& Capone, A. Sternberg P Jr, L'Hernault N. Pathologic features of surgically excised subretinal neovas- 
cular membranes in age-related macular degeneration. Am J Ophthalmol. (1991). , 112(6), 647-656.

[274] Ibrahim, M, Chair, B, \& Kartz, D. The injured cells: the role of dendritic cell system as a sentinel receptor pathway. Immunol Today. (1995). , 16, 181-186.

[275] Matyszak, M, \& Perry, V. The potential role of dendritic cells in immune-mediated inflammatory diseases in the central nervous system. Neuroscience. (1996). , 74, 599-608.

[276] Luft, F. C, Mervaala, E, Muller, D. N, Gross, V, Schmidt, F, Joon, K. P, et al. Hypertension-induced end-organ damage: a new transgenic approach to an old problem. Hypertension. (1999). , 33, 212-218.

[277] Alexander, R. W. Hypertension and the pathogenesis of atherosclerosis: oxidative stress and the mediation of arterial inflammatory response, a new perspective. Hypertension. (1995). , 25, 155-161.

[278] Yla-herttuala, S, Lipton, B. A, Rosenfeld, M. E, Srakioja, T, Yoshimura, T, \& Leonard, E. J. Expression of monocyte chemoattractant protein-1 in macrophage-rich areas of human and rabbit atherosclerotic lesions. Proc Natl Acad Sci USA.(1991). , 88, 5252-5256.

[279] Yu X Dluz SGraves DT, Zhang L, Antoniades HN, Hollander W. Elevated expression of monocyte chemoattractant protein-1 by vascular smooth muscle cells in hypercholesterolemic primates. Proc Natl Acad Sci USA. (1992). , 89, 6953-6957.

[280] Capers, Q, Alexander, R. W, Lou, P, De Leon, H, Wilcox, J. N, \& Ishizaka, N. Monocyte chemoattractant protein-1 expression in aortic tissues of hypertensive rats. Hypertension. (1997). , 30, 1397-1402.

[281] BehrTM; Wang, XK; Aijar, N; Coatney, RW; Li, X; Koster, P. Monocyte chemoattractant protein-1 is upregulated in rats with volume overloaded congestive heart failure. Circulation, (2000). , 102, 1315-1322.

[282] Hilgers, K. F, Hartner, A, Porst, M, Mai, M, Wittmann, M, \& Hugo, C. Monocyte chemoattractant protein-1 and macrophage infiltration in hypertensive kidney injury. Kidney Int. (2000). , 58, 2408-2419.

[283] Hernandez-presa, M, Bustos, C, Ortego, M, Tunon, J, Renedo, G, Ruiz-ortega, M, \& Egido, J. Angiotensin-converting enzyme inhibition prevents arterial nuclear factorkappa B activation, monocyte chemoattractant protein-1 expression, and macrophage infiltration in a rabbit model of early accelerated atherosclerosis. Circulation. (1997). , 95, 1532-1541.

[284] Ruiz-ortega, M, Ruperez, M, Lorenzo, O, Esteban, V, Blanco, J, \& Mezzano, S. Angiotensin II regulates the synthesis of proinflammatory cytokines and chemokines in the kidney. Kidney Int. (2002). suppl 82):12-22. 
[285] Tham, D. M. Martin-McNulty B, Wang YX, Wilson DW, Vergona R, Sullivan ME. Angiotensin II is associated with activation of NF-kappa B-mediated genes and downregulation of PPARs. Physiol Genom. (2002). , 11, 21-31.

[286] Yoshimura, T, \& Leonard, E. J. Identification of high affinity receptors for human monocyte chemoattractant protein-1 on human monocytes. J Immunol. (1990). , 145, 292-297.

[287] Charo, I. F, Myers, S. J, Herman, A, Franci, C, Connolly, A. J, \& Coughlin, S. R. Molecular cloning and functional expression of two monocyte chemoattractant protein-1 receptors reveals alternative splicing of the carboxyl-terminal trails. Proc Natl Acad Sci USA. (1994). , 91, 2752-2756.

[288] Uetama, T, Ohno-matsui, K, Nakahama, K, Morita, I, \& Mochizuki, M. Phenotypic change regulates monocyte chemoattractant protein-1 (MCP-1) gene expression in human retinal pigment epithelial cells. J Cell Physiol. (2003). , 197, 77-85.

[289] Higgins, G. T, Wang, J. H, Dockery, P, Cleary, P. E, \& Redmond, H. P. Induction of angiogenic cytokine expression in cultured RPE by ingestion of oxidized photoreceptor outer segments. Invest Ophthalmol Vis Sci. (2003). , 44, 1775-1782.

[290] Ambati, J, Anand, A, Fernandez, S, Sakurai, E, Lynn, B. C, Kuziel, W. A, Rollins, B. J, \& Ambati, B. K. An animal model of age-related macular degeneration in senescent Ccl-2- or Ccr-2-deficient mice. Nat Med. (2003). , 9, 1390-1397.

[291] Tuo, J, Bojanowski, C. M, Zhou, M, Shen, D, Ross, R. J, Rosenberg, K. I, Cameron, D. J, Yin, C, Kowalak, J. A, Zhuang, Z, Zhang, K, \& Chan, C. C. Murine ccl2/cx3cr1 deficiency results in retinal lesions mimicking human age-related macular degeneration. Invest Ophthalmol Vis Sci. (2007). , 48, 3827-3836.

[292] Holtkamp, G. M, De Vos, A. F, Peek, R, \& Kijlsta, A. Analysis of the secretion pattern of monocyte chemotactic protein-1 (MCP-1) and transforming growth factor-beta 2 (TGF-beta2) by human retinal pigment epithelial cells. Clin Exp Immunol. (1999). , $118,35-40$.

[293] Zheng, J, Singh, S, Fan, W, \& Mclaughlin, B. Gene expression in human retinal pigment epithelial cells (ARPE-19) during wound healing. Exp Eye Res (Suppl). (2000). S113.

[294] Pons, M, \& Marin-castano, M. E. Cigarette smoke-related hydroquinone dysregulates MCP-1, VEGF and PEDF expression in retinal pigment epithelium in vitro and in vivo. PLoS ONE, (2011). e16722.

[295] Behr, T. M, Willette, R. N, Coatney, R. W, Berova, M, Angermann, C. E, \& Anderson, K. Eprosartan improves cardiac performance, reduces cardiac hypertrophy and mortality and downregulates myocardial MCP-1 and inflammation in hypertensive heart disease. J Hypertens. (2004). , 22, 583-592. 
[296] Basso, N, Paglia, N, Stella, I, De Cavanagh, E. M, Ferder, L, Arnaiz, M, \& Inserra, F. Protective effect of the inhibition of the renin-angiotensis system on aging. Regul Pept. (2005). , 128, 247-252.

[297] Diz, D, \& Lewis, K. Dahl memorial lecture: the renin-angiotensisn system and aging. Hypertension. (2008). , 52, 37-43.

[298] Funakoshi, Y, Ichiki, T, Shimokawa, H, Egashira, K, Takeda, K, \& Kaibuchi, K. Rhokinase mediates angiotensin II-induced monocyte chemoattractant protein-1 expression in rat vascular smooth muscle cells. Hypertension, (2001). , 38, 100-104.

[299] Wu, L, Iwai, M, Nakagami, H, Li, Z, Chen, R, \& Suzuki, J. Roles of angiotensin II type 2 receptor stimulation associated with selective angiotensin II type 1 receptor blockade with valsartan in the improvement of inflammation-induced vascular injury. Circulation, (2001). , 104, 2716-2721.

[300] Sozzani, S, Luini, W, Molino, M, Jilek, P, Bottazzi, B, \& Cerletti, C. The signaling transduction pathway involved in the migration induced by a monocyte chemotactic cytokine. J Immunol. (1991). , 147, 2215-2221.

[301] Chen, X. L, Tummala, P. E, Olbrych, M. T, Alexander, R. W, \& Medford, R. M. Angiotensin II induces monocyte chemoattractant protein-1 gene expression in rat vascular smooth muscle cells. Circ Res. (1998). , 83, 952-959.

[302] Locati, M, Zhou, D, Luini, W, Evangelista, V, Mantovani, A, \& Sozzani, S. Rapid induction of arachidonic acid release by monocyte chemotactic protein- 1 and related chemokines: role of $\mathrm{Ca}^{2+}$ influx, synergism with platelet-activating factor and significance for chemotaxis. J Biol Chem. (1994). , 269, 4746-4753.

[303] Yu, B. P, \& Chung, H. Y. Adaptive mechanisms to oxidative stress during aging. Mech Ageing Dev. (2006). , 127, 436-443.

[304] Kim, H. J, Jung, K. J, Yu, B. P, Cho, C. G, Choi, J. S, \& Chung, H. Y. Modulation of redox-sensitive transcription factors by calorie restriction during aging. Mech Ageing Dev. (2002). , 123, 1589-1595.

[305] Chung, H. Y, Kim, H. J, Kim, K. W, Choi, J. S, \& Yu, B. P. Molecular inflammation hypothesis of aging based on the anti-aging mechanism of calorie restriction. Microsc Res Tech. (2002). , 59, 264-272.

[306] Miyata, N, Yamakoshi, Y, \& Nakanishi, I. Reactive species responsible for biological actions of photo excited fullerenes. Yakugaku Zasshi. (2002). , 120, 1007-1016.

[307] Murkies, A. Phytoestrogens what is the current knowledge? Aust Fam Physician. (1998). SS51, 47.

[308] Joly, S, Samardzija, M, Wenzel, A, Thiersch, M, \& Grimm, C. Nonessential role of beta3 and beta5 integrin subunits for efficient clearance of cellular debris after light-induced photoreceptor degeneration. Invest Ophthalmol Vis Sci. (2009). , 50, 423-1432. 
[309] Ohno-matsui, K, Morita, I, Tombran-tink, J, Mrazek, D, \& Onodera, M. Novel mechanism for age-related macular degeneration: an equilibrium shift between the angiogenesis factors VEGF and PEDF. J Cell Physiol. (2001). , 189, 323-333.

[310] Adamis, A. P, Shima, D. T, Yeo, K. T, Yeo, T. K, Brown, L. F, Berse, B, Amore, D, Folkman, P. A, \& Synthesis, J. and secretion of vascular permeability factor/vascular endothelial growth factor by human retinal pigment epithelial cells. Biochem Biophys Res Commun. (1993). , 193, 631-638.

[311] Husain, D, Ambati, B, Adamis, A. P, \& Miller, J. W. Mechanisms of age-related macular degeneration. Ophthalmol Clin North Am. (2002). , 15, 87-91.

[312] Kwak, N, Okamoto, N, Wood, J. M, \& Campochiaro, P. A. VEGF is major stimulator in model of choroidal neovascularization. Invest Ophthalmol Vis Sci. (2000). , 41, 3158-3164.

[313] Tong, J. P, \& Yao, Y. F. Contribution of VEGF and PEDF to choroidal angiogenesis: a need for balanced expressions. Clin Biochem. (2006). , 39, 267-276.

[314] Witmer, A. N, Vrensen, G. F, Van Noorden, C. J, \& Schlingemann, R. O. Vascular endothelial growth actors and angiogenesis in eye disease. Prog Retin Eye Res. (2003). , $22,1-29$.

[315] Kliffen, M, Sharma, H. S, Mooy, C. M, Kerkvliet, S, \& De Jong, P. T. Increased expression of angiogenic growth factors in age-related maculopathy. Br J Ophthalmol. (1997). , 81, 54-162.

[316] Kvanta, A, Algvere, P. V, Berglin, L, \& Seregard, S. Subfoveal fibrovascular membranes in age-related macular degeneration express vascular endothelial growth factor. Invest Ophthalmol Vis Sci. (1996). , 37, 1929-1934.

[317] Lopez, P. F, Sippy, B. D, Lambert, H. M, Thach, A. B, \& Hinton, D. R. Transdifferentiated retinal pigment epithelial cells are immunoreactive for vascular endothelial growth factor in surgically excised age-related macular degeneration-related choroidal neovascular membranes. Invest Ophthalmol Vis Sci. (1996). , 37, 855-868.

[318] Reich, S. J, Fosnot, J, Kuroki, A, Tang, W, Yang, X, Maguire, A. M, Bennett, J, \& Tolentino, M. J. Small interfering RNA (siRNA) targeting VEGF effectively inhibits ocular neovascularization in a mouse model. Mol Vis. (2003). , 9-210.

[319] Olsson, A. K, Dimberg, A, Kreuger, J, \& Claesson-welsh, L. VEGF receptor signalling- in control of vascular function. Nat Rev Mol Cell Biol. (2006). , 7, 59-371.

[320] Yi, X, Ogata, N, Komada, M, Yamamoto, C, Takahashi, K, Omori, K, \& Uyama, M. Vascular endothelial growth factor expression in choroidal neovascularization in rats. Graefes Arch Clin Exp Ophthalmol. (1997). , 235, 313-319.

[321] Dawson, D. W, Volpert, O. V, Gillis, P, Crawford, S. E, Xu, H, Benedict, W, \& Bouck, N. P. Pigment epithelium-derived factor: a potent inhibitor of angiogenesis. Science, (1999). , 285, 245-248. 
[322] Bhutto, I. A, Mcleod, D. S, Hasegawa, T, Kim, S. Y, Merges, C, Tong, P, \& Lutty, G. A. Pigment epithelium-derived factor (PEDF) and vascular endothelial growth factor (VEGF) in aged human choroid and eyes with age-related macular degeneration. Exp Eye Res. (2006). , 82, 99-110.

[323] Ogata, N, Wada, M, Otsuji, T, Jo, N, Tombran-tink, J, \& Matsumura, M. Expression of pigment epithelium-derived factor in normal adult rat eye and experimental choroidal neovascularization. Invest Ophthalmol Vis Sci. (2002). , 43, 1168-1175.

[324] Holekamp, N. M, Bouck, N, \& Volpert, O. Pigment epithelium-derived factor is deficient in the vitreous of patients with choroidal neovascularization due to age-related macular degeneration. Am J Ophthalmol. (2002). , 134, 220-227.

[325] Bamias, G, \& Martin, C. rd, Marini M, et al: Expression, localization, and functional activity of TL1A, a novel Th1-polarizing cytokine in inflammatory bowel disease. J Immunol (2003). , 171, 4868-4874.

[326] Prehn, J. L, Mehdizadeh, S, Landers, C. J, et al. Potential role for TL1A, the new TNFfamily member and potent costimulator of IFN-gamma, in mucosal inflammation. Clin Immunol (2004). , 112, 66-77.

[327] Al-lamki, R. S, Wang, J, Tolkovsky, A. M, et al. TL1A both promotes and protects from renal inflammation and injury. J Am Soc Nephrol (2008). , 19, 953-960.

[328] Bamias, G, Siakavellas, S. I, Stamatelopoulos, K. S, Chryssochoou, E, \& Papamichael, C. and Sfikakis PP: Circulating levels of TNF-like cytokine 1A (TL1A) and its decoy receptor 3 (DcR3) in rheumatoid arthritis. Clin Immunol. (2008). , 129, 249-255.

[329] Zhang, N, Sanders, A. J, Ye, L, \& Jiang, W. G. Vascular endothelial growth inhibitor in human cancer (Review). Int J of Molecular Medicone. (2008). , 24, 3-8.

[330] Deng, W, Gu, X, Lu, Y, Gu, C, Zheng, Y, Zhang, Z, Chen, L, Yao, Z, \& Li, L. Y. Downmodulation of TNFSF15 in ovarian cancer by VEGF and MCP-1 is a pre-requisite for tumor neovascularization. Angiogenesis. (2011). Dec 31. (Epub ahead of print

[331] Apte, R. S, Barreiro, R. A, Duh, E, Volpert, O, \& Ferguson, T. A. Stimulation of neovascularization by the anti-angiogenic factor PEDF. Invest Ophthalmol Vis Sci. (2004). , 45, 4491-4497.

[332] Ohno-matsui, K, Yoshida, T, Uetama, T, Mochizuki, M, \& Morita, I. Vascular endothelial growth factor upregulates pigment epithelium-derived factor expression via VEGFR-1 in human retinal pigment epithelial cells. Biochem Biophys Res Commun. (2003). , 303, 962-967.

[333] Pons, M, \& Marin-castaño, M. E. Nicotine increases the VEGF/PEDF ratio in retinal pigment epithelium: a possible mechanism for CNV in passive smokers with AMD. Invest Ophthalmol Vis Sci. (2011). , 52(6), 3842-53. 
[334] Fang, L, Chen, M. F, Xiao, Z. L, Yu, G. L, Chen, X. B, \& Xie, X. M. The Effect of Endothelial Progenitor Cells on Angiotensin II-induced Proliferation of Cultured Rat Vascular Smooth Muscle Cells. J Cardiovasc Pharmacol. (2011). , 58(6), 617-25.

[335] Guo, R. W, Yang, L. X, Li, M. Q, Pan, X. H, Liu, B, \& Deng, Y. L. Stimand Orai1-mediated store-operated calcium entry is critical for angiotensin II-induced vascular smooth muscle cell proliferation. Cardiovasc Res. (2012). Jan 2. (Epub ahead of print), 1.

[336] Yang, L. L, Li, D. Y, Zhang, Y. B, Zhu, M. Y, Chen, D, \& Xu, T. D. Salvianolic acid A inhibits angiotensin II-induced proliferation of human umbilical vein endothelial cells by attenuating the production of ROS. Acta Pharmacol Sin. 2012 Jan; doi:aps. (2011). Epub 2011 Nov 21., 33(1), 41-8.

[337] Zhu, N, Zhang, D, Chen, S, Liu, X, Lin, L, Huang, X, Guo, Z, Liu, J, Wang, Y, Yuan, W, \& Qin, Y. Endothelial enriched microRNAs regulate angiotensin II-induced endothelial inflammation and migration. Atherosclerosis. (2011). , 215(2), 286-93.

[338] Martini, A, Bruno, R, Mazzulla, S, Nocita, A, \& Martino, G. Angiotensin II regulates endothelial cell migration through calcium influx via T-type calcium channel in human umbilical vein endothelial cells. Acta Physiol (Oxf). (2010). , 198(4), 449-55.

[339] Montiel, M, De La Blanca, E. P, \& Jiménez, E. Angiotensin II induces focal adhesion kinase/paxillin phosphorylation and cell migration in human umbilical vein endothelial cells. Biochem Biophys Res Commun. (2005). , 327(4), 971-8.

[340] Nadal, J. A, Scicli, G. M, Carbini, L. A, \& Scicli, A. G. Angiotensin II stimulates migration of retinal microvascular pericytes: involvement of TGF-beta and PDGF-BB. Am J Physiol Heart Circ Physiol. (2002). H , 739-48.

[341] Buharalioglu, C. K, Song, C. Y, Yaghini, F. A, Ghafoor, H. U, Motiwala, M, Adris, T, Estes, A. M, \& Malik, K. U. Angiotensin II-induced process of angiogenesis is mediated by spleen tyrosine kinase via VEGF receptor-1 phosphorylation. Am J Physiol Heart Circ Physiol. (2011). H , 1043-55.

[342] Benndorf, R, Böger, R. H, Ergün, S, Steenpass, A, \& Wieland, T. Angiotensin II type 2 receptor inhibits vascular endothelial growth factor-induced migration and in vitro tube formation of human endothelial cells. Circ Res. (2003). , 93(5), 438-47.

[343] Espinosa-HeidmannDG; Sall, J; Hernandez, EP; Cousins, SW. Basal laminar deposit formation in APO B100 transgenic mice: complex interactions between dietary fat, blue light, and vitamin E. Invest Ophthalmol Vis Sci. (2004). , 45(1), 260-266.

[344] Pons, M, Cousins, S. W, Alcazar, O, Striker, G. E, \& Marin-castaño, M. E. Angiotensin II-induced MMP-2 activity and MMP-14 and basigin protein expression are mediated via the angiotensin II receptor type 1-mitogen-activated protein kinase 1 pathway in retinal pigment epithelium implications for age-related macular degeneration. Am J Pathol. (2011). , 178(6), 2665-81. 
